\title{
CgIB adhesins secreted at bacterial focal adhesions mediate gliding motility
}

Salim T. Islam ${ }^{1,2,3^{*}}$, Laetitia My ${ }^{3}$, Nicolas Y. Jolivet ${ }^{1,2}$, Akeisha M. Belgrave ${ }^{4,5}$, Betty Fleuchot $^{3}$, Gael Brasseur ${ }^{3}$, Laura M. Faure ${ }^{3}$, Gaurav Sharma ${ }^{6,7}$, David J. Lemon ${ }^{8}$, Fares Saïdi ${ }^{1,2}$, JeanBernard Fiche ${ }^{9}$, Benjamin P. Bratton ${ }^{5}$, Mitchell Singer ${ }^{6}$, Anthony G. Garza ${ }^{8}$, Marcelo Nollmann ${ }^{9}$, Joshua W. Shaevitz ${ }^{5}$, Tâm Mignot ${ }^{3 *}$

${ }^{1}$ Armand Frappier Health \& Biotechnology Research Centre, Institut National de la Recherche Scientifique, Université du Québec, Institut Pasteur International Network, Laval, QC, H7V 1B7, Canada

2 PROTEO, the Quebec Network for Research on Protein Function, Engineering, and Applications, Université Laval, Quebec, QC, G1V 0A6, Canada

${ }^{3}$ Laboratoire de Chimie Bactérienne, CNRS - Université Aix-Marseille UMR7283, Institut de Microbiologie de la Méditerranée, Marseille, 13009, France

${ }^{4}$ Integrated Sciences Program, Harrisburg University of Science \& Technology, Harrisburg, PA, 17101, USA

${ }^{5}$ Lewis-Sigler Institute for Integrative Genomics, Princeton University, Princeton, NJ, 08540, USA

${ }^{6}$ Department of Microbiology and Molecular Genetics, University of California - Davis, Davis, CA, 95616, USA

${ }^{7}$ Institute of Bioinformatics and Applied Biotechnology, Electronic City, Bengaluru, Karnataka, 560100, India

${ }^{8}$ Department of Biology, Syracuse University, Syracuse, NY, 13210, USA

${ }^{9}$ Centre de Biochimie Structurale, CNRS UMR5048, INSERM U1054, Montpellier, 34090, France

*co-corresponding authors

Tâm Mignot

E-mail: tmignot@imm.cnrs.fr Phone: (+33) 0491164077 ext. 4506
Salim T. Islam

E-mail: salim.islam@iaf.inrs.ca

Phone: (+1) 450-687-5010 ext. 8897 


\section{Abstract:}

The predatory deltaproteobacterium Myхососсus xanthus uses a helically-trafficked motor at bacterial focal adhesion (bFA) sites to power gliding motility. Using TIRF and force microscopy, we herein identify the integrin $\alpha \mathrm{I}$-domain-like outer-membrane (OM) lipoprotein $\mathrm{CglB}$ as an essential substratum-coupling protein of the gliding motility complex. Similar to most known OM lipoproteins, $\mathrm{CglB}$ is anchored on the periplasmic side of the OM and thus a mechanism must exist to secrete it to the cell surface in order for it to interact with the underlying substratum. We reveal this process to be mediated by a predicted OM $\beta$-barrel structure of the gliding complex. This OM platform was found to regulate the conformational activation and secretion of $\mathrm{CglB}$ across the OM. These data suggest that the gliding complex promotes surface exposure of $\mathrm{CglB}$ at bFAs, thus explaining the manner by which forces exerted

by inner-membrane motors are transduced across the cell envelope to the substratum; they also uncover a novel protein secretion mechanism, highlighting the ubiquitous connection between secretion and bacterial motility.

1

\section{Keywords:}

bacterial motility, integrins, protein secretion systems, molecular motor, cell-surface lipoprotein, 5 protein folding, disulphide bonds, von Willebrand Factor A, TonB-dependent transporter, outermembrane exchange 


\section{INTRODUCTION:}

Directed surface motility of cells from all biological kingdoms involves highly-dynamic cell-substratum interactions. In eukaryotic cells, this process involves the engagement and activation of surface-exposed integrin(-like) adhesins, directionally transported by molecular motors (myosin) via integrin coupling to the internal cytoskeleton (actin) ${ }^{1}$. For metazoan organisms, nascent integrin adhesions to the extracellular matrix (ECM) lead to integrin nucleation and the formation of large eukaryotic focal adhesion (eFA) sites; these assemblies remain fixed-in-space relative to a translocating cell, promoting local traction, transduction of motor forces, and cell translocation ${ }^{2}$. Such surface motility is not restricted to eukaryotic cells. Long known to move on surfaces in the absence of outward appendages (such as flagella or type IV pili) via a process termed "gliding motility", individual cells of the Gram-negative predatory deltaproteobacterium Myxococcus xanthus were shown to utilize a trans-envelope multi-protein Agl-Gliding transducer (Glt) complex (Fig. 1A) to power gliding motility ${ }^{4,5}$. In motile cells, these complexes associate at the leading pole and move directionally in the bacterial inner membrane (IM) toward the lagging cell pole, following a right-handed helical trajectory ${ }^{6-8}$ (Fig. 1A). These rotational movements likely probe the substratum beneath gliding cells, leading to immobilization of the Agl-Glt complex at fixed bacterial focal adhesion (bFA) sites as well as cell translocation via left-handed rotation of the bacterium around its long axis ${ }^{8}$ (Fig. 1A).

At the molecular scale, the mechanisms that promote force transmission and adhesion at bFAs are not known. The IM components of the motility complex assemble at the pole on a cytoplasmic scaffold formed by bacterial actin MreB, the Ras-like protein MglA and the coiledcoil AglZ protein ${ }^{9,10}$. The IM complex contains the molecular motor AgIRQS, a

TolQR/ExbBD/MotAB-like channel that uses the proton gradient formed across the bacterial IM to energize long-range movements of the IM complex in the bacterial envelope ${ }^{11}$. However, the manner in which these intracellular motions are coupled to the substratum in order to propel the cell is unknown. One hypothesis states that trafficking motor units deform the peptidoglycan meshwork in the periplasm, propagating surface wave deformations and viscous interactions between the outer membrane (OM) and the substratum (Fig. 1A, panel i). However, observations and mechanical modelling of cell-cell collision events suggest that interactions between a gliding cell and the substratum are elastic in nature, consistent with localized adhesion points and the existence of an anchored adhesin ${ }^{12}$ (Fig. 1A, panel i). In the cell envelope, the IM 
motor moves by establishing transient contacts with a complex of Glt proteins localized in the

89 OM (herein called the OM platform, see below), linked via periplasmic domains of retractile proteins that traverse the peptidoglycan meshwork ${ }^{8}$ (Fig. 1A). When in contact with the

91 substratum, these motions tether the OM platform at bFAs, which is proposed to create local

92 adhesions and movement of the cell (Fig. 1A). Consistent with localized adhesion at bFA sites,

93 gliding cells abandoned patches of OM motility-complex proteins on the substratum at positions

94 formerly occupied by bFA $\operatorname{sites}^{8}$. However, given that the OM platform is required for motor

95 movements, it could not be assessed whether the OM platform is directly responsible for

96 adhesion to the substratum ${ }^{3,8}$ and thus, the manner of adhesion, a core aspect of the motility

97 mechanism, remained unaddressed.

The proteins GltA, GltB, GltH, and GltK constitute the proposed OM platform (Fig. 1A, panel ii). While the exact structure of this platform is not known, GltA, GltB, and GltH are all localized in the OM and are predicted to form integral OM $\beta$-barrels s,4,8,13,14 $_{\text {(Fig. 1, }}$

101 Supplementary Fig. S1A-C). GltA and GltB interact with each other, as well as with GltC 102 present in the periplasmic leaflet of the $\mathrm{OM}^{13}$ (the function of GltC is not addressed herein).

103 GltK and GltH interactions have yet to be defined but data presented in our investigation suggest 104 that these proteins are functionally associated with the OM platform. Herein, we also identify the $105 \mathrm{OM}$ lipoprotein $\mathrm{CglB}^{15}$ as a main substratum-coupling adhesin of the Agl-Glt gliding motility 106 apparatus associated with the OM platform. Specifically, the results support the presence of a 107 protein assembly formed by GltA, B, H, and K that regulates CglB surface exposure, secreting it 108 to the cell surface upon stimulation of the motility complex at bFAs. 


\section{RESULTS:}

110

111

112

113

114

115

116

117

118

119

120

121

122

123

124

125

126

127

128

129

130

131

132

133

134

135

\section{GltA, B, and $\mathrm{H}$ form a putative integral OM protein complex}

The Glt OM platform contains predicted OM-spanning $\beta$-barrel proteins (Fig. 1, Supplementary Fig. S1A-C) and thus is unlikely to mediate direct substratum-anchoring of the motility complex. To probe the integral OM nature of these proteins, we tested the sensitivity of GltA, GltB, and GltH in the OM to digestion by Proteinase K. In this assay, proteins that are largely surface-exposed are rapidly digested by addition of exogenous protease, unlike proteins that are protected by the membrane environment ${ }^{13,16}$. As expected for predicted integral OM proteins, GltA, GltB, and GltH were not readily susceptible to digestion by Proteinase K at the surface in WT cells (Fig. 1B,C,D). To probe the presence of an OM-platform protein complex, the Proteinase K susceptibility of a given constituent was tested in the absence of a different OM-platform protein; the rationale was that cell-surface topology for various OM-platform proteins could be altered due to a disrupted interaction network resulting from the missing platform component. As previously detected ${ }^{13}$, neither GltA nor GltB was stable in a mutant background lacking the other, as reflected by the lower levels of GltA in $\Delta g l t B$ cells and GltB in $\Delta g l t A$ cells (compared to WT) (Fig. 1B,C, Supplementary Fig. S1D). This is consistent with the demonstrated interactions between these integral OM proteins ${ }^{13}$. Absence of GltK did not alter Proteinase K susceptibility of GltA, GltB, or GltH, indicating that this periplasm-facing OM lipoprotein ${ }^{13}$ does not affect the topology of the OM-platform proteins (Fig. 1B,C,D). However, the absence of GltH rendered GltA and GltB more Proteinase K-sensitive (Fig. 1B,C).

Similarly, GltH was more sensitive to Proteinase K digestion in the absence of GltA or GltB (Fig. 1D). The potential for these Proteinase K-susceptibility changes to be due to general OM defects in the respective mutants is unlikely as none of the mutant strains demonstrate obvious membrane and/or cell fitness defects ${ }^{13}$. These (and previous ${ }^{13}$ ) data thus support the existence of an integral OM complex formed by GltABH proteins (Fig. 1A, panel ii). Functional analysis of the role of the OM platform in regulating gliding-complex adhesion to the substratum was subsequently evaluated below. 


\section{CglB, a predicted $\alpha$-integrin-like protein, is a candidate motility adhesin}

We next searched for a candidate adhesin that might interact with the OM platform. The $\mathrm{CglB}$ protein is an ideal candidate because it is essential for efficient gliding motility $4,15,17,18$ (Supplementary Fig. S2A), localizes to the bacterial $\mathrm{OM}^{14}$, and is pulled down as prey with various gliding complex members via GST chromatography using Glt-protein bait ${ }^{5}$. The $c g l B$ gene also co-occurs with those encoding the Agl-Glt machinery in bacterial genomes, supporting a functional link (Supplementary Fig. S3). Along with all Agl-Glt gliding apparatus components, we also found CglB to be required for "polymertropism" (Supplementary Fig. S2D), as determined by the ability of $M$. xanthus to preferentially spread in the direction of aligned substratum polymers ${ }^{19-21}$. This suggests that these proteins may play a role in probing the physical properties of the substratum at bFAs, similar to eukaryotic integrins that interact with the substratum and sense its physical properties at $\mathrm{eFAs}^{22-24}$.

Fold-recognition analysis of $\mathrm{CglB}$ indicated structural analogies with numerous metazoan $\alpha$-integrins and structurally-similar Apicomplexan parasite gliding motility adhesins MIC2 and TRAP (from Toxoplasma and Plasmodium, respectively) ${ }^{25,26}$ (Supplementary Table S2). The top bacterial match was the $\alpha \mathrm{I} / \alpha \mathrm{A}$-like GBS104 adhesive tip pilin ${ }^{27}$ from Streptococcus agalactiae (Supplementary Table S2). Integrins typically possess an $\alpha$ subunit in which a Cterminal domain of seven repeating beta blades constitutes a beta-propeller domain ${ }^{28}$. Of the 18 human $\alpha$-subunit variants, half possess an additional module (termed $\alpha \mathrm{I}$ or $\alpha \mathrm{A}$ ) in-between the $2^{\text {nd }}$ and $3^{\text {rd }}$ propeller blades containing a VWA domain ${ }^{29}$, characterized by a Rossmann fold with multiple $\alpha$-helices shielding an interior $\beta$-sheet ${ }^{30}$. VWA domains typically function in cell adhesion and can be found in numerous proteins of the eukaryotic ECM. Generation of a CglB tertiary structure model, combined with analysis of evolutionarily-coupled amino acid positions within the protein, confirmed that $\mathrm{CglB}$ likely adopts the above-described $\alpha \mathrm{I} / \alpha \mathrm{A}$ structure containing a VWA domain (Fig. 2A, Supplementary Fig. S1E). In particular, the VWA

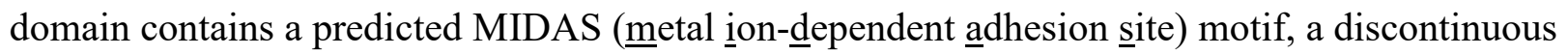
structural feature (Asp-x-Ser-x-Ser...Thr...Asp). At this site, the coordination of a divalent metal ion (e.g. $\mathrm{Mg}^{2+} / \mathrm{Mn}^{2+} / \mathrm{Ca}^{2+}$ ) induces structural changes in VWA domains upon ligand binding that stabilize this adhesive domain in a high-affinity state for the ligand ${ }^{31}$. Incidentally, CglB-dependent gliding by individual cells on a hard substratum (Fig. 2C) was also found to require the presence of divalent cations (Supplementary Figure S2G). Highly-conserved 
167 potential MIDAS residues in CglB map to D56, S58, S60, T182 and D211 (Fig. 2A, inset). We

168 tested the functional significance of the putative CglB MIDAS motif in a complementation

169 assay, ectopically expressing $\mathrm{CglB}_{\mathrm{WT}}, \mathrm{CglB}_{\mathrm{D} 56 \mathrm{~A}}$, and $\mathrm{CglB}_{\mathrm{S} 58 \mathrm{~A}}$ from the native $c g l B$ promoter.

170 Contrary to $\Delta c g l B$ cells in which $\mathrm{CglB}_{\mathrm{WT}}$ expression restored motility, $\mathrm{CglB}_{\mathrm{D} 56 \mathrm{~A}}$ was stably

171 expressed (unlike $\mathrm{CglB}_{558 \mathrm{~A}}$ ) but unable to complement gliding deficiency (Supplementary Fig.

172 S2E, F).

173 An intact VWA domain thus appears essential for CglB stability and single-cell gliding

174 motility. Direct demonstration of metal binding by the MIDAS motif of purified CglB was not

175 possible due to insurmountable purification challenges attributed to the high CglB Cys content

176 (17 out of 416 aa $=4.1 \%$ ) (Supplementary Fig. S2B), with the majority of these residues

177 predicted to localize in flexible loops (Fig. 2A). These Cys residues likely form structure-

178 determining intra-protein disulphide bonds, as titration of the reducing agent DTT resulted in a

179 migration shift from faster- to slower-moving CglB-specific bands via SDS-PAGE and $\alpha$-CglB

180 Western immunoblot (Fig. 2B). These data are also consistent with the high sensitivity of

181 single-cell gliding motility to low substratum concentrations of DTT (Supplementary Fig.

182 S2C). Taken together, the VWA domain MIDAS motif and intra-protein disulphide bonds are

183 likely important structural determinants of $\mathrm{CglB}$. 


\section{CglB is essential for substratum-coupling of the Agl-Glt machinery}

We subsequently investigated the contribution of $\mathrm{CglB}$ to surface coupling of the Agl-Glt complex. To probe the role of CglB in bFA formation, we analyzed the dynamics of AglZ-YFP clusters in cells on hard agar for the $\triangle c g l B$ mutant (which stably expresses AglZ-YFP [Supplementary Fig. S4A]). AglZ-YFP clusters still appeared in $\Delta c g l B$ cells; however, in marked contrast to WT cells, AglZ-YFP clusters in $\Delta c g l B$ cells were not stationary relative to the substratum but rather moved directionally from one pole to the other (Fig. 2C,D and Supplementary Fig. S4B). This behaviour was similar to that observed in non-adhered motility complexes $^{8}$. CglB is therefore required to assemble bFAs on hard agar surfaces. The function of $\mathrm{CglB}$ is clearly distinct from the OM-platform $\beta$-barrel proteins because trafficking AglZ-YFP clusters are not formed in any of the $\Delta g l t A / B / H$ mutant backgrounds ${ }^{8}$.

In $\Delta c g l B$ cells, trafficking AglZ-YFP clusters move in-and-out of the epifluorescence focal plane as they rotate counter-clockwise around the cell envelope (Fig. 1A, Supplementary Fig. S4B), making them difficult to precisely track and thus accurately study their dynamic properties. To resolve these difficulties, we recently developed a TIRFM assay in which $M$. xanthus cells glide in chitosan-coated microfluidic chambers (Supplementary Fig. S4C); in this system, trafficking AglZ-YFP clusters are also observable in WT cells due to the suboptimal nature of the chitosan surface for bFA adhesion ${ }^{8,32}$. Since the depth-of-field in TIRFM is restricted to near the cell-substratum interface, photobleaching is reduced and thus tracking of the trafficking AglZ-YFP clusters near the ventral face of the cell can be performed at high spatio-temporal resolution ${ }^{8}$. On chitosan, $\Delta c g l B$ cells were also non-motile and again, immobilized AglZ-YFP clusters could not be detected (Supplementary Fig. S4C). Trafficking AglZ-YFP clusters in $\triangle c g l B$ cells behaved similarly to those in WT cells; although slight effects were observed via TIRFM on the trafficking frequency of AglZ-YFP clusters (from the leading to the lagging cell poles), the trafficking speed and lifetime of AglZ-YFP clusters were unchanged in the absence of CglB (Fig. 2E-H). Since AglZ-YFP trafficking reflects the activity of the motility engine, we conclude that $\mathrm{CglB}$ does not affect motor activity, but rather its adhesion to the underlying substratum at bFAs.

To test the contribution of adhesive properties by $\mathrm{CglB}$ to the tip of the motility complex, we adopted a force microscopy approach; herein, force generation by the motility complex can be directly monitored in live $M$. xanthus cells immobilized atop a semi-solid $0.7 \%$ agarose 
215 matrix deposited on glass slides ${ }^{11}$. Within this setting, the motility complex cannot propel cells

216 (likely because it cannot adhere) but its activity can transport polystyrene beads deposited by an

217 optical trap directly on the cell surface (Fig. 2I). Trafficking gliding-machinery units that collide

218 and recruit such beads move them directionally over long distances ${ }^{11,12}$ (Supplementary Fig.

219 S4D). We therefore tested whether bead transport requires the CglB adhesin. Whereas beads

220 were transported multiple times, at lengths up to $\sim 8 \mu \mathrm{m}$, along the surface of WT cells, such

221 events were absent in $\Delta c g l B$ cells (Fig. 2J). This demonstrates that bead recruitment and

222 trafficking requires $\mathrm{CglB}$, consistent with adhesive and force transduction functions for CglB.

223 Taken together, we conclude that $\mathrm{CglB}$ is required for tethering the gliding motility

224 complex to an engaged extracellular motif, be it a solid surface for cell gliding or cargo for

225 transport in immobilized cells. Contrary to the OM-platform proteins GltA, B, and $\mathrm{H}^{8}$ (see

226 below), CglB is not required for Agl-Glt-complex assembly and trafficking suggesting that it

227 functions to couple trafficking units to the substratum, as would be expected for an adhesin. 


\section{The Glt OM platform regulates $\mathrm{CglB}$ exposure and retention at the cell surface}

Our various attempts to localize $\mathrm{CglB}$ in gliding cells were unsuccessful due to loss of protein functionality when fused to fluorescent protein or epitope tags (the folding of $\mathrm{CglB}$ in the periplasmic space, as well as its transit across the OM, are likely limiting steps, see below). Localizing CglB to the cell surface is nevertheless essential because $\mathrm{CglB}$ is an $\mathrm{OM}$ lipoprotein ${ }^{14,15}$; as such it would canonically be thought to insert into the periplasmic leaflet of the OM, though the prevalence of surface-exposed lipoproteins is becoming more widely acknowledged ${ }^{33-35}$. Indeed, Proteinase $\mathrm{K}$ shaving of liquid-grown cells (in which the motility complex is not active) did not affect $\mathrm{CglB}$ stability, suggesting that $\mathrm{CglB}$ is periplasmicallyoriented under these conditions (Supplementary Fig. S5A). One possibility is that CglB surface exposure is directly regulated by the Glt OM platform. To explore this possibility, we first compared CglB levels in whole-cell samples of each respective glt mutant strain. While present at comparable levels in $\Delta g l t C, D, E, F, G, H, I$, and $J$ backgrounds, cell-associated CglB was severely depleted in OM-platform mutants $\Delta g l t A, \Delta g l t B$, and $\Delta g l t K$ (but not $\Delta g l t H$ ) (Fig. 3A).

Fractionation analysis revealed that $\mathrm{CglB}$ was still produced by the $\Delta g l t A / B / K$ mutants (Fig. 3B); however, unlike in WT cells - where CglB was detected in whole-cell and outer-membrane vesicle (OMV) fractions - $\mathrm{CglB}$ in these three mutant backgrounds was only recovered in culture supernatants (Fig. 3B, Supplementary Fig. S5B). In the $\Delta g l t A$ and $\Delta g l t B$ mutants, such shedding to the supernatant was not observed for GltK (Fig. 3B), another OM lipoprotein required for gliding motility which remains OMV-associated, nor for the intracellular protein MglA, which was detected at levels comparable to the WT strain (Fig. 3B); together, these data indicate that cell integrity is not affected when components of the OM platform are disrupted. Therefore, cell-association (and thus OM localization) of CglB depends on GltA, GltB, and GltK.

Supernatant-localized CglB migrates faster than cell-associated CglB via SDS-PAGE (in both whole-cell and OMV samples) under equivalent denaturing conditions (Fig. 3B), suggesting that supernatant $\mathrm{CglB}$ is of reduced molecular weight and may have been proteolytically cleaved. Further support for proteolytic processing of $\mathrm{CglB}$ was provided via mass spectrometry analysis of tryptic peptides obtained from immunoprecipitated supernatant $\mathrm{CglB}$, which revealed that the first 76 N-terminal residues were unaccounted for (Supplementary Fig. S5C). Our efforts at Nterminal sequencing of supernatant $\mathrm{CglB}$ were inconclusive, and as such we were unable to 
determine the specific identity of the amino acids at the new N-terminus of the truncated protein. Thus CglB may be cleaved by a protease prior to its release into the supernatant. To test this hypothesis, we screened the effect of various protease inhibitors for their capacity at restoring CglB localization to the cell envelope. Growth in the presence of EDTA restored cell-associated CglB in this background (Fig. 3C). Similarly, EDTA also restored cell-associated CglB in the $\Delta g l t K$ and $\Delta g l t A$ mutants (Fig. 3D; see below for discussion of doublet band). Resuspension of EDTA-grown $\Delta g l t B$ cells in EDTA-free buffer resulted in the resumption of CglB release from the cells, indicating that $\mathrm{CglB}$ restoration is not permanent, consistent with a protease inhibition effect (Supplementary Fig. S5D). Since EDTA chelates divalent cations, CglB release from $\Delta g l t K / B / A$ cells would be consistent with the activity of a metalloprotease. While the involvement of a putative protease in $\mathrm{CglB}$ surface shedding awaits further clarification, the results suggest that interactions between $\mathrm{CglB}$, GltA, GltB, and GltK regulate $\mathrm{CglB}$ cell-surface association.

To determine the subcellular site of CglB proteolytic processing in the $\Delta g l t A, B$ and $K$ mutants, we took advantage of the fact that EDTA blocks proteolysis and probed surfaceexposure of $\mathrm{CglB}$ via the Proteinase K shaving assay. In marked contrast to WT cells and in the presence of EDTA, cell-associated CglB (Fig. 3D) was immediately digested by Proteinase K in the $\Delta g l t K, \Delta g l t B$, and $\Delta g l t A$ backgrounds (Fig. 3E, see below for discussion of doublet band). Interestingly, upon digestion of full-length $\mathrm{CglB}$ in $\Delta g l t A$ cells, there was an immediate appearance of a $\sim 34 \mathrm{kDa} \mathrm{CglB}$ degradation product that persisted throughout the time course, suggesting that it was protected from further digestion. This protection required GltK and GltB as the $\sim 34 \mathrm{kDa}$ product was almost undetectable in these backgrounds (discussed further below). GltH is not as central as GltA and GltB with respect to surface retention of CglB because CglB remains cell-associated in the gltH mutant (Fig. 3A). Nevertheless, CglB also shows increased sensitivity to Proteinase $\mathrm{K}$ in the absence of GltH (with the appearance and steady accumulation of an $\sim 34 \mathrm{kDa}$ Proteinase K-resistant band), suggesting that a fraction of the CglB population is also surface exposed (Fig. 3E). These results thus indicate that $\mathrm{CglB}$ becomes surface-exposed in the absence of individual OM-platform components GltA, B, K, and to a lesser extent GltH (see Discussion). 


\section{The Glt OM proteins are required for CglB exposure at the cell surface}

290

291

292

293

294

295

296

297

298

299

300

301

302

303

304

305

306

307

308

309

Two hypotheses could explain the cell-surface protease sensitivity of CglB in $\Delta g l t A / B / K / H$ cells: (i) $\mathrm{CglB}$ accesses the cell surface via an as-yet unknown system and interacts with the Glt OM platform proteins, which shield it from the action of the putative surface metalloprotease. Alternatively, (ii) the Glt OM platform proteins are directly responsible for CglB cell-surface exposure through a regulated process that becomes constitutive as soon as one of its components (i.e. GltA, B, K, and to a lesser extent $\mathrm{H}$ ) is removed.

To discriminate between these hypotheses, we probed cell-association of CglB in $\triangle g l t A B H$ triple-mutant cells lacking any of the $\beta$-barrel components of the OM platform. The level of cell-associated $\mathrm{CglB}$ in these triple-mutant cells was markedly restored (although not fully to WT levels, possibly due to stabilization of CglB by interactions with the OM gliding proteins) (Fig. 3F). This rules out the first hypothesis. Using various combinations of double $\beta$ barrel component knockouts, $\mathrm{CglB}$ restoration was found to minimally require the simultaneous deletion of $g l t A$ and $g l t H$ (Fig. 3F). To examine whether the restoration of cell-associated CglB was due to a lack of surface exposure of the adhesin, we performed Proteinase $\mathrm{K}$ shaving of $\triangle g l t A B H$ cells. In this background, $\mathrm{CglB}$ was fully protected from digestion by Proteinase $\mathrm{K}$, illustrating that $\mathrm{CglB}$ is no longer surface-exposed (Fig. 3G). Taken together, the above results indicate that interactions between GltA, B, K and $\mathrm{H}$ regulate $\mathrm{CglB}$ exposure at the cell surface. Importantly, full Proteinase K-protection of $\mathrm{CglB}$ in the $\triangle g l t A B H$ triple mutant (i) is a strong indication that these proteins play a central role in modulating $\mathrm{CglB}$ surface exposure, and (ii) rules out non-specific OM defects in the absence of OM platform components.

Page 12 of 70 


\section{GltK is required for CglB function in vivo}

While analysing CglB restoration in EDTA-grown cells, CglB was observed to migrate as two bands in WT cells: a major slower-migrating band and a minor faster-migrating band (Fig. 3D). In similar conditions, only the faster-moving band was observed in the $\Delta g l t K$ background. Thus, GltK could be involved in the formation of the slower-migrating species, a process in which it may be assisted by GltB and to a lesser extent by GltA, because the slowermigrating form accumulated to various ratios in these mutants, with almost full efficiency in the $\Delta g l t A$ mutant (Fig. 3D). It is not currently clear if the two CglB forms result from a stabilization or maturation effect of GltK on $\mathrm{CglB}$, but the slower-migrating $\mathrm{CglB}$ band constitutes the most abundant species in WT extracts (Fig. 3D) and thus probably represents the functional form of $\mathrm{CglB}$, which we subsequently confirmed (see below).

GltK could potentially interact with $\mathrm{CglB}$ via $\mathrm{Cys}$ residues as it also possesses a high Cys ratio (9 out of $184 \mathrm{aa}=4.9 \%$ ) relative to other Glt proteins (Supplementary Fig. S2B) and displays redox-dependent folding (Fig. 4A); but in the absence of an in vitro assay with purified proteins, this could not be directly tested. Nevertheless, the potential for GltK to promote CglB function in vivo was examined via two further experiments. First, TIRFM-analyzed clusters in $\Delta g l t K$ cells revealed cluster behaviour analogous to that observed in $\Delta c g l B$ cells (Fig. 2C-G); namely, clusters travelled directionally within $\Delta g l t K$ cells with lifetimes equivalent to those in WT cells, but with higher trafficking frequency (Fig. 4B, C, D). The trafficking speed of clusters was found to be statistically faster in $\Delta g l t K$ cells compared to WT (Supplementary Fig. S4E), but within the same tight range already described for $\Delta c g l B$ cells (Fig. 2F). In contrast, no trafficking clusters were observed in $\Delta g l t A$ cells (Fig. 4B), consistent with previous results ${ }^{8}$. This demonstrates that although GltA is required for cluster formation and trafficking, GltK is not (similar to CglB). Combined with the Proteinase K-susceptibility data (Fig. 1B, C), these results suggest that in the absence of GltK, the OM platform is assembled and conducive to AglZ-YFP trafficking but that CglB-mediated adhesion is not functional.

We next sought to genetically demonstrate that GltK permits CglB to function in vivo. We thus exploited the known ability of $M$. xanthus to transfer OM lipoproteins between compatible cells by a process known as OM exchange $(\mathrm{OME})^{36}$. During OME, direct interactions of TraA OM receptors lead to transient OM fusion synapses between adjacent cells and efficient exchange of OM lipids and lipoproteins between contacting cells ${ }^{37,38}$. In this 
manner, OME of $\mathrm{CglB}$ can efficiently rescue gliding motility when donor $\mathrm{CglB}^{+}$cells are mixed with recipient $\mathrm{CglB}^{-}$cells $^{15}$. GltK (previously $\mathrm{CglC}$ ) is also a transferable OM lipoprotein ${ }^{13,17}$. Therefore, we reasoned that if $\Delta g l t K$ cells were mixed with $\Delta c g l B$ cells, motility rescue of the $\Delta c g l B$ cells would only occur if bi-directional OME allows GltK transfer (from the $\Delta c g l B$ donor cells) to activate $\mathrm{CglB}$ in the $\Delta g l t K$ cells (Fig. $4 \mathrm{E}$ ). To ensure that gliding motility rescue could only arise from the trans-complementation of the $\Delta c g l B$ cells, an $\operatorname{agl} Q$ mutation was added to the $\mathrm{CglB}^{+}$donor, thus deleting an essential component of the Agl gliding motor ${ }^{11}$. This motor protein cannot be transferred via OME as it is an integral IM protein. Introduction of a fluorescent mCherry marker into the $\mathrm{CglB}^{-}$recipient strain allowed for (i) direct observation of motility rescue (Fig. 4F) and (ii) separation of $\mathrm{mCherry}^{+}$cells via fluorescence-activated cell sorting (FACS) (Fig. 4G) for testing of CglB transfer by Western immunoblot. The $\triangle a g l Q$ donor strain functioned as an effective donor for both $\mathrm{CglB}$ and GltK, ensuring that the experiment could be performed (Fig. 4F, Mix $1 \&$ Mix 2). Upon mixing $\Delta a g l Q \Delta g l t K$ doublemutant cells $\left(\mathrm{GltK}^{-} \mathrm{CglB}^{+}\right)$with $\mathrm{mCherry}^{+} \Delta \operatorname{cglB}\left(\mathrm{GltK}^{+} \mathrm{CglB}^{-}\right)$cells, gliding motility of the mCherry $^{+}$cells was restored (Fig. 4F, Mix 3). Western immunoblotting of FACS-separated mCherry $^{+}$cells (Fig. 4G) confirmed that this gliding restoration was due to CglB transfer (Fig. $4 \mathrm{H})$.

The prediction that GltK transfer from $\mathrm{GltK}^{+} \mathrm{CglB}^{-}$cells to $\mathrm{GltK}^{-} \mathrm{CglB}^{+}$cells is essential for $\mathrm{CglB}$ transfer and stimulation of $\mathrm{GltK}^{+} \mathrm{CglB}^{-}$cell motility was tested by mixing $\triangle a g l Q$ $\Delta g l t K$ cells $\left(\mathrm{GltK}^{-} \mathrm{CglB}^{+}\right)$with an $\mathrm{mCherry}^{+} \Delta c g l B \Delta g l t K\left(\mathrm{CglB}^{-} \mathrm{GltK}^{-}\right)$strain. In this case, no motility stimulation was observed (Fig. 4E,F, Mix 4) nor was any CglB transferred via OME (Fig. 4H). The lack of CglB transfer is likely due to a defect in CglB maturation/stabilization that occurs in the absence of GltK because mixing a $\Delta g l t A$ mutant — where CglB is also secreted but where the slower-migrating CglB form accumulates to near-WT levels (Fig. 3D) — with a $\Delta c g l B$ mutant still resulted in efficient motility stimulation (GltA itself is not transferable [Supplementary Fig. S6]). GltK is thus required for $\mathrm{CglB}$ function in vivo by promoting the accumulation of the slower-migrating $\mathrm{CglB}$ band, which either occurs as GltK protects $\mathrm{CglB}$ from proteolysis or promotes a maturation step. 


\section{Discussion:}

Previously, we demonstrated that on hard surfaces Myxococcus cells are propelled by directionally-transported Agl-Glt complexes that become tethered at bFAs where they exert traction forces against the underlying substratum ${ }^{8}$. However, while we demonstrated that the external OM Glt proteins are effectively anchored to the surface, the specific protein(s) conferring the adhesive properties, as well as the mechanism by which such adhesion is regulated to promote forward movements, remained unknown. The characterization of $\mathrm{CglB}, \mathrm{a}$ protein first studied $>40$ years ago ${ }^{17}$, and its interactions with the OM Glt proteins provides a solution to these questions.

Together, the data described in our current investigation indicate that $\mathrm{CglB}$ exposure at the cell surface and its proper functioning is a complex process requiring the concerted actions of a host of additional proteins such as GltK, GltB, GltA, and GltH. Combining these data with previously-published findings, we propose the following model for $\mathrm{CglB}$-mediated surface coupling of the Agl-Glt complex at bFAs:

(i) Following its assembly at the leading cell pole, the cytoplasmic-IM-periplasmic Agl-Glt complex contacts the periplasmic face of OM gliding machinery modules, constituted by GltKBAH "loaded" with CglB, through the peptidoglycan meshwork; this initiates a right-handed helical movement of the machinery toward the lagging cell pole. No bFA is formed until the complex reaches the "ventral side" of the cell that lies in contact with the underlying substratum (Fig. 5, Step 1).

(ii) Once the cytoplasmic-IM-periplasmic module contacts a substratum-associated OM module, the contractile force/action of the cytoplasmic-IM-periplasmic module on the OM complex "fires" CglB into activated contact with the substratum (Fig. 5, Step 2). Substratum-anchored CglB is thus connected across the OM by GltK and the associated GltABH OM proteins, interacting with other periplasmic Glt proteins ${ }^{8}$. This physically links the substratum and the IM motor, allowing for force transduction (Fig. 5, Step 3, see below).

(iii) After the power stroke of the IM constituents of the Agl-Glt machinery, the substratumadhered OM module is displaced, resulting in displacement of the OM and peptidoglycan sacculus (Fig. 5, Step 4). Displacement requires substratum-bound CglB to be turned over to allow new OM modules (containing $\mathrm{CglB}$ not yet bound to the substratum) to 
interact with the IM motor (Fig. 5, Step 4) and to propel the screw-like movement of the cell (Fig. 5, Step 5). Such turnover could occur by site-specific proteolysis of CglB, regulated by the GltABHK complex (Fig. 5, Step 3). This hypothesis is attractive because proteolytic turnover also occurs for integrin adhesions in metazoans ${ }^{39}$ and deregulation of $\mathrm{CglB}$ secretion triggers cell-surface cleavage of $\mathrm{CglB}$ at its $\mathrm{N}$-terminus. However, this proteolytic event could also be a natural consequence of unregulated surface exposure of the adhesin in liquid-grown cells, with other potential adhesincycling mechanisms functioning instead on solid surfaces. mechanism explaining the manner in which this protein accesses the cell surface. While OM lipoproteins are generally thought to be exposed on the periplasmic leaflet of the OM, surfaceexposed lipoproteins have recently come to the fore in bacterial cell biology ${ }^{34}$. Although several scenarios have been proposed, the surface-exposure mechanism has not been solved for most of these lipoproteins ${ }^{33}$. Interestingly in Escherichia coli, RcsF, an OM lipoprotein sensor of cellenvelope stress, becomes exposed at the cell surface as it interacts with the $\beta$-barrel porin $\mathrm{OmpA}^{40,41}$. For $\mathrm{CglB}$, our results suggest that $\mathrm{OM}$ translocation could be more complex and driven by a dedicated system formed by the GltA, B, H, and K proteins. On the periplasmic leaflet of the OM, GltK promotes CglB function via a maturation or stabilization process, which is also somewhat assisted by GltA and GltB. It is not currently clear whether GltA, B, and $\mathrm{H}$ form a complex that secretes $\mathrm{CglB}$ directly or whether it regulates the secretion activity of another system. While the latter cannot be formally ruled out, the data suggests that GltH and GltA could form pores that secrete CglB redundantly, with GltH functioning as the major pore: (i) GltH is responsible for constitutive $\mathrm{CglB}$ secretion in the $\Delta g l t A, B$, and $K$ mutants, and (ii) the simultaneous deletion of $g l t A$ and $g l t H$ abolishes $\mathrm{CglB}$ secretion. The CglB adhesin is partially accessible to Proteinase $\mathrm{K}$ in the absence of GltH (whereas it is fully protected in WT cells) also suggesting the existence of a minor GltH-independent route to the cell surface. Solving the actual structure and exact interactions within the OM platform is an ambitious endeavour, but it will be ultimately necessary to understand the manner in which interactions between three predicted porin-like proteins regulate CglB surface exposure. 
CglB secretion in liquid-grown cells is not observed in WT cells and is likely a byproduct of the sensitized genetic backgrounds. Thus in WT cells CglB surface exposure appears tightly controlled. We propose that CglB is only exposed at bFAs following dynamic interactions between the IM and OM complexes ${ }^{8}$. The exact protein interaction cascade has yet to be defined, but the proton-motor-associated IM-spanning proteins GltG/J have been proposed to undergo motor-driven extension/retraction cycles in a retractile mechanism that would allow cyclic interaction with the OM complex through the peptidoglycan ${ }^{8}$. Both proteins carry predicted TolA/TonB-like flexible periplasmic domains and globular periplasmic TonB_C domains $^{3,8}$. In ExbBD-TonB systems, these domains interact with TonB-box motifs in OM receptor proteins. Both OM $\beta$-barrel proteins GltB and GltA contain extended, unstructured Nterminal domains, with a potential TonB-box consensus sequence in the former ${ }^{8}$. Thus, the motorized IM proteins could mechanically act on the OM platform loaded with $\mathrm{CglB}$, resulting in its export past the OM (through the OM platform or as-yet unidentified proteins) and activation of the adhesin upon engagement of the substratum. Conceptually, this mechanism could be compared to the firing of a gunlock cannon in which an arm (GltG/J) exerts mechanical force on a lanyard (TonB box on the Glt OM module), resulting in firing of a projectile (CglB) through the barrel of the cannon (GltABH).

We therefore propose that the gliding motility complex functions akin to a secretion apparatus, in which a trafficking unit permits the surface exposure and cycling of an adhesin when assembled at bFAs. Energy for the secretion process would come from the $\mathrm{H}^{+}$gradient ${ }^{11}$.

451 In bacteria, TonB-dependent transporters (TBDTs) are generally viewed as macromolecular 452 import systems for siderophores and carbohydrates, but recently, the Myxococcus $\beta$-barrel TBDT 453 Oar was found to be required for secretion of a developmental protease across the $\mathrm{OM}^{42}$. Thus, 454 protein secretion may be an overlooked function of TBDTs, which should now be taken into account when studying these systems. In particular, the secretory function of the Agl-Glt system 456 may shed light on its evolutionary origin. Previously, we demonstrated that the Agl-Glt system 457 potentially evolved from a general class of envelope systems with functions as diverse as cellular motility and spore coat assembly ${ }^{43,44}$. Bacterial genome-mining analyses indicate that

459 deltaproteobacterial Agl-Glt-like systems may have evolved following acquisition and a

460 dramatic expansion of a widely-conserved gammaproteobacterial "core" complex ${ }^{43,44}$.

461 Importantly, this proposed core system is constituted by seven conserved genes (encoding AglQ, 
R, S, GltC, D, E, and G homologues) including one encoding a putative TBDT (AglRQS-GltG) and $\mathrm{OM}$ proteins in the periplasmic leaflet (GltD and E). The original function of the core complex is not known but its composition could be sufficient for protein secretion. This scenario

465 is hypothetical but the results reported herein demonstrate that Myxococcus gliding motility and

466 protein secretion are intertwined; this appears to be a common theme across diverse bacterial

467 motility mechanisms as exemplified by flagellar motility (Type-III secretion), twitching motility

468 (Type-IV pili/Type-II secretion), and Bacteroidetes gliding motility ${ }^{45,46}$. Bacteroidetes gliding

469 presents an interesting parallel: a Type-IX secretion system secretes a gliding motility adhesin

470 (SprB) which becomes propelled along the cell surface by the gliding machinery ${ }^{47-50}$. In fact, the

471 Type-IX secretion system may be directly embedded into the Bacteroidetes gliding machinery;

472 thus although they are evolutionarily distant, Bacteroidetes and myxobacterial gliding motility

473 may follow similar operational principles.

$474 \quad$ Finally, the discovery that $\mathrm{CglB}$ acts as an essential adhesin of the gliding motility

475 complex further highlights functional parallels between bFA and eFA mechanisms. In

476 eukaryotic cells, the migration of surface-adhered cells via eFA-based locomotion involves the

477 coordinated actions of a trans-envelope suite of proteins to transduce integrin-mediated cell-

478 substratum adhesion to mechanical force and movement to propel the cell forward. Adhesion to

479 the substratum at sites of activated integrins is regulated in multiple ways, including via cellular

480 chaperones ${ }^{51}$ and surface proteases ${ }^{39,52}$. Similar to eFAs, bFAs also interact with a secreted

$481 \mathrm{ECM}^{53}$; herein the $\mathrm{CglB}$ VWA domain could potentially probe the physical properties of the

482 substratum, akin to the scenario in eukaryotic integrins ${ }^{22-24}$. Thus, the fundamental requirements

483 for integrin-coupled focal adhesion-based motility may be similar in metazoan, protozoan, and

484 bacterial cells. These parallels could be important to further elucidate the mechanisms by which

485 motility promotes multicellular behaviors ${ }^{54}$ : similar to eukaryotic integrins, $\mathrm{CglB}$ could act as a

486 sensor, regulating cell-cell interactions during development and predation. 


\section{ACKNOWLEDGEMENTS:}

The authors would like to thank (i) Joel Selkrig and Nicholas Nickerson for valuable suggestions and troubleshooting regarding protease accessibility, (ii) Robert Fieldhouse for

490 insightful discussions on protein modelling and evolutionary couplings, (iii) Sabrina Gauthier for cloning pSWU30-pCglBwT, (iv) Lotte Søgaard-Andersen for the kind gift of $\alpha-\mathrm{GltK}$, $\alpha$-GltB, and $\alpha$-GltA polyclonal antibodies, (v) Vincent Géli for the contribution of $\alpha$-mCherry polyclonal

493 antibodies, (vi) Alain Roussel and Renaud Vincentelli (CNRS - Aix-Marseille University,

494 Architecture et function des macromolecules biologiques) for $\mathrm{CglB}$ protein used to generate 495 pAb, and (vii) Régine Lebrun, Pascal Mansuelle, and Rémy Puppo of the Mediterranean Institute 496 of Microbiology's Proteomics Platform for insightful discussions and sample processing for 497 mass spectrometry. A Discovery operating grant (no. RGPIN-2016-06637) from the Natural

498 Sciences and Engineering Research Council of Canada and a Discovery Award (2018-1400)

499 from the Banting Research Foundation fund work in the lab of S.T.I. The former, as well as 500 graduate studentships from the PROTEO research network, support N.Y.J.'s and F.S.'s studies.

501 Work in the lab of T.M. is supported through a European Research Council (ERC) starting grant 502 (DOME 261105) and a coup d'élan pour la recherche française award (2011) from the

503 Bettencourt-Schueller foundation. Work in the J.W.S. lab was supported by a grant (CAREER 504 PHY-0844466) from the National Science Foundation (NSF). S.T.I. was previously supported 505 by a post-doctoral fellowship in T.M.'s group from the Canadian Institutes of Health Research 506 and the AMIDEX excellence program of Aix-Marseille University. L.M.F. was funded by 507 T.M.'s ERC grant and a $4^{\text {th }}$-year thesis fellowship from the Fondation ARC. B.P.B was 508 supported by funds from the Glenn Centers for Aging Research and the National Institutes of 509 Health (P50 GM071508). Work from the M.S. lab was supported by a grant from the NSF 510 (IOS135462). None of the abovementioned funding sources had any input in the preparation of 511 this article, or in the work described herein. 


\section{Author Contributions:}

513 STI and TM conceived of and planned the study. STI performed bright field microscopy

514 and stereoscopy. STI and BJB carried out epifluorescence microscopy, with fluorescent cluster

515 analysis by TM. JBF completed TIRFM, with analysis by LMF. STI, NYJ, and FS quantified

516 cell motility. STI and AMB performed force microscopy, with analysis by AMB and JWS. LM

517 and GB carried out FACS experiments. GS generated phylogenetic data. STI performed protein

518 modelling and evolutionary coupling analysis. STI, LM, and BF generated mutant constructs.

519 DJL tested polymertropism responses, with analysis by STI and DJL. STI, LM, and NYJ

520 performed all Proteinase $\mathrm{K}$ digestions and processed all Western blots. LM performed

521 fractionation assays. BF generated anti-CglB pAb. STI and TM wrote the manuscript. STI and

522 TM generated figures. STI, MN, MS, AGG, JWS, and TM contributed personnel and/or funding

523 support. 
bioRxiv preprint doi: https://doi.org/10.1101/2020.07.22.216333; this version posted July 22, 2020. The copyright holder for this preprint (which was not certified by peer review) is the author/funder, who has granted bioRxiv a license to display the preprint in perpetuity. It is made available under aCC-BY-NC-ND 4.0 International license.

\section{DECLARATION OF INTERESTS:}

525 The authors declare no competing interests. 


\section{REFERENCES:}

1 Sun Z, Guo SS, \& Fässler R, Integrin-mediated mechanotransduction. J Cell Biol 215, 445456 (2016).

2 Kanchanawong P, Shtengel G, Pasapera AM, Ramko EB, Davidson MW, Hess HF, \& Waterman CM, Nanoscale architecture of integrin-based cell adhesions. Nature 468, 580584 (2010).

3 Islam ST \& Mignot T, The mysterious nature of bacterial surface (gliding) motility: a focal adhesion-based mechanism in Myxococcus xanthus. Semin Cell Dev Biol 46, 143-154 (2015).

4 Luciano J, Agrebi R, Le Gall AV, Wartel M, Fiegna F, Ducret A, Brochier-Armanet C, \& Mignot T, Emergence and modular evolution of a novel motility machinery in bacteria. PLOS Genet 7, e1002268 (2011).

5 Nan B, Mauriello EMF, Sun I-H, Wong A, \& Zusman DR, A multi-protein complex from Myxococcus xanthus required for bacterial gliding motility. Mol Microbiol 76, 1539-1554 (2010).

6 Nan B, Bandaria JN, Moghtaderi A, Sun I-H, Yildiz A, \& Zusman DR, Flagella stator homologs function as motors for myxobacterial gliding motility by moving in helical trajectories. Proc Natl Acad Sci USA 110, E1508-E1513 (2013).

7 Fu G, Bandaria JN, Le Gall AV, Fan X, Yildiz A, Mignot T, Zusman DR, \& Nan B, MotAB-like machinery drives the movement of MreB filaments during bacterial gliding motility. Proc Natl Acad Sci U S A 115, 2484-2489 (2018).

8 Faure LM, Fiche J-B, Espinosa L, Ducret A, Anantharaman V, Luciano J, Lhospice S, Islam ST, Tréguier J, Sotes M, Kuru E, Van Nieuwenhze MS, Brun Y, Théodoly O, L A, Nollmann M, \& Mignot T, The mechanism of force transmission at bacterial focal adhesion complexes. Nature 539, 530-535 (2016).

9 Mauriello EMF, Mouhamar F, Nan B, Ducret A, Dai D, Zusman DR, \& Mignot T, Bacterial motility complexes require the actin-like protein, MreB and the Ras homologue, MglA. EMBO J 29, 315-326 (2010).

10 Treuner-Lange A, Macia E, Guzzo M, Hot E, Faure L, Jakobczak B, Espinosa L, Alcor D, Ducret A, Keilberg D, Castaing JP, Gervais SL, Franco M, Søgaard-Andersen L, \& Mignot $\mathrm{T}$, The small G-protein MglA connects to the MreB actin cytoskeleton at bacterial focal adhesions. J Cell Biol 210, 243-256 (2015).

11 Sun M, Wartel M, Cascales E, Shaevitz JW, \& Mignot T, Motor-driven intracellular transport powers bacterial gliding motility. Proc Natl Acad Sci USA 108, 7559-7564 (2011).

12 Balagam R, Litwin DB, Czerwinski F, Sun M, Kaplan HB, Shaevitz JW, \& Igoshin OA, Myxococcus xanthus gliding motors are elastically coupled to the substrate as predicted by the focal adhesion model of gliding motility. PLoS Comput Biol 10, e1003619 (2014). 
13 Jakobczak B, Keilberg D, Wuichet K, \& Søgaard-Andersen L, Contact- and protein transferdependent stimulation of assembly of the gliding motility machinery in Myxococcus xanthus. PLOS Genet 11, e1005341 (2015).

14 Kahnt Jr, Aguiluz K, Koch Jr, Treuner-Lange A, Konovalova A, Huntley S, Hoppert M, Søgaard-Andersen L, \& Hedderich R, Profiling the outer membrane proteome during growth and development of the social bacterium Myxococcus xanthus by selective biotinylation and analyses of outer membrane vesicles. J Proteome Res 9, 5197-5208 (2010).

15 Rodriguez AM \& Spormann AM, Genetic and molecular analysis of $c g l B$, a gene essential for single-cell gliding in Myxococcus xanthus. J Bacteriol 181, 4381-4390 (1999).

16 Selkrig J et al., Discovery of an archetypal protein transport system in bacterial outer membranes. Nat Struct Mol Biol 19, 506-510 (2012).

17 Hodgkin J \& Kaiser D, Cell-to-cell stimulation of movement in nonmotile mutants of Myxococcus. Proc Natl Acad Sci USA 74, 2938-2942 (1977).

18 Youderian P, Burke N, White DJ, \& Hartzell PL, Identification of genes required for adventurous gliding motility in Myxococcus xanthus with the transposable element mariner. Mol Microbiol 49, 555-570 (2003).

19 Lemon DJ, Yang X, Srivastava P, Luk Y-Y, \& Garza AG, Polymertropism of rod-shaped bacteria: movement along aligned polysaccharide fibers. Sci Rep 7, 7643 (2017).

20 Lemon DJ, Schutzman DA, \& Garza AG, Bacterial surface spreading is more efficient on nematically aligned polysaccharide substrates. J Bacteriol 200, e00610-00617 (2018).

21 Fontes M \& Kaiser D, Myxococcus cells respond to elastic forces in their substrate. Proc Natl Acad Sci USA 96, 8052-8057 (1999).

22 Lazopoulos KA \& Stamenović D, Durotaxis as an elastic stability phenomenon. J Biomech 41, 1289-1294 (2008).

23 Vincent LG, Choi YS, Alonso-Latorre B, del Álamo JC, \& Engler AJ, Mesenchymal stem cell durotaxis depends on substrate stiffness gradient strength. Biotechnol J 8, 472-484 (2013).

24 Lo C-M, Wang H-B, Dembo M, \& Wang Y-1, Cell movement is guided by the rigidity of the substrate. Biophys J 79, 144-152 (2000).

25 Song G, Koksal AC, Lu C, \& Springer TA, Shape change in the receptor for gliding motility in Plasmodium sporozoites. Proc Natl Acad Sci USA 109, 21420-21425 (2012).

26 Song G \& Springer TA, Structures of the Toxoplasma gliding motility adhesin. Proc Natl Acad Sci USA 111, 4862-4867 (2014). 
27 Krishnan V, Dwivedi P, Kim BJ, Samal A, Macon K, Ma X, Mishra A, Doran KS, Ton-That H, \& Narayana SVL, Structure of Streptococcus agalactiae tip pilin GBS104: a model for GBS pili assembly and host interactions. Acta Crystallogr D Biol Crystallogr 69, 1073-1089 (2013).

28 Chouhan B, Denesyuk A, Heino J, Johnson MS, \& Denessiouk K, Conservation of the human integrin-type beta-propeller domain in bacteria. PLOS ONE 6, e25069 (2011).

29 Shimaoka M \& Springer TA, Therapeutic antagonists and conformational regulation of integrin function. Nat Rev Drug Discov 2, 703-716 (2003).

30 Whittaker CA \& Hynes RO, Distribution and evolution of von Willebrand/integrin A domains: widely dispersed domains with roles in cell adhesion and elsewhere. Mol Biol Cell 13, 3369-3387 (2002).

31 Shimaoka M, Takagi J, \& Springer TA, Conformational regulation of integrin structure and function. Annu Rev Biophys Biomol Struct 31, 485-516 (2002).

32 Tréguier J, Bugnicourt L, Gay G, Diallo M, Islam ST, Toro A, David L, Théodoly O, Sudre $\mathrm{G}, \&$ Mignot T, Chitosan films for microfluidic studies of single bacteria and perspectives for antibiotic susceptibility testing. mBio 10, e01375-01319 (2019).

33 Wilson MM \& Bernstein HD, Surface-exposed lipoproteins: an emerging secretion phenomenon in Gram-negative bacteria. Trends Microbiol 24, 198-208 (2016).

34 Konovalova A \& Silhavy TJ, Outer membrane lipoprotein biogenesis: Lol is not the end. Philos Trans R Soc Lond B Biol Sci 370 (2015).

35 Hooda Y \& Moraes TF, Translocation of lipoproteins to the surface of gram negative bacteria. Curr Opin Struct Biol 51, 73-79 (2018).

36 Cao P, Dey A, Vassallo CN, \& Wall D, How myxobacteria cooperate. J Mol Biol 427, 37093721 (2015).

37 Cao P \& Wall D, Direct visualization of a molecular handshake that governs kin recognition and tissue formation in myxobacteria. Nat Commun 10, 3073 (2019).

38 Ducret A, Fleuchot B, Bergam P, \& Mignot T, Direct live imaging of cell-cell protein transfer by transient outer membrane fusion in Myxococcus xanthus. eLife 2, e00868 (2013).

39 Giebeler N \& Zigrino P, A disintegrin and metalloprotease (ADAM): historical overview of their functions. Toxins 8, 122 (2016).

40 Cho S-H, Szewczyk J, Pesavento C, Zietek M, Banzhaf M, Roszczenko P, Asmar A, Laloux G, Hov A-K, Leverrier P, Van der Henst C, Vertommen D, Typas A, \& Collet J-F, Detecting envelope stress by monitoring $\beta$-barrel assembly. Cell 159, 1652-1664 (2014). 
41 Konovalova A, Perlman DH, Cowles CE, \& Silhavy TJ, Transmembrane domain of surfaceexposed outer membrane lipoprotein RcsF is threaded through the lumen of $\beta$-barrel proteins. Proc Natl Acad Sci USA 111, E4350-E4358 (2014).

42 Gómez-Santos N, Glatter T, Koebnik R, Świątek-Połatyńska MA, \& Søgaard-Andersen L, A TonB-dependent transporter is required for secretion of protease PopC across the bacterial outer membrane. Nat Commun 10, 1360 (2019).

43 Wartel M, Ducret A, Thutupalli S, Czerwinski F, Le Gall A-V, Mauriello EMF, Bergam P, Brun YV, Shaevitz J, \& Mignot T, A versatile class of cell surface directional motors gives rise to gliding motility and sporulation in Myxococcus xanthus. PLoS Biol 11, e1001728 (2013).

44 Agrebi R, Wartel M, Brochier-Armanet C, \& Mignot T, An evolutionary link between capsular biogenesis and surface motility in bacteria. Nat Rev Microbiol 13, 318-326 (2015).

45 Costa TRD, Felisberto-Rodrigues C, Meir A, Prevost MS, Redzej A, Trokter M, \& Waksman G, Secretion systems in Gram-negative bacteria: structural and mechanistic insights. Nat Rev Microbiol 13, 343-359 (2015).

46 McBride MJ, Bacteroidetes gliding motility and the Type IX secretion system. Microbiol Spectr 7 (2019).

47 Nelson SS, Bollampalli S, \& McBride MJ, SprB is a cell surface component of the Flavobacterium johnsoniae gliding motility machinery. J Bacteriol 190, 2851-2857 (2008).

48 Nakane D, Sato K, Wada H, McBride MJ, \& Nakayama K, Helical flow of surface protein required for bacterial gliding motility. Proc Natl Acad Sci U S A 110, 11145-11150 (2013).

49 Shrivastava A, Roland T, \& Berg Howard C, The screw-like movement of a gliding bacterium is powered by spiral motion of cell-surface adhesins. Biophys $J \mathbf{1 1 1}, 1008-1013$ (2016).

50 Shrivastava A \& Berg HC, A molecular rack and pinion actuates a cell-surface adhesin and enables bacterial gliding motility. Sci $A d v$ 6, eaay6616 (2020).

51 Murphy-Ullrich JE \& Sage EH, Revisiting the matricellular concept. Matrix Biol 37, 1-14 (2014).

52 Kelwick R, Desanlis I, Wheeler GN, \& Edwards DR, The ADAMTS (A Disintegrin and Metalloproteinase with Thrombospondin motifs) family. Genome Biol 16, 1-16 (2015).

53 Ducret A, Valignat M-P, Mouhamar F, Mignot T, \& Theodoly O, Wet-surface-enhanced ellipsometric contrast microscopy identifies slime as a major adhesion factor during bacterial surface motility. Proc Natl Acad Sci USA 109, 10036-10041 (2012).

54 Islam ST, Vergara Alvarez I, Saïdi F, Guiseppi A, Vinogradov E, Sharma G, Espinosa L, Morrone C, Brasseur G, Guillemot J-F, Benarouche A, Bridot J-L, Ravicoularamin G, 
674

675

676

677

678

679

680

681

682

683

684

685

686

687

688

689

690

691

692

693

694

695

696

$697 \quad 66$

698

699

Cagna A, Gauthier C, Singer M, Fierobe H-P, Mignot T, \& Mauriello EMF, Modulation of bacterial multicellularity via spatio-specific polysaccharide secretion. PLOS Biol 18, e3000728 (2020).

55 Reese MG, Application of a time-delay neural network to promoter annotation in the Drosophila melanogaster genome. Comput Chem 26, 51-56 (2001).

56 Goldman BS et al., Evolution of sensory complexity recorded in a myxobacterial genome. Proc Natl Acad Sci USA 103, 15200-15205 (2006).

57 Han K, Li ZF, Peng R, Zhu LP, Zhou T, Wang LG, Li SG, Zhang XB, Hu W, Wu ZH, Qin N, \& Li YZ, Extraordinary expansion of a Sorangium cellulosum genome from an alkaline milieu. Sci Rep 3, 2101 (2013).

58 Huntley S, Hamann N, Wegener-Feldbrugge S, Treuner-Lange A, Kube M, Reinhardt R, Klages S, Muller R, Ronning CM, Nierman WC, \& Sogaard-Andersen L, Comparative genomic analysis of fruiting body formation in Myxococcales. Mol Biol Evol 28, 1083-1097 (2011).

59 Huntley S, Kneip S, Treuner-Lange A, \& Søgaard-Andersen L, Complete genome sequence of Myxococcus stipitatus strain DSM 14675, a fruiting myxobacterium. Genome Announc 1, e00100-00113 (2013).

60 Huntley S, Zhang Y, Treuner-Lange A, Kneip S, Sensen CW, \& Sogaard-Andersen L, Complete genome sequence of the fruiting myxobacterium Corallococcus coralloides DSM 2259. J Bacteriol 194, 3012-3013 (2012).

61 Ivanova $\mathrm{N}$ et al., Complete genome sequence of Haliangium ochraceum type strain (SMP2T). Stand Genomic Sci 2, 96-106 (2010).

62 Li Z-F, Li X, Liu H, Liu X, Han K, Wu Z-H, Hu W, Li F-f, \& Li Y-Z, Genome sequence of the halotolerant marine bacterium Myxococcus fulvus HW-1. J Bacteriol 193, 5015-5016 (2011).

63 Müller S, Willett JW, Bahr SM, Darnell CL, Hummels KR, Dong CK, Vlamakis HC, \& Kirby JR, Draft genome sequence of Myxococcus xanthus wild-type strain DZ2, a model organism for predation and development. Genome Announc 1, e00217-00213 (2013).

64 Schneiker S et al., Complete genome sequence of the myxobacterium Sorangium cellulosum. Nat Biotech 25, 1281-1289 (2007).

65 Sharma G, Khatri I, \& Subramanian S, Complete genome of the starch-degrading myxobacteria Sandaracinus amylolyticus DSM 53668T. Genome Biol Evol 8, 2520-2529 (2016).

66 Sharma G, Narwani T, \& Subramanian S, Complete genome sequence and comparative genomics of a novel myxobacterium Myxococcus hansupus. PLOS ONE 11, e0148593 (2016). 
67 Stevens DC, Young J, Carmichael R, Tan J, \& Taylor RE, Draft genome sequence of gephyronic acid producer Cystobacter violaceus strain $\mathrm{Cb}$ vi76. Genome Announc 2, e01299-01214 (2014).

68 Sharma G \& Subramanian S, Unravelling the complete genome of Archangium gephyra DSM $2261 \mathrm{~T}$ and evolutionary insights into myxobacterial chitinases. Genome Biol Evol 9, 1304-1311 (2017).

69 Sharma G, Khatri I, \& Subramanian S, Comparative genomics of myxobacterial chemosensory systems. J Bacteriol 200, e00620-00617 (2018).

$70 \mathrm{Wu}$ M \& Eisen JA, A simple, fast, and accurate method of phylogenomic inference. Genome Biol 9, R151 (2008).

71 Stamatakis A, RAxML-VI-HPC: maximum likelihood-based phylogenetic analyses with thousands of taxa and mixed models. Bioinformatics 22, 2688-2690 (2006).

72 Nudleman E, Wall D, \& Kaiser D, Cell-to-cell transfer of bacterial outer membrane lipoproteins. Science 309, 125-127 (2005).

73 Pathak DT \& Wall D, Identification of the $c g l C, c g l D, c g l E$, and $c g l F$ genes and their role in cell contact-dependent gliding motility in Myxococcus xanthus. J Bacteriol 194, 1940-1949 (2012).

74 Johnson LS, Eddy SR, \& Portugaly E, Hidden Markov model speed heuristic and iterative HMM search procedure. BMC Bioinformatics 11, 431 (2010).

75 Letunic I \& Bork P, Interactive tree of life (iTOL) v3: an online tool for the display and annotation of phylogenetic and other trees. Nucleic Acids Res 44, W242-W245 (2016).

76 Rice P, Longden I, \& Bleasby A, EMBOSS: The European molecular biology open software suite. Trends Genet 16, 276-277 (2000).

77 Drozdetskiy A, Cole C, Procter J, \& Barton GJ, JPred4: a protein secondary structure prediction server. Nucl Acids Res (2015).

78 Letunic I, Doerks T, \& Bork P, SMART: recent updates, new developments and status in 2015. Nucl Acids Res 43, D257-D260 (2015).

79 Söding J, Biegert A, \& Lupas AN, The HHpred interactive server for protein homology detection and structure prediction. Nucl Acids Res 33, W244-W248 (2005).

80 Källberg M, Wang H, Wang S, Peng J, Wang Z, Lu H, \& Xu J, Template-based protein structure modeling using the RaptorX web server. Nat Protoc 7, 1511-1522 (2012).

81 Barbato A, Benkert P, Schwede T, Tramontano A, \& Kosinski J, Improving your targettemplate alignment with MODalign. Bioinformatics 28, 1038-1039 (2012). 
$733 \quad 82 \quad$ Sali A \& Blundell TL, Comparative protein modelling by satisfaction of spatial restraints. $J$ $734 \quad$ Mol Biol 234, 779-815 (1993).

73583 Vehlow C, Stehr H, Winkelmann M, Duarte JM, Petzold L, Dinse J, \& Lappe M, CMView: 736 interactive contact map visualization and analysis. Bioinformatics 27, 1573-1574 (2011).

73784 Wang S, Li W, Zhang R, Liu S, \& Xu J, CoinFold: a web server for protein contact

738 prediction and contact-assisted protein folding. Nucleic Acids Res 44, W361-W366 (2016).

73985 Ducret A, Quardokus EM, \& Brun YV, MicrobeJ, a tool for high throughput bacterial cell 740 detection and quantitative analysis. Nat Microbiol 1, 16077 (2016).

74186 Wang S, Arellano-Santoyo H, Combs PA, \& Shaevitz JW, Measuring the bending stiffness 742 of bacterial cells using an optical trap. J Vis Exp, e2012 (2010). 


\section{Figure Titles AND LegendS:}

Figure 1: Evidence of an Integral OM Complex Formed by GItA, B, and H.

A) Gliding motility mediated by bFAs in M. xanthus. Following their assembly at the leading pole, motility complexes move toward the lagging cell pole in a counter clockwise (CCW) rotational trajectory. Clockwise $(\mathrm{CW})$ and $\mathrm{CCW}$ directionalities are defined by observing the cell cylinder from the leading pole in the $y, z$ plane. When the complexes interact with the substratum, they form bacterial focal adhesion (bFA, concentric circles) sites and propel rotational movements of the cell. Panel (i): bFAs are formed according to two possible mechanisms: In the viscous interaction model, the periplasmic complex accumulates at bFAs and pushes against the elastic peptidoglycan (PG) to create cell envelope deformations at bFAs and thus create viscous interactions with the substratum. The function of the outer-membrane (OM) complex is not accounted for in this model. In the elastic model, the periplasmic complex establishes transient interactions through the PG, contacting the OM complex which itself interacts with the substratum via an unknown adhesive molecule (pink circle). Panel (ii): Proposed Glt OM platform based on previous reports and this study. The OM localization of GltA, GltB, GltH, GltC and GltK is based on structural bioinformatic as well as fractionation analyses presented

761 here and elsewhere ${ }^{4,13,14}$. The integral association of GltA, B and $\mathrm{H}$ is based on bioinformatic 762 and Proteinase $\mathrm{K}$ accessibility assays in this study and another report ${ }^{13}$. Direct GltA-GltB,

763 GltA-GltC, and GltB-GltC interactions were already biochemically demonstrated by pull-down 764 assays $^{13}$. The connection with GltH is further indicated from results reported in this study. The periplasmic leaflet (orange) and outer leaflet (yellow) of the OM are indicated. Legend: Peri, 766 periplasm.

767 Western immunoblot of B) GltA, C) GltB, and D) GltH susceptibility to digestion by Proteinase $768 \mathrm{~K}$ in OM-module Agl-Glt mutant strains. Digestion aliquots were removed at 15-min intervals 769 and TCA-precipitated to stop digestion. Legend for Panels B, C, and D: ४, full-length protein;

$770 \bigcirc$, loading control (non-specific protein band labelled by the respective $\alpha-\mathrm{GltA} / \alpha-\mathrm{GltB} / \alpha-\mathrm{GltH}$ $771 \mathrm{pAb})$. 


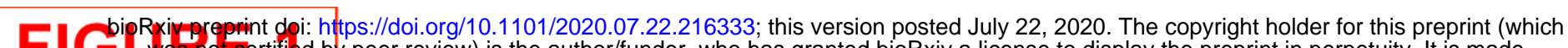
FIGURE
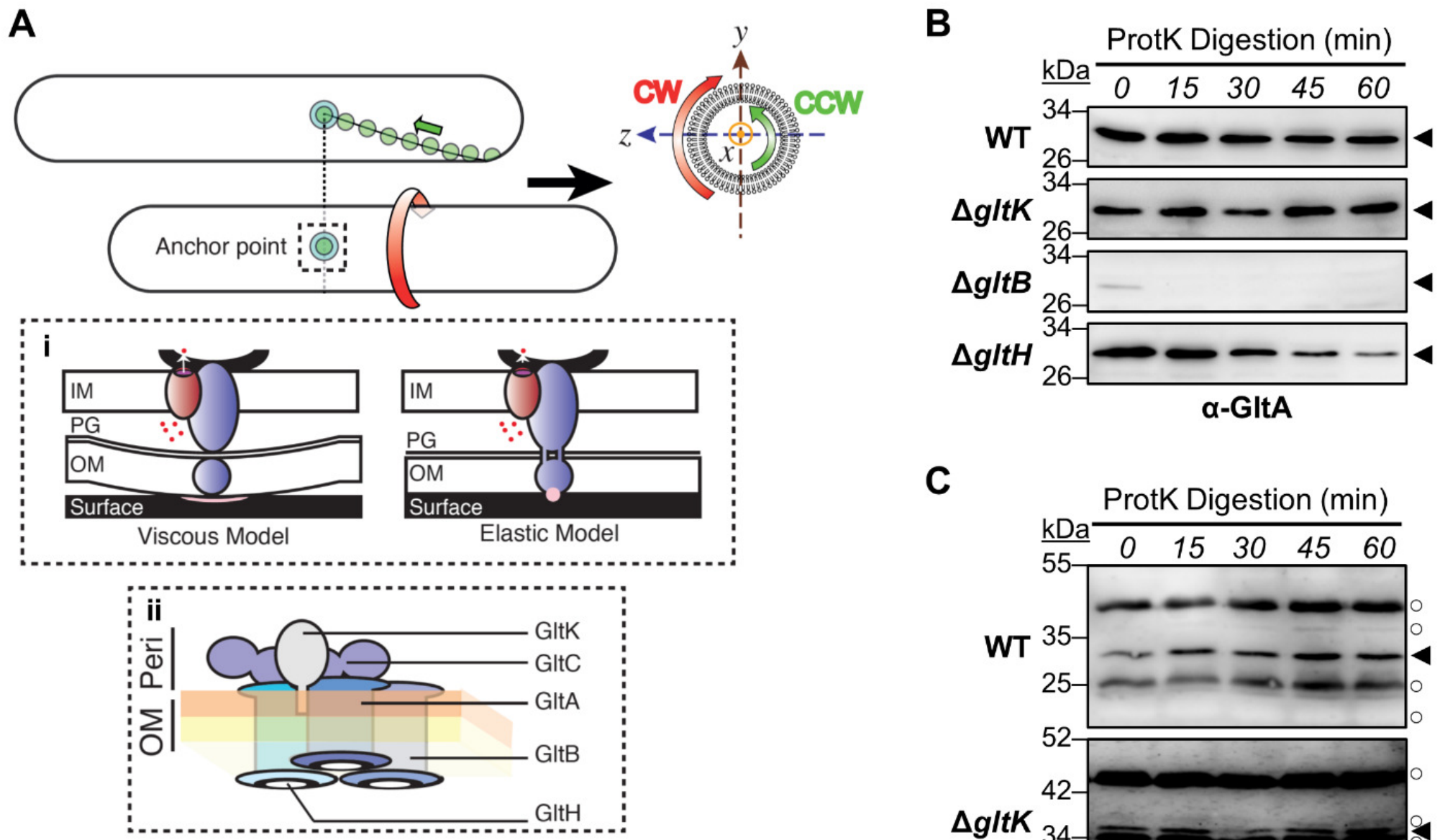

C
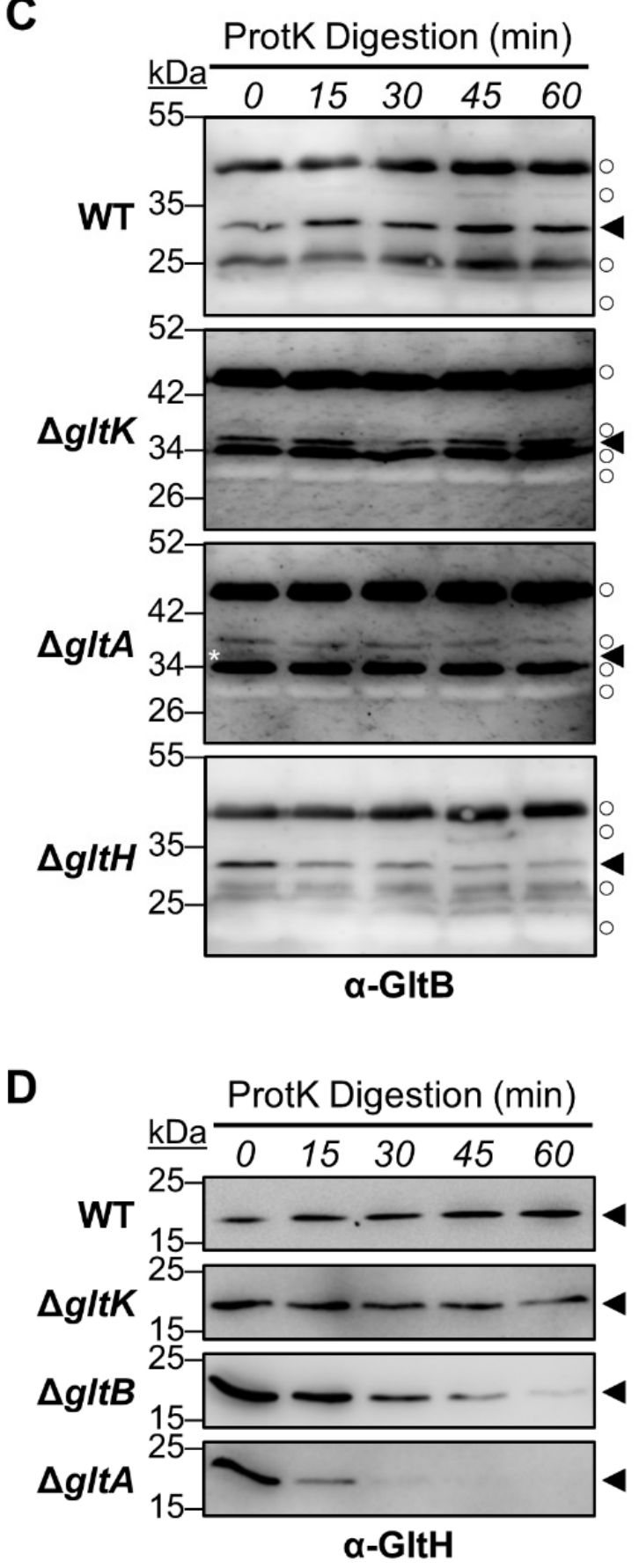


\section{Figure 2: CglB, a protein with a potential $\alpha$-integrin-like fold, is essential for motility}

774

775

776

777

778

779

780

781

782

783

784

\section{complex adhesion to the substratum}

A) Tertiary structure homology model of $\mathrm{CglB}$. The $\mathrm{N}$ - and C-terminus of the protein are indicated. Colour code: yellow, $\beta$-strands; red, $\alpha$-helices, black spheres, Cys residues. Dotted line denotes a magnified view of the MIDAS motif containing residues D56, S58, S60, T182, D211. See also Supplementary Figs. S1E, S2E, F and Supplementary Table S2.

B) $\alpha$-CglB Western blot of WT whole-cell extracts treated with increasing concentrations of DTT to break disulphide bonds. Legend: ४, full-length CglB; ○, loading control (non-specific protein band labelled by $\alpha-C g 1 B$ pAb). See also Supplementary Fig. S2B.

C) Kymograph in WT vs. $\Delta c g l B$ cells indicating AglZ-YFP cluster position over time (hashed lines). Scale bar: $2 \mu \mathrm{m}$. Legend: white arrowheads, AglZ-YFP clusters followed for their entire lifetime; black arrowheads, AglZ-YFP clusters followed for an incomplete lifetime. See also Supplementary Fig. S4B.

D) Mean-squared displacement (MSD) analysis of AglZ-YFP cluster position tracking in WT (n $=48$ clusters $)$ and $\Delta c g l B(\mathrm{n}=23$ clusters $)$ M. xanthus cells. The mean of MSD at each time interval is displayed $\pm \mathrm{SEM}$, with a second-order polynomial line fit to each dataset.

E) Frequency of trafficking Agl-Glt complexes via TIRFM (of AglZ-YFP) on chitosan-coated glass surfaces in PDMS microfluidic chambers for WT $(\mathrm{n}=44$ cells $)$ and $\Delta \operatorname{cglB}(\mathrm{n}=41$ cells $)$ strains. The distribution of the two datasets are significantly different $(*)$, as calculated via unpaired two-tailed Mann-Whitney U-test $(p<0.05)$. See also Supplementary Fig. S4C.

F) Speed of Agl-Glt complex trafficking via TIRFM (of AglZ-YFP) on chitosan-coated glass surfaces in PDMS microfluidic chambers for WT $(\mathrm{n}=260$ clusters $)$ and $\Delta c g l B(\mathrm{n}=371$ clusters $)$ strains. The distribution of the two datasets are not significantly different, as calculated via unpaired two-tailed Mann-Whitney U-test $(p>0.05)$. See also Supplementary Fig. S4C. G) Stability of trafficking Agl-Glt complexes via TIRFM (of AglZ-YFP) on chitosan-coated glass surfaces in PDMS microfluidic chambers for WT $(\mathrm{n}=333$ clusters $)$ and $\Delta \operatorname{cglB}(\mathrm{n}=409$ clusters) strains. The distribution of the two datasets are not significantly different, as calculated via unpaired two-tailed Mann-Whitney U-test $(p>0.05)$. See also Supplementary Fig. S4C. H) Directionality of trafficked Agl-Glt complexes via TIRFM (of AglZ-YFP) on chitosancoated glass surfaces for WT $(\mathrm{n}=44$ cells $)$ and $\Delta \operatorname{cglB}(\mathrm{n}=41$ cells $)$ strains. "Front" and "back" are defined as cell poles with high and low AglZ-YFP fluorescence intensity, respectively. 
804 Relative to the respective reference WT cluster type, only the distribution of front-to-back

805 clusters were significantly different in the $\Delta c g l B$ cells $(p<0.05)$; all other cluster types did not

806 display distributions different from WT $(p>0.05)$, as calculated via unpaired two-tailed Mann-

807 Whitney U-test. See also Supplementary Fig. S4C.

808 I) Trafficking of surface-deposited polystyrene beads on $M$. xanthus cells. Images were acquired 809 at $10 \mathrm{~s}$ intervals. See also Supplementary Fig. S4D.

810 J) Length of tracked bead runs $>0.1 \mu \mathrm{m}$ in M. xanthus cells. Images from $10 \mathrm{~s}$ intervals were 811 analyzed. See also Supplementary Fig. S4D. 
FI FIGURE-2: available under aCC-BY-NC-ND 4.0 International license.

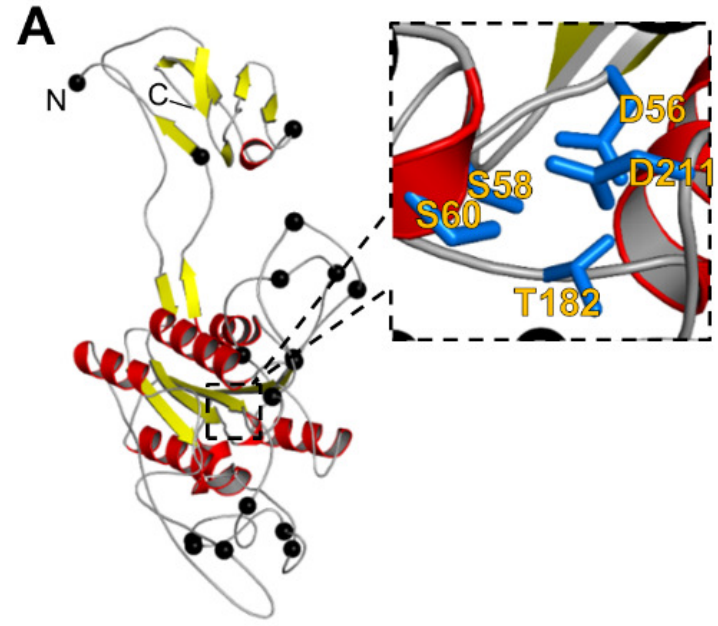

C

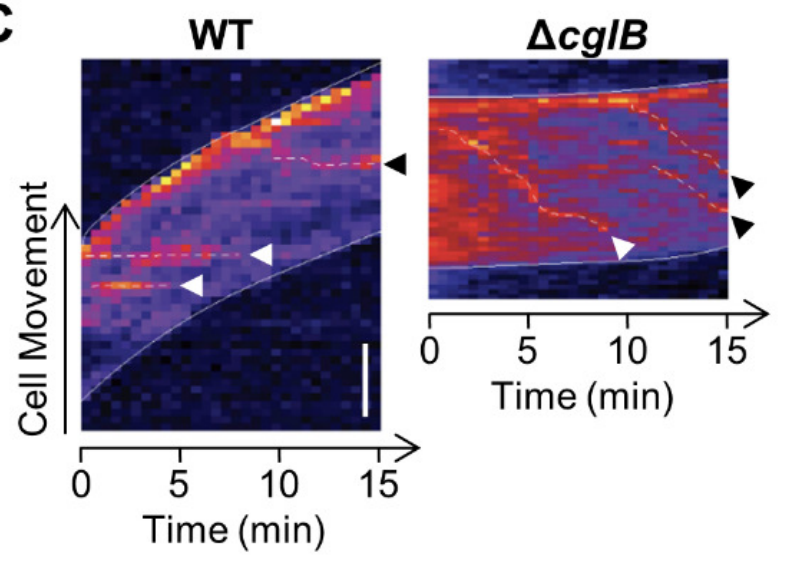

B

\section{CglB Unfolding Under Reducing Conditions}

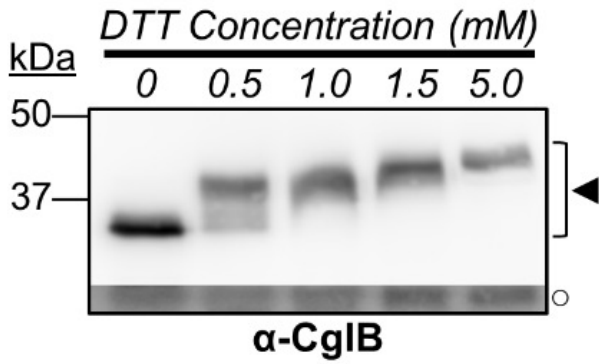

D

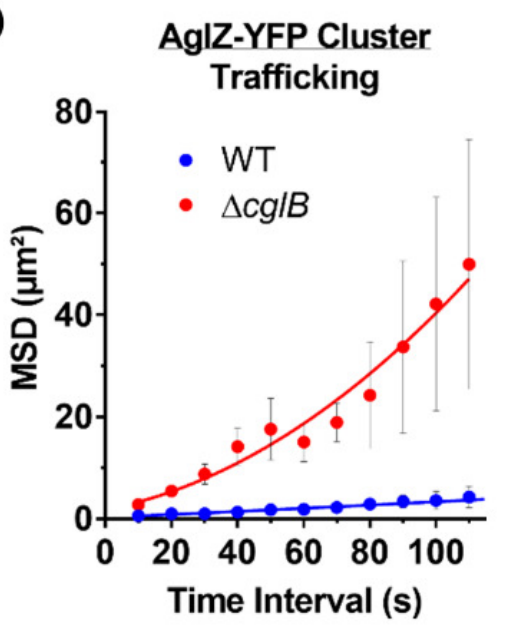

E
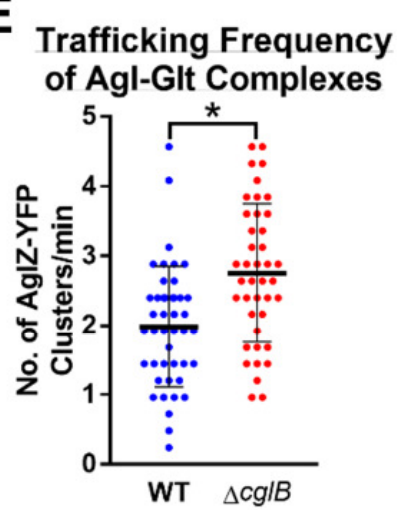

F

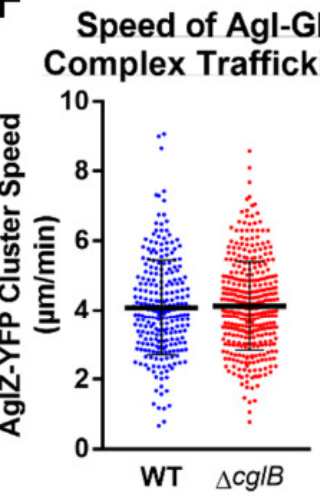

G

Stability of Agl-Glt Complexes

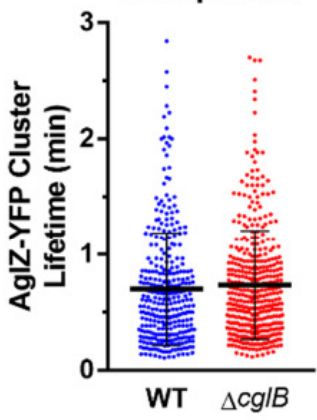

H
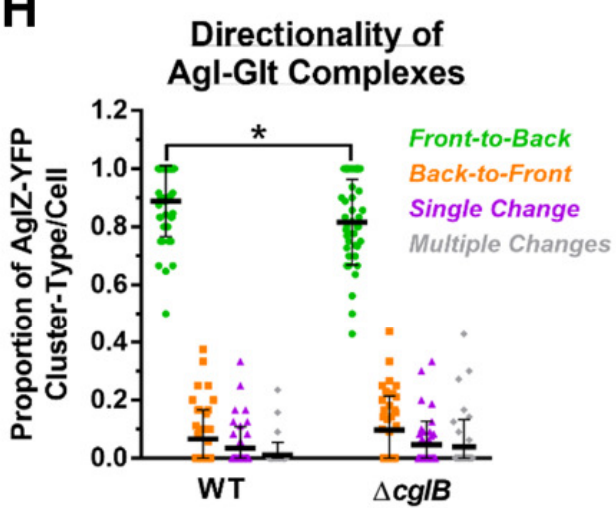

I

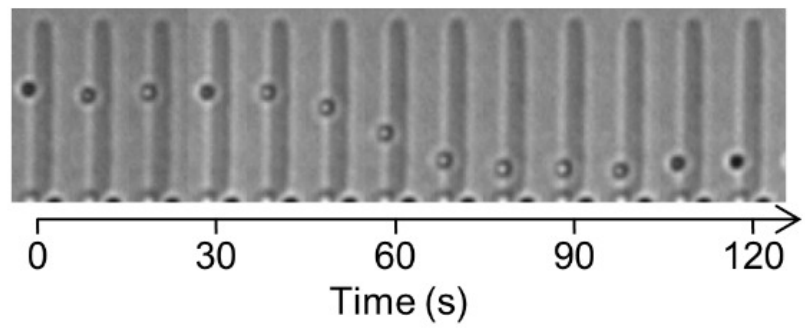

$\Delta c g / B$

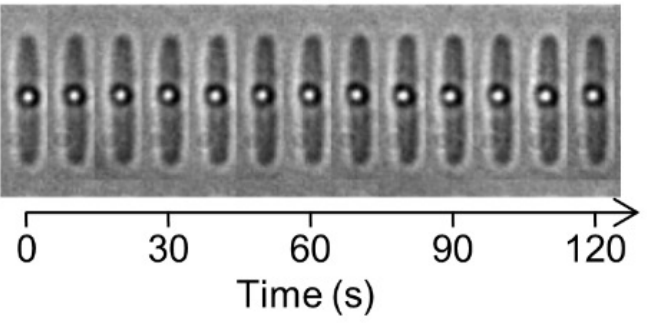

J

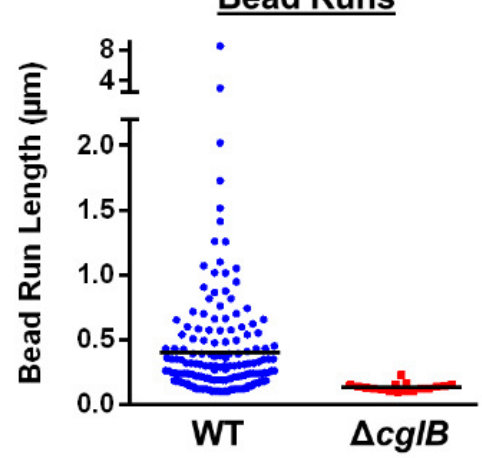


$813 \quad$ Figure 3: CglB Secretion is Mediated by the Glt OM Platform

$814 \alpha$-CglB Western blots from:

815 A) Whole-cell extracts from different $\Delta g l t$ mutants. Non-adjacent lanes on the blot are separated

816 by vertical black lines. White space separates two distinct blots processed at the same time.

817 B) Fractionated samples containing whole cells (WC), supernatants (Sup), and outer-membrane

818 vesicles (OMV) from various genetic backgrounds. Detection of the gliding motility OM

819 lipoprotein GltK was added as a control, with the protein only detected in WC and OMV

820 samples, showing that the various mutations do not affect OM integrity, with the supernatant

821 localization in this instance being specific to CglB. MglA is a cytoplasmic protein added as a

822 control to show that cell lysis is negligible and does not account for the presence of $\mathrm{CglB}$ in

823 supernatants. Legend: 4, full-length protein; ○, loading control (non-specific protein band

824 labelled by the respective $\mathrm{pAb}$ ).

825 C) Whole-cell extracts from $\Delta g l t B$ cells grown in the presence of different protease inhibitors.

826 White space separates two distinct blots from the same experiment.

827 D) Restoration of cell-associated CglB in EDTA-grown $\Delta g l t K / B / A$ cells. Different ratios of the

828 slower- and faster-migrating bands were observed depending on the mutation of the specific

829 strain. Lower, darker zones on each blot correspond to sections of the same blot image for which

830 the contrast has been increased to highlight lower-intensity protein bands. Legend: 4 , full-

831 length $\mathrm{CglB}$; $\circ$, loading control (non-specific protein band labelled by $\alpha-\mathrm{CglB}$ pAb).

832 E) Protein samples from cells resuspended in TPM buffer and digested with exogenous

833 Proteinase K. Aliquots of the digestion mixture were removed at 15-min intervals and TCA-

834 precipitated to stop digestion. "P" and "PEDTA" denote lanes containing the untreated parent

835 strain and the parent strain grown in the presence of EDTA, respectively. Lower, darker zones

836 on each blot correspond to sections of the same blot image for which the contrast has been

837 increased to highlight lower-intensity protein bands. Legend: 4 , full-length $\mathrm{CglB}$; $\leftarrow, \mathrm{CglB}$

838 degradation band; $\circ$, loading control (non-specific protein band labelled by $\alpha$-CglB antibody).

839 See also Supplementary Fig. S5A.

840 F) Whole-cell extracts from different combinations of $\Delta g l t$ OM-module mutations in the same

841 strain. Non-adjacent lanes on the blot are separated by vertical black lines. Legend: 4 , full-

842 length $\mathrm{CglB}$; , loading control (non-specific protein band labelled by $\alpha$-CglB pAb). 
bioRxiv preprint doi: https://doi.org/10.1101/2020.07.22.216333; this version posted July 22, 2020. The copyright holder for this preprint (which

was not certified by peer review) is the author/funder, who has granted bioRxiv a license to display the preprint in perpetuity. It is made available under aCC-BY-NC-ND 4.0 International license.

843 G) Protein samples from cells resuspended in TPM buffer and digested with exogenous

844 Proteinase K. Aliquots of the digestion mixture were removed at 15-min intervals and TCA-

845 precipitated to stop digestion. Legend: ४, full-length $\mathrm{CglB}$; ○, loading control (non-specific

846 protein band labelled by $\alpha-\mathrm{CglB} \mathrm{pAb}$ ). 
A Whole copivpreprint doi: https://doi.org/10.1101/2020.07.22.216333; this version posted July 22, 2020. The copyright holder for thisspreprint (whieh

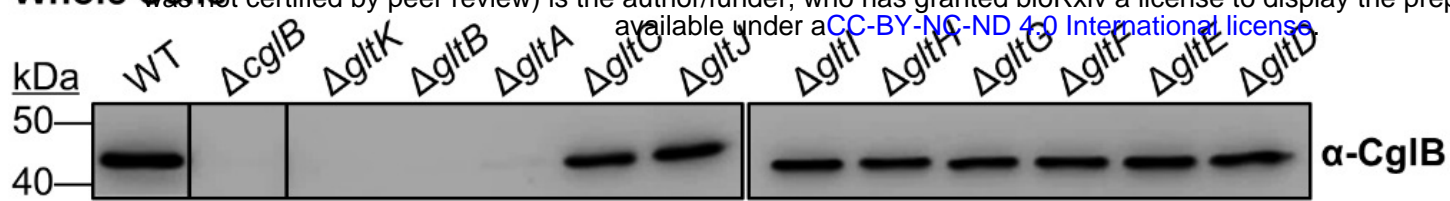

B

Differential CglB Subcellular Localization in $\Delta g / t A / B / K$ Mutants

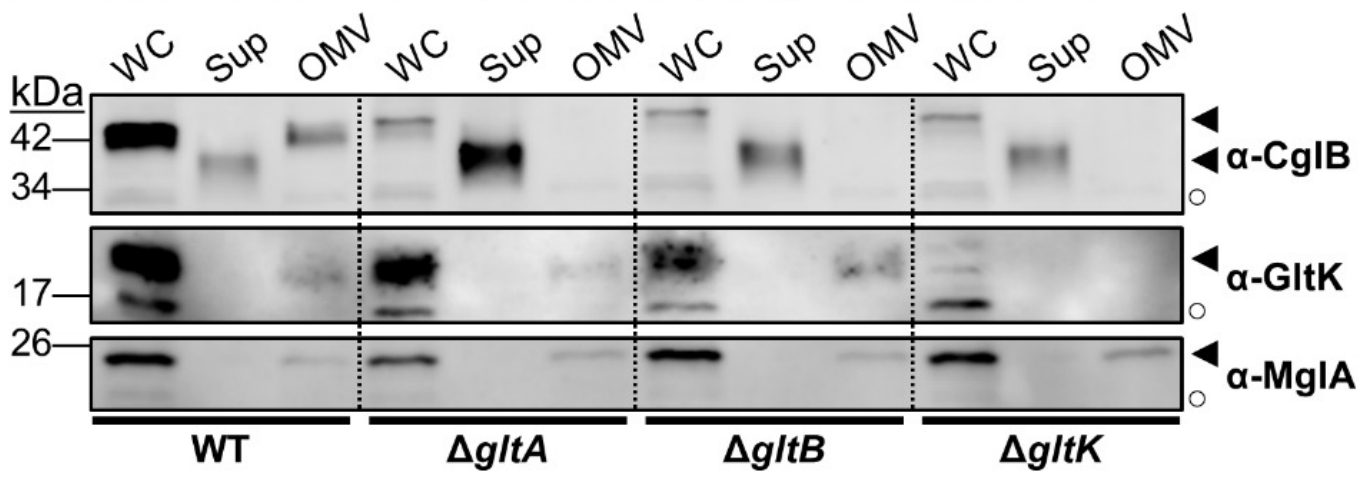

C

Protease Inhibition

(Whole Cells)

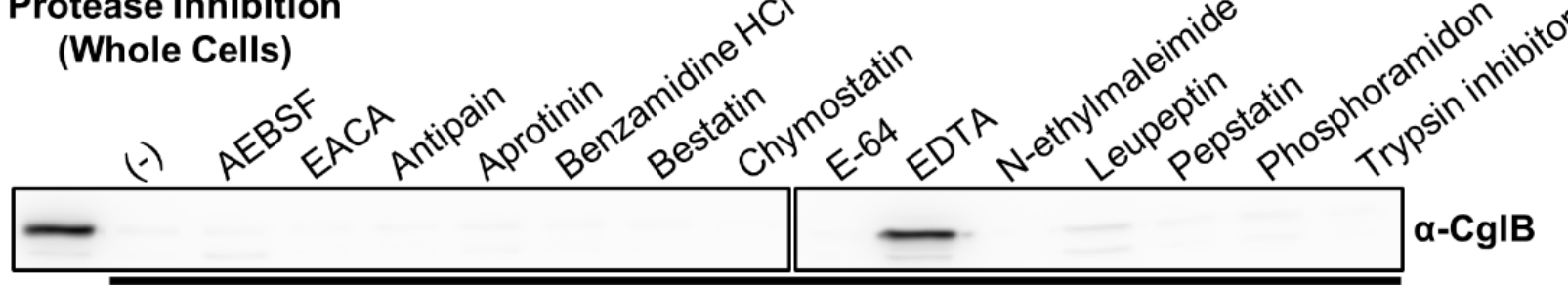

WT

$\Delta \boldsymbol{g l t} \boldsymbol{B}$ (grown in presence of protease inhibitors)

Restoration of CgIB in Whole Cells

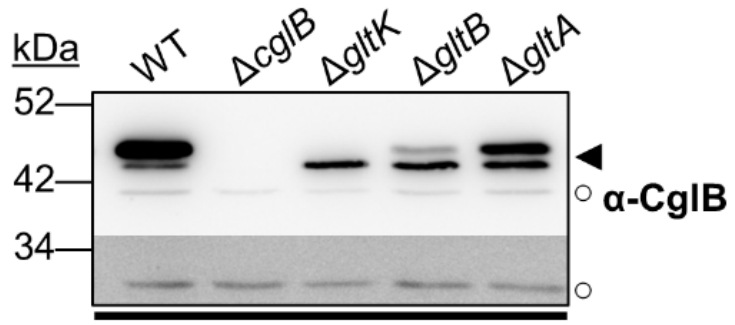

Cells grown with EDTA

(TCA, acetone treated)

$\mathbf{F}$

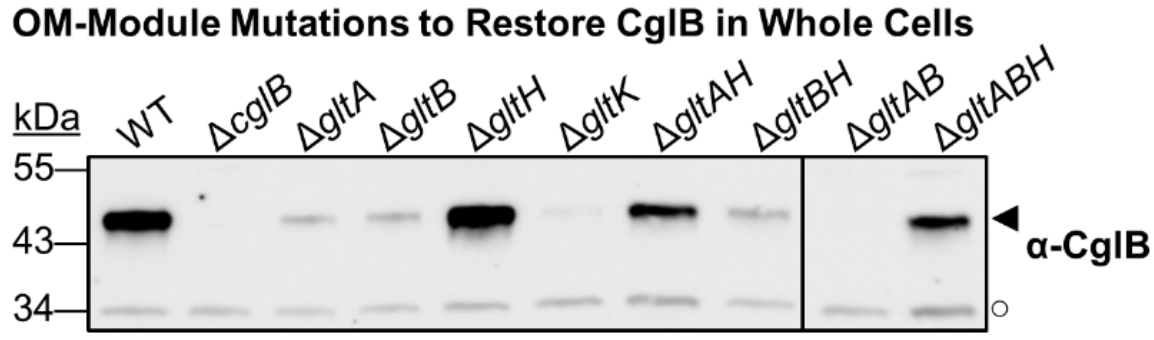

\section{OM-Module \\ Mutations \\ That Block \\ CgIB ProtK \\ Sensitivity}

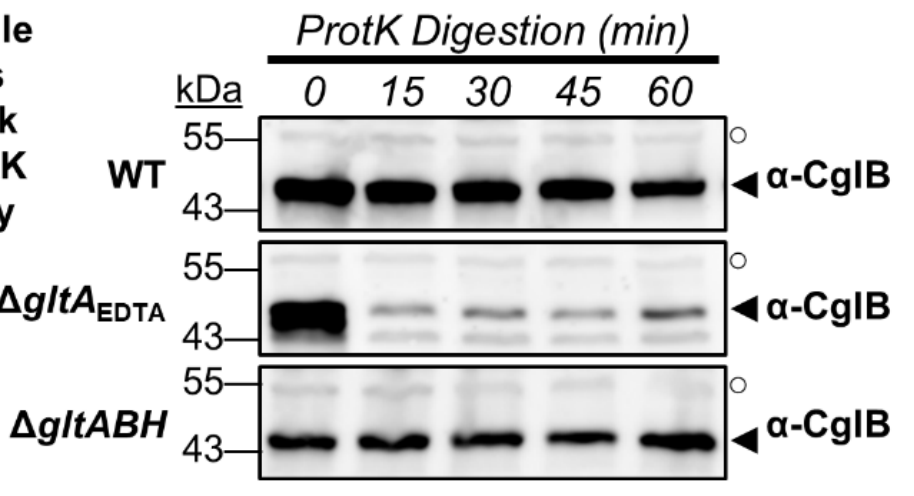

E Surface Exposure of Restored CgIB
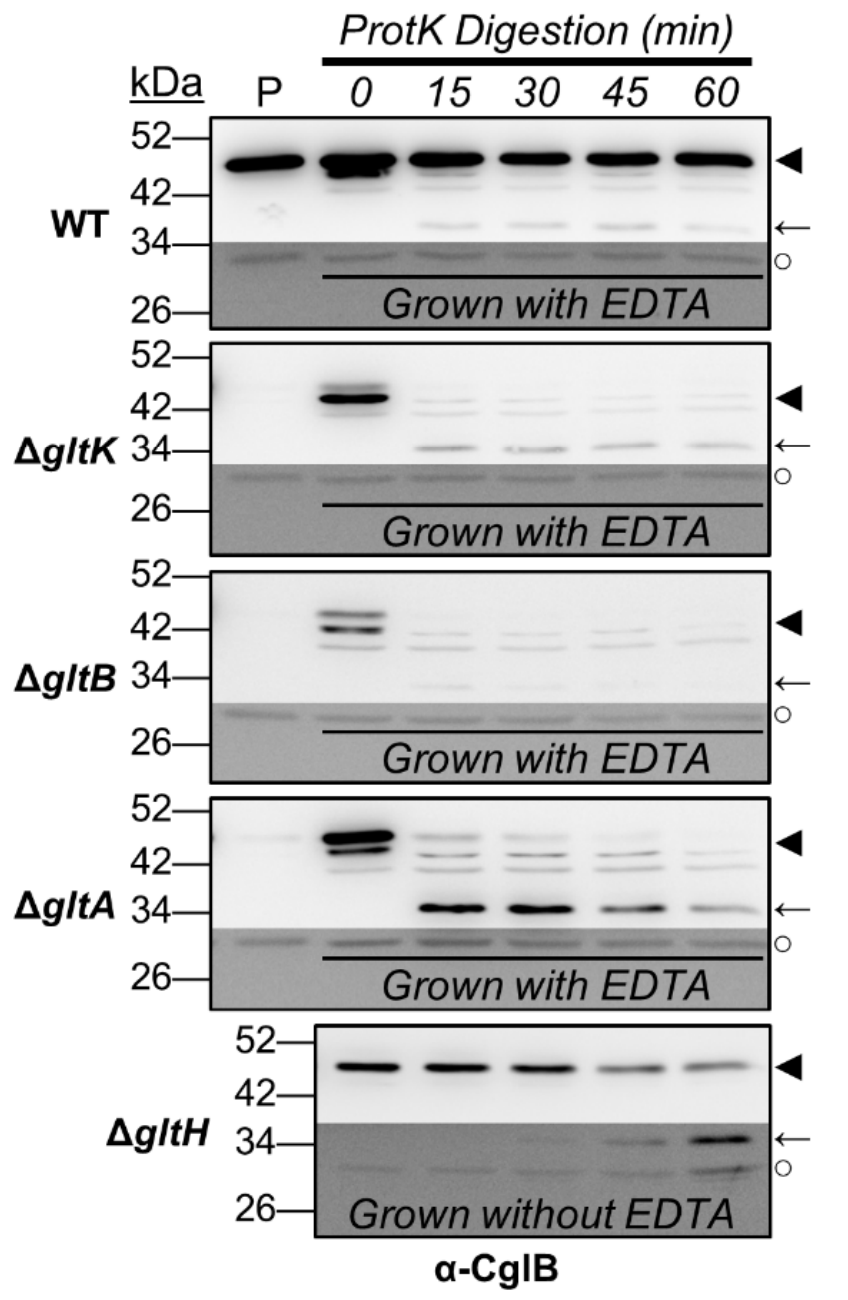


\section{Figure 4: Role of GltK in CgIB Function}

849 A) $\alpha$-GltK Western blot of WT whole-cell extracts treated with increasing concentrations of DTT to break disulphide bonds. Legend: ४, full-length GltK; O, loading control (non-specific protein

851 band labelled by $\alpha$-GltK pAb). See also Supplementary Fig. S2B.

852 B) Kymograph of $\Delta g l t A$ vs. $\Delta g l t K$ cells showing AglZ-YFP cluster position over time. Scale

853 bar: $2 \mu \mathrm{m}$. Legend: white arrowheads, AglZ-YFP clusters followed for their entire lifetime; black

854 arrowheads, AglZ-YFP clusters followed for an incomplete lifetime. See also Supplementary

855 Fig. S4C.

856 C) Frequency of trafficking Agl-Glt complexes via TIRFM (of AglZ-YFP) on chitosan-coated

857 glass surfaces in PDMS microfluidic chambers for WT $(\mathrm{n}=37$ cells $)$ and $\Delta g l t K(\mathrm{n}=44$ cells $)$

858 strains. The distribution of the two datasets are significantly different $(*)$, as calculated via 859 unpaired two-tailed Mann-Whitney U-test $(p<0.05)$. See also Supplementary Fig. S4C.

860 D) Stability of trafficking Agl-Glt complexes via TIRFM (of AglZ-YFP) on chitosan-coated

861 glass surfaces in PDMS microfluidic chambers for WT ( $\mathrm{n}=90$ clusters) and $\Delta g l t K(\mathrm{n}=223$

862 clusters) strains. The distribution of the two datasets are not significantly different, as calculated

863 via unpaired two-tailed Mann-Whitney U-test $(p>0.05)$. See also Supplementary Fig. S4C.

864 E) Schematic of inter-strain mixes to study OME and the interplay between GltK and CglB.

865 F) Gliding motility restoration in mCherry $^{+}$cells via trans-complementation following OME.

866 Note that motile single cells, as well as gliding-dependent flares emanating from swarm fronts

867 (which are dependent on collective effects of single-cell motility), are only observable when

$868 \mathrm{CglB}$ is efficiently transferred (white arrows). Scale bar: $20 \mu \mathrm{m}$.

869 G) $M$. xanthus cells from strain-mixing experiments to probe GltK-dependent CglB transfer via

870 OME. Left panel: Fluorescence profile of the total cell population after $6 \mathrm{~h}$ of cell mixing on an

871 agar substratum, as determined via flow cytometry. Right panel: FACS analysis of the mCherry ${ }^{+}$

872 cell population after sorting.

873 H) Western immunoblot to detect the presence of $\mathrm{CglB}$ and mCherry following OME via various

874 strain-strain mixes. Legend: 4 , full-length protein; $\circ$, loading control (non-specific protein band

875 labelled by respective pAb). 
DioRxivpreprint doi: https://doi.org/10.1101/2020.07.22.216333; this version posted July 22, 2020. The copyright holder for this preprint (which -1 yas notcertified by peer review) is the author/funder, who has granted bioRxiv a license to display the preprint in perpetuity. It is made available under aCC-BY-NC-ND 4.0 International license.

\section{A GltK Unfolding Under Reducing} Conditions

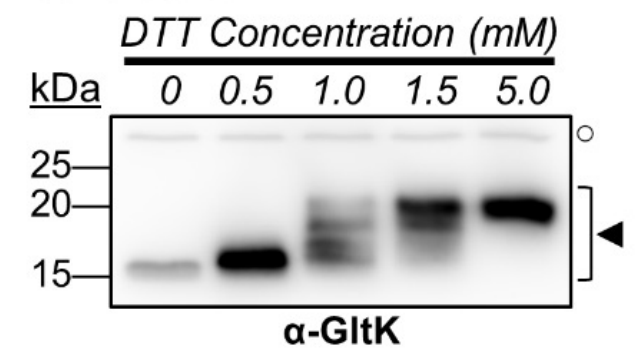

C Trafficking Frequency of Agl-Glt Complexes
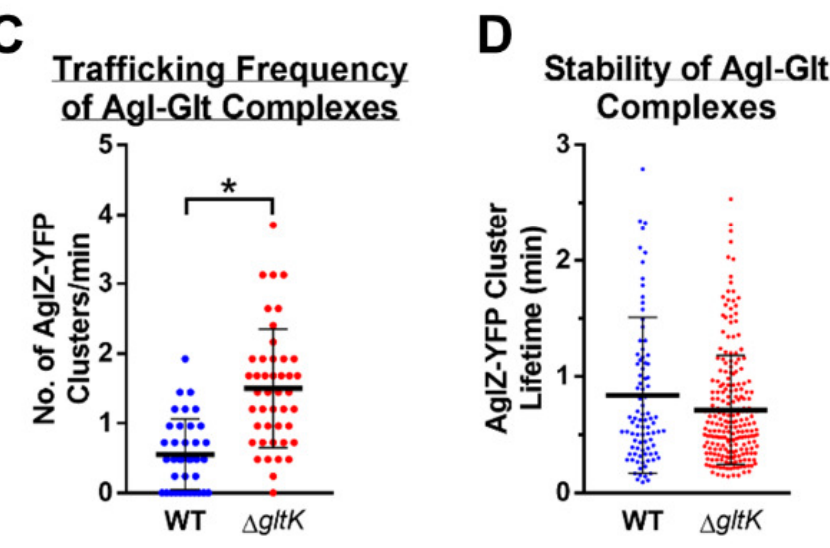
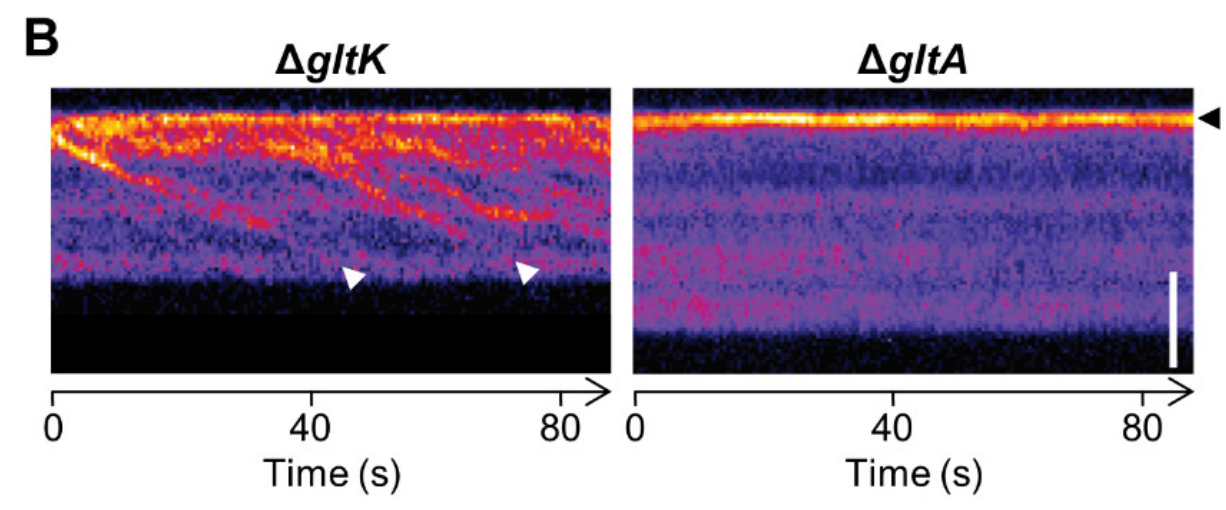

$\mathbf{F}$
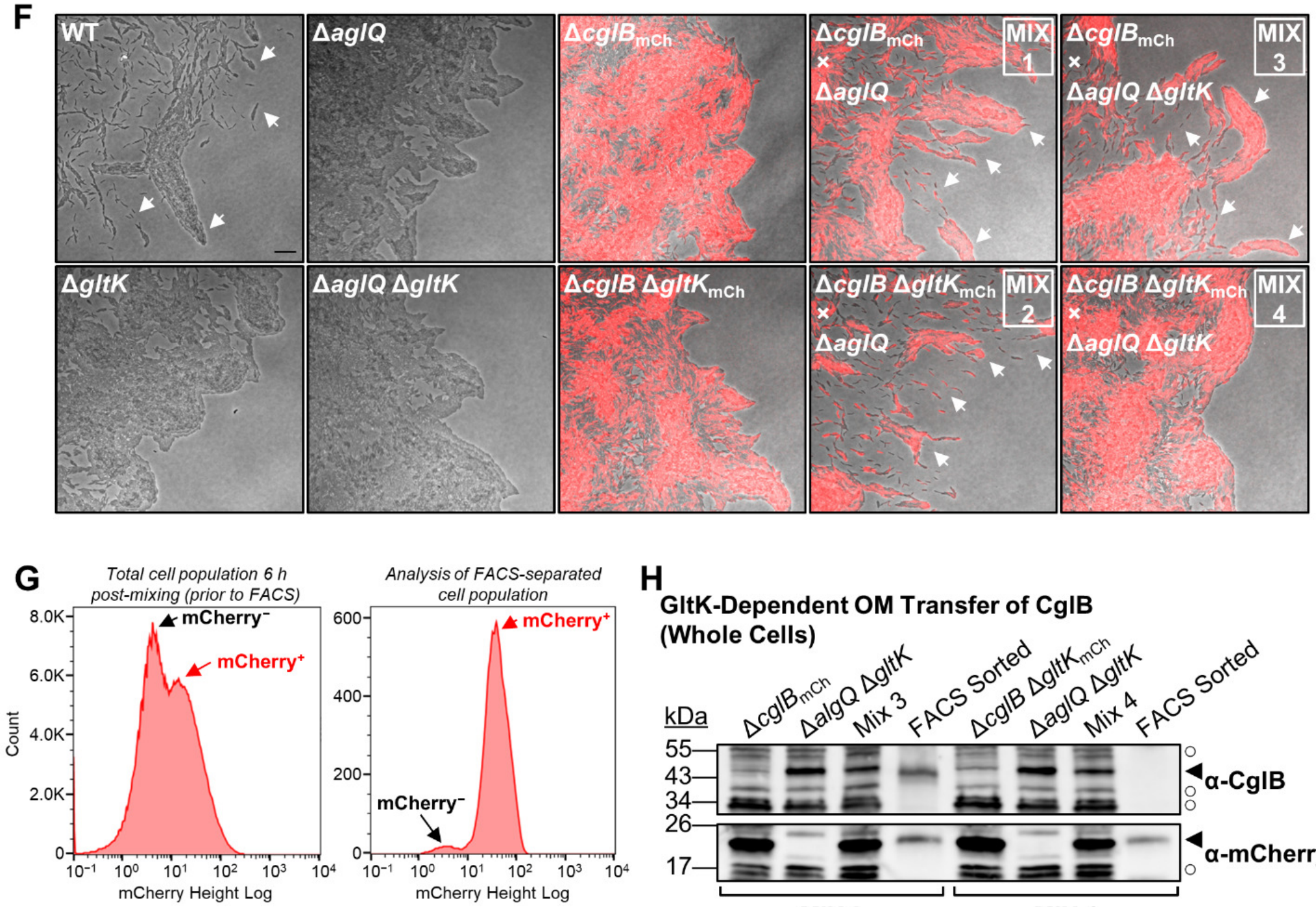

H

GItK-Dependent OM Transfer of CgIB (Whole Cells)

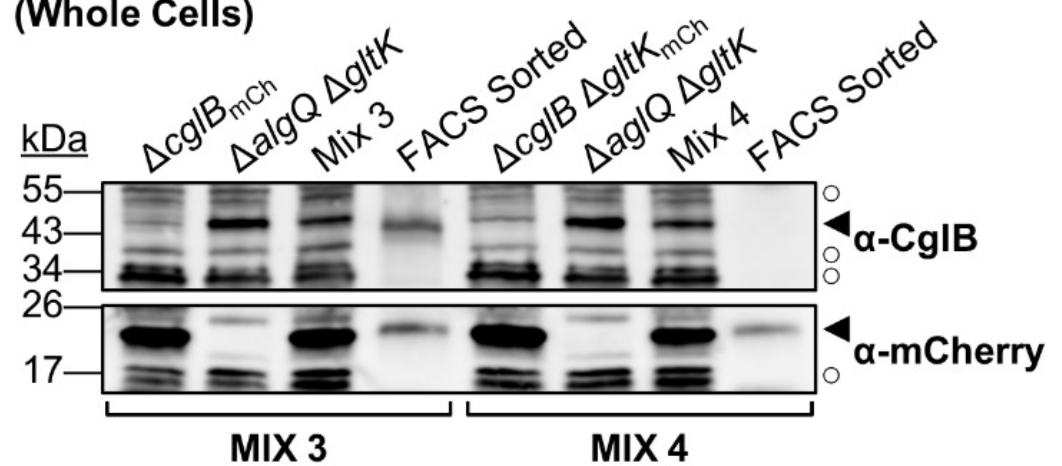


877 Figure 5: Proposed Model for Agl-GIt Complex Substratum-Tethering by CglB at bFAs.

878 Step 1: At bFAs, the PMF-driven (red dots) mechanical action of the IM motor complex allows

879 dynamic interactions of the IM complex with the OM platform via flexible protein periplasmic

880 domains. Step 2: These domains promote localized CglB activation via GltK and secretion of

$881 \mathrm{CglB}$ across the $\mathrm{OM}$, requiring the OM-platform structure. $\mathrm{CglB}$ then interacts with the

882 underlying substratum via its integrin-like domain, thus mediating force transduction at bFAs.

883 Step 3: After the power stroke of the IM machinery, the "used" OM platform is displaced.

884 Adhesin turnover must occur to allow the motility complex to engage new CglB-loaded OM

885 platform complexes and mediate forward propulsion. The exact turnover mechanism remains to

886 be identified and could involve action of a surface metalloprotease to release $\mathrm{CglB}$ from the OM

887 platform. Step 4: Displacement of the "used" OM platform, coupled with release of the "used"

888 adhesin, promotes forward propulsion of the cell body, while the IM complex remains spatially

889 fixed relative to the substratum. The IM complex subsequently recruits the adjacent inactive

890 CglB-loaded OM platform and brings it in register. Step 5: This again locally activates a new

891 CglB secretion and processing cycle. This creates an OM-platform adhesin flow at bFAs,

892 propelling the cell forward. For simplicity a single Agl-Glt complex is shown at a bFA, but it is

893 possible that bFAs are formed by several co-localized complexes that act in concert. 


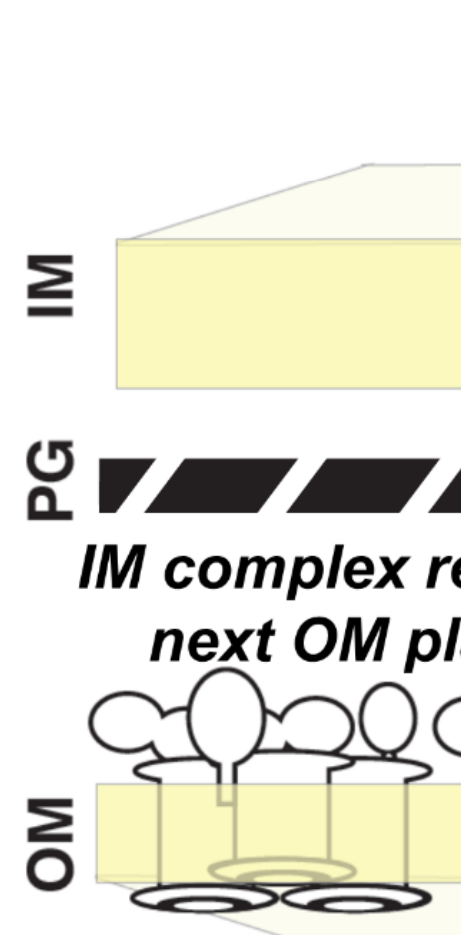

Substratum
New CgIB secretion 5 \& processing cycle is initiated
(1) IM complex transduces force to OM platform
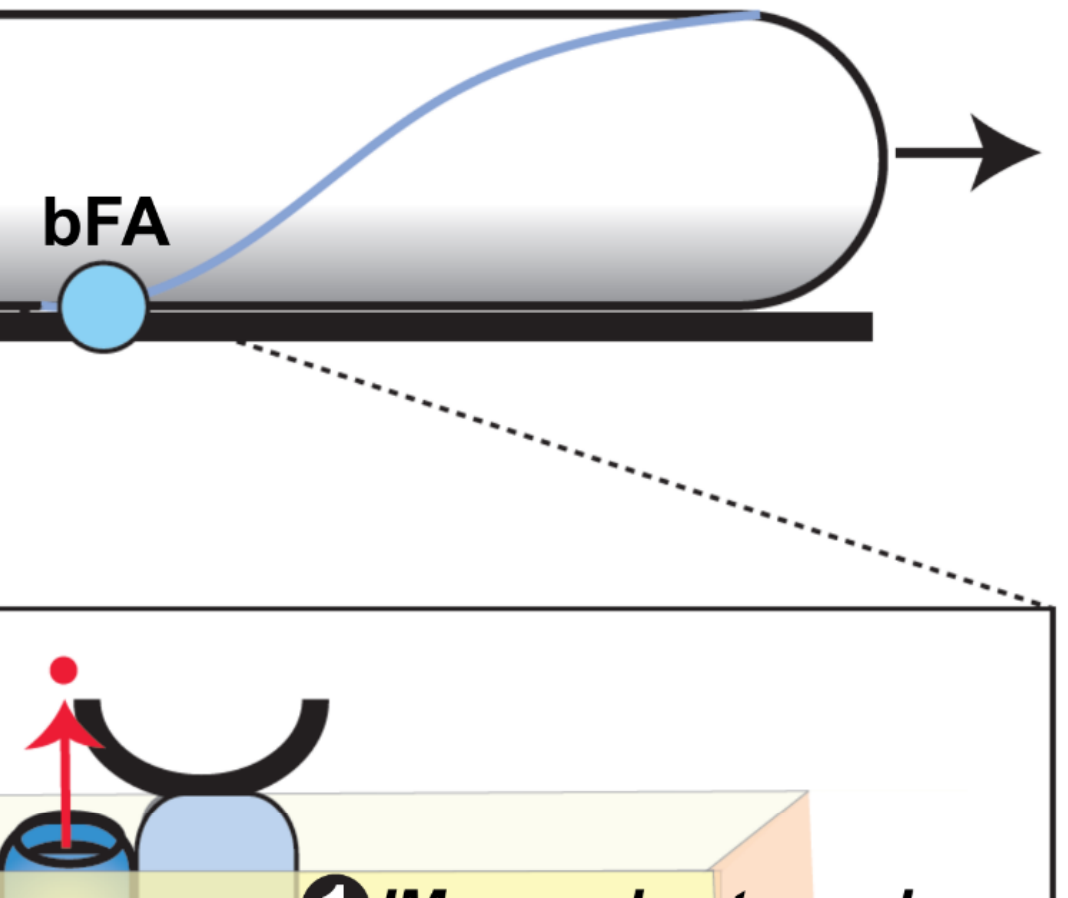

recruits 4

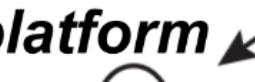

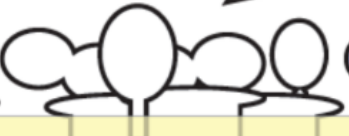

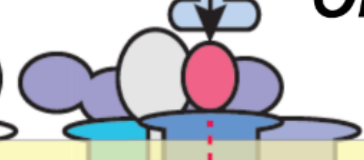

2 CgIB secreted across OM, binds substratum
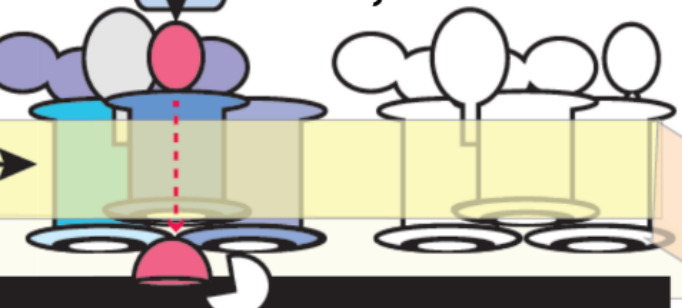

3

After power stroke, OM platform displaced, CglB adhesin removed by proteolysis

4 Cell moves, IM complex stays fixed relative to
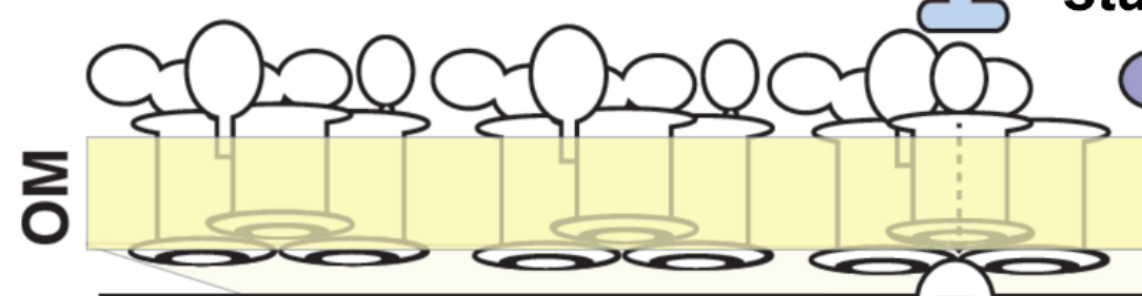
substratum 
METHODS:

\section{Bacterial Cell Culture and Phenotypic Analysis}

M. xanthus strains were cultured in CYE $(10 \% \mathrm{w} / \mathrm{v}$ Bacto Casitone peptone, $5 \% \mathrm{w} / \mathrm{v}$

yeast extract, $1 \% \mathrm{w} / \mathrm{v} \mathrm{MgCl}_{2}, 10 \mathrm{mM}$ MOPS [pH 7.4]) broth with shaking (220 rpm), or on CYE solidified with $1.5 \%$ agar, at $32{ }^{\circ} \mathrm{C}$. To examine the effects of protease inhibition on $\mathrm{CglB}$ liberation, cells were grown in the presence of individual protease inhibitor panel constituents fluoride $\mathrm{HCl}$ (AEBSF) $(1 \mathrm{mM}), \varepsilon$-aminocaproic acid (EACA) $(5 \mathrm{mg} / \mathrm{mL})$, antipain $\mathrm{HCl}(100$ $\mathrm{mM})$, N-ethylmaleimide $(500 \mu \mathrm{M})$, leupeptin hemisulfate $(75 \mu \mathrm{M})$, pepstatin $\mathrm{A}(1 \mu \mathrm{M})$, phosphoramidon disodium salt $(10 \mu \mathrm{M})$, and soybean trypsin inhibitor $(1 \mu \mathrm{M})$. Cell resuspensions were done in TPM buffer $\left(10 \mathrm{mM}\right.$ Tris- $\mathrm{HCl}, \mathrm{pH}$ 7.6, $8 \mathrm{mM} \mathrm{MgSO}_{4}$, and $1 \mathrm{mM}$ $\mathrm{KH}_{2} \mathrm{PO}_{4}$ ). For OME tests, strains were grown to exponential phase in $20 \mathrm{~mL} \mathrm{CYE}$, then resuspended in TPM buffer to an $\mathrm{OD}_{600}$ of 5.0. For strain-mixing experiments, cell resuspensions were mixed together at a 1:1 ratio. Samples were then spotted $(10 \mu \mathrm{L})$ on a CTT $1.5 \%$ agar plate and incubated $\left(32{ }^{\circ} \mathrm{C}, 48 \mathrm{~h}\right)$ prior to microscopy analysis and/or harvest. All strains and plasmids used are listed in Supplementary Table S1.

\section{Polymertropism Testing}

Aspect ratio (AR) vs. time experiments and analyses were adapted from previous work ${ }^{21}$ and were conducted as described previously ${ }^{19}$. Briefly, M. xanthus cells were grown in CYE

919 by resuspension in CYE broth to a final concentration of $5 \times 10^{9}$ cells $/ \mathrm{mL}$ and inoculation $(4 \mu \mathrm{L})$ of compressed and uncompressed square CYE agar plates. Agar in compressed plates was

921 squeezed against the plate wall and held in position by the insertion of a length of $5.56 \mathrm{~mm}$ outer 922 diameter Tygon tubing ${ }^{21}$. Plates were incubated at $30^{\circ} \mathrm{C}$ and the colony perimeters marked after $92324,48,72,96$, and $120 \mathrm{~h}$. Upon experiment completion, the AR of each swarm at each time 924 point was calculated by dividing the colony width by the colony height such that an elongated

925 swarm produced an AR greater than one, while a round swarm produced an AR near-or-equal to one. Linear best-fit lines were plotted for each replicate dataset, followed by slope (AR/time) 
927 determination. Slope values were averaged for each strain, then normalized as a percentage of

928 the AR/time for the WT strain.

929

930

931

932

933

934

935

936

937

938

939

940

941

942

943

944

945

946

947

948

949

950

951

952

953

954

955

956

957

\section{DNA Manipulations}

The upstream region of $c g l B$ (from -213 bp), including a promoter region (from -190 bp to $-141 \mathrm{bp}$ ) predicted by BDGP 55 , as well as $c g l B$ itself was amplified via PCR using Q5 highfidelity DNA polymerase, followed by digestion of the product and plasmid pSWU30 with HindIII-HF (5') and SacI-HF (3'), then ligation via T4 DNA ligase (all enzymes from NEB) to yield $\mathrm{pCglB}_{\mathrm{WT}}$. Oligonucleotide primers for QuikChange site-directed mutagenesis were generated using PrimerX (http://bioinformatics.org/primerx/). Sequencing results were analyzed by Sequencher and/or ApE software.

\section{Generation of $\alpha-C g l B$ polyclonal antibodies}

CglB (lacking signal peptide) elaborating a C-terminal hexa-histidine tag ( $\mathrm{CglB}_{21-416-}$ His6) was purified under denaturing conditions. Fractions were collected in $50 \mathrm{mM}$ Tris $\mathrm{pH} 8.0$, $300 \mathrm{mM} \mathrm{NaCl}, 250 \mathrm{mM}$ imidazole, $6 \mathrm{M}$ urea and used to immunize rabbits (Eurogentec, 28-day speedy protocol). The $\alpha-\mathrm{CglB} 1^{\circ} \mathrm{pAb}$ produced was then tested for specificity by using the wildtype and the $\Omega \operatorname{cglB}$ strains. The $\alpha$-GltA, $\alpha-\mathrm{GltB}$, and $\alpha-\mathrm{GltH} 1^{\mathrm{o}} \mathrm{pAb}$ were raised previously ${ }^{4,13}$.

\section{Phylogeny and gene co-occurrence}

This study explored 27 myxobacterial genomes, distributed within 3 suborders and 10 families $^{56-69}$, in addition to 58 outgroup genomes (members from 32 non-Myxococcales Deltaproteobacteria, $4 \alpha$-, $6 \beta$-, $9 \gamma$-, 4 £-proteobacteria, 2 Firmicutes, and 1 Actinobacteria). Highly-conserved gapless concatenated alignment of 25 housekeeping protein sequences ${ }^{66,70}$ was subjected to RAxML to build a maximum likelihood phylogenetic tree using JTT Substitution Matrix and 100 bootstrap values $^{71}$. Sequential distribution of gliding motility genes, i.e. agl, glt $(\mathrm{M} 1, \mathrm{G} 1 \text { and G2 clusters) })^{4}$ and $\operatorname{cgl} \mathrm{B}^{15,72,73}$ was identified within all 85 genomes under study using two iterations of homology searching via JackHMMER (HMMER 3.1b1 [May 2013]) ${ }^{74}$ with an E-value cut-off of $1 \mathrm{e}^{-5}$, query coverage of $35 \%$, and $35 \%$ sequence similarity. The relative distribution of gliding motility proteins was mapped to the multi-protein phylogeny using iTol v $3^{75}$. The strip right to the phylogeny depicts the taxonomic classes (from top to 
958

959

960

961

962

963

964

965

966

967

968

969

970

971

972

973

974

975

976

977

978

979

980

981

982

983

984

985

986

987

988

bottom: Myxococcales, non-Myxococcales $\delta$-proteobacteria, $\alpha$-, $\beta$-, $\gamma$-proteobacteria, and fibrobacteres respectively).

\section{Tertiary structure homology detection \& modelling}

Pair-wise alignments were performed with EMBOSS Needle software ${ }^{76}$. Protein secondary structure was analyzed via Jpred $4^{77}$, with domain detection performed using SMART $^{78}$. Preliminary identification of structural homologues to CglB, GltK, GltB, GltA, and GltH was carried out using fold-recognition searches of the Protein Data Bank using HHpred ${ }^{79}$ and Raptor $\mathrm{X}^{80}$. To improve template-target alignments, outputs were manually curated in MODalign ${ }^{81}$ to minimize breaks in predicted target secondary structure motifs. Curated alignments to well-matched templates were then input into MODELLER ${ }^{82}$ to generate a $3^{\circ}$ structure homology model.

$\mathrm{CMView}^{83}$ was used to identify intra-protein contacts between $\mathrm{C} \alpha$ positions within model structures with a minimum sequence separation of 10 amino acids. Evolutionarily-coupled amino acid positions within proteins were identified using CoinFold ${ }^{84}$, with the higheststringency $L$ (length of the protein) number of coupled residues extracted. Positions of coupled amino acids as well as intra-protein contacts were individually plotted in GraphPad Prism v.6, followed by tricolour overlay using Image J to identify overlapping positions and colour swapping in Photoshop (Adobe) to improve clarity.

\section{SDS-PAGE, in-gel fluorescence, and Western immunoblotting}

For detection of proteins from whole cells via Western immunoblot, TPM-washed cells were sedimented and resuspended at $\mathrm{OD}_{600} 1.0$ in $1 \times$ Laemmli sample buffer containing 5\% $\beta$ mercaptoethanol for reducing SDS-PAGE (unless otherwise indicated). Samples were boiled (10 min), loaded $(20 \mu \mathrm{L})$ on 10-well $1 \mathrm{~mm}$-thick gels, then resolved on $10 \%$ acrylamide gels $(80 \mathrm{~V}$ for $45 \mathrm{~min}$ for stacking, $120 \mathrm{~V}$ for $75 \mathrm{~min}$ for resolving), then electroblotted (100 V for $60 \mathrm{~min}$ ) to nitrocellulose membranes. Blots were rinsed with Tris-buffered saline (TBS) buffer, blocked for $30 \mathrm{~min}$ at room temperature with 5\% milk in TBS, then incubated rocking overnight in the 4 ${ }^{\circ} \mathrm{C}$ cold room in 1:10 $000 \alpha$-CglB, or 1:3000 $\alpha$-GltH, or 1:1000 $\alpha$-mCherry pAb mixture in TBS with $0.05 \%$ Tween-20 (TBS-T). The next day, blots were rinsed twice ( 5 min) with TBS-T, incubated with goat $\alpha$-rabbit $2^{\circ}$ antibody conjugated to HRP (1:5000) (Bio-Rad) in TBS-T at 
room temperature $(1 \mathrm{~h})$, then rinsed twice $(5 \mathrm{~min})$ again with TBS-T. For all detections using $\alpha$ GltA (1:5000) and $\alpha$-GltB (1:5000) pAb, identical processing steps were followed, but using PBS-based buffers (instead of TBS). All immunoblots were developed using the SuperSignal West Pico (Thermo) chemiluminescence substrate, captured on either a GE Imager with ImageQuant software or an Amersham Imager 600 machine.

For fractionated whole cell-supernatant-OMV samples in $1 \times$ Laemmli buffer, samples were boiled (10 min) and loaded $(20 \mu \mathrm{L})$ on 15-well 4-20\% acrylamide precast gradient gels (Biorad). Supernatant-alone samples were similarly boiled and loaded on a cast $10 \%$ acrylamide gel. Gels were resolved at $120 \mathrm{~V}$, followed by electroblotting to nitrocellulose membranes at $100 \mathrm{~V}$. Immunodetection was performed with diluted polyclonal antisera as follows: $\alpha-\mathrm{CglB}$ (1:10 000), $\alpha$-MglA (1:5000), and $\alpha$-GltK (1:5000). Detection via secondary antibody was done with goat $\alpha$-rabbit mAb (1:5000) conjugated to HRP (Biorad). Immunoblots were developed using the SuperSignal West Femto (Thermo) chemiluminescence substrate, captured on GE Imager with ImageQuant software.

For analysis of AglZ-YFP in-gel fluorescence, TPM-washed cells were resuspended in $1 \times$ non-reducing Laemmli sample buffer to an $\mathrm{OD}_{600}$ of 4.0. Cell resuspensions were heated for $30 \min \left(65^{\circ} \mathrm{C}\right)$, loaded $(20 \mu \mathrm{L})$ on an $8 \%$ SDS-PAGE gel, and resolved for 45 min at $80 \mathrm{~V}$, then $75 \mathrm{~min}$ at $120 \mathrm{~V}$. Cultures, cell resuspensions, and SDS-PAGE gels (before, during, and after resolution) were all shielded from ambient light to reduce photobleaching of the YFP moiety. Resolved gels were scanned on a Typhoon FLA9500 flat-bed imager (GE Healthcare). AglZYFP was excited with a $473 \mathrm{~nm}$ laser, with fluorescence captured using the BPB1 filter (PMT 800). Pre-stained protein ladder bands were detected via excitation with a $635 \mathrm{~nm}$ laser and capture using the LPR filter (PMT 800). Quantification of band fluorescence intensity was performed using ImageJ via the "plot lanes" function, followed by determination of the area under the curve. AglZ-YFP signal for each lane was normalized to the faster-migrating autofluorescent band in the same lane; these values were then expressed as a percentage of the signal in WT cells for a given biological replicate.

\section{Sample Fractionation}

To separate supernatant and outer-membrane vesicle (OMV) fractions, WT, $\Delta g l t A, \Delta g l t B$ and $\Delta g l t K$ vegetative cells were grown in CYE medium to $\mathrm{OD}_{600} 0.7$. Intact cells were first 
1020

1021

1022

1023

1024

1025

1026

1027

1028

1029

1030

1031

1032

1033

1034

1035

1036

1037

1038

1039

1040

1041

1042

1043

1044

1045

1046

1047

1048

1049

1050

eliminated by sedimentation at $7830 \mathrm{rpm}(10 \mathrm{~min}, \mathrm{RT})$. After addition of $1 \mathrm{mM} \mathrm{PMSF}$, supernatants were sedimented at $125000 \times g\left(2 \mathrm{~h}, 4^{\circ} \mathrm{C}\right)$. The resulting pellets (OMV fraction) and supernatants (soluble fractions) were then treated separately. The OMV pellets were washed with TPM, sedimented again at $125000 \times g\left(2 \mathrm{~h}, 4^{\circ} \mathrm{C}\right)$, and then resuspended directly in $500 \mu \mathrm{L}$ $1 \times$ Laemmli protein sample buffer. The soluble supernatant fractions were treated with TCA (10 $\%$ final concentration) for $30 \mathrm{~min}$ on ice and then sedimented at $11000 \mathrm{rpm}\left(1 \mathrm{~h}, 4{ }^{\circ} \mathrm{C}\right)$. The resulting pellets (precipitated proteins) were washed with $100 \%$ acetone, sedimented at $7830 \mathrm{rpm}$ $\left(10 \mathrm{~min}, 4^{\circ} \mathrm{C}\right.$ ), and dried overnight at RT. Dried pellets were then resuspended in $1.5 \mathrm{~mL} \mathrm{TPM}$, sedimented at $15000 \mathrm{rpm}\left(30 \mathrm{~min}, 4^{\circ} \mathrm{C}\right)$ and finally resuspended in $500 \mu \mathrm{L} 1 \times$ Laemmli protein sample buffer.

For isolation of supernatant-alone samples, $50 \mathrm{~mL}$ CYE cultures (inoculated at $\mathrm{OD}_{600}$ $0.02)$ were grown overnight with shaking $\left(220 \mathrm{rpm}, 32^{\circ} \mathrm{C}\right)$ to $\mathrm{OD}_{600} 0.2-0.3$, sedimented $(6000 \times$ $g, 15 \mathrm{~min}, 20^{\circ} \mathrm{C}$ ), followed by passage of supernatants through a $0.22 \mu \mathrm{m}$ syringe filter to remove any intact cells and cell debris. Filtered supernatants were each spun through a Vivaspin 203 -kDa cutoff column with polyethersulfone membrane $\left(8000 \times g, 60 \mathrm{~min}, 22^{\circ} \mathrm{C}\right.$, fixed-angle rotor) to concentrate proteins contained therein to $1 \mathrm{~mL}$ final volume. Concentrated supernatants were then sedimented in a tabletop ultracentrifuge (MLA130 rotor, $120000 \times g, 1.25 \mathrm{~h}, 4{ }^{\circ} \mathrm{C}$ ) to remove any OMVs or cell debris left in the samples. Clarified $1 \mathrm{~mL}$ supernatant samples were transferred to microfuge tubes and treated with $200 \mu \mathrm{L} \mathrm{100 \%} \mathrm{TCA} \mathrm{to} \mathrm{precipitate} \mathrm{the} \mathrm{proteins.}$ Tubes were heated at $65^{\circ} \mathrm{C}$ for $5 \mathrm{~min}$, then spun $(16300 \times \mathrm{g}, 20 \mathrm{~min}, \mathrm{RT})$ to sediment precipitate. TCA-precipitated pellets were washed with $1 \mathrm{~mL}$ acetone, sedimented $(16300 \times g$, $20 \mathrm{~min}, \mathrm{RT}$ ), followed by supernatant aspiration. Protein pellets were left uncapped in the chemical hood overnight to ensure evaporation of acetone. Pellets were resuspended in $500 \mu \mathrm{L}$ $2 \times$ Laemmli sample buffer lacking reducing agent, then diluted to $1 \times$ with $\mathrm{ddH}_{2} \mathrm{O}$.

\section{Immunoprecipitation \& mass spectrometry}

Cells of $\Delta g l t B$ from $100 \mathrm{~mL}$ CYE cultures were sedimented $\left(4000 \times g, 24{ }^{\circ} \mathrm{C}, 15 \mathrm{~min}\right)$. Supernatants were decanted, pooled, and passed through a $0.2 \mu \mathrm{m}$ syringe filter. Filtered supernatant was then concentrated using four Vivaspin20 columns (10 kDa cutoff) (Sartorius), spun at $8000 \times g\left(20^{\circ} \mathrm{C}\right)$ in a fixed-angle centrifuge, with the supernatant concentrated to the dead volume limit of each column. Concentrated supernatants $(\sim 80 \mu \mathrm{L}$ each $)$ were subsequently 
1051

1052

1053

1054

1055

1056

1057

1058

1059

1060

1061

1062

1063

1064

1065

1066

1067

1068

1069

1070

1071

1072

1073

1074

1075

1076

1077

1078

1079

1080

1081

pooled, and diluted 1:2 with filter-sterilized 1× PBS (binding buffer) to equilibrate sample $\mathrm{pH}$. Separately, a single $1 \mathrm{~mL}$ Pierce Protein A column (Thermo) per each pooled supernatant was equilibrated in filter-sterilized binding buffer at room temperature as per the manufacturer's instructions. Filtered $\alpha-\mathrm{CglB}$ antiserum $(1 \mathrm{~mL})$ was sedimented in a microfuge to remove remnant cells and/or debris $(4000 \times g, 5 \mathrm{~min})$, diluted 1:1 with binding buffer, then sedimented at $12000 \times$ $g$ to clarify the sample as binding buffer addition may have resulted in lipoprotein precipitation. The Protein A column was primed by passage of $5 \mathrm{~mL}$ binding buffer. To bind antibody to the column, the $2 \mathrm{~mL}$ of diluted antiserum was added to the top of the column and allowed to drip through, followed by washing with $15 \mathrm{~mL}$ of binding buffer to remove unbound $\mathrm{pAb}$. The $\sim 960$ $\mu \mathrm{L}$ of supernatant concentrate was added to the top of the column and allowed to distribute throughout the resin bed at room temperature $(60 \mathrm{~min})$. The column was then again washed with $15 \mathrm{~mL}$ binding buffer. To elute bound $\mathrm{pAb}$ (and any associated proteins) from the column, $5 \mathrm{~mL}$ of elution buffer $(0.1 \mathrm{M}$ glycine, $\mathrm{pH}$ to 2.5 with $\mathrm{HCl})$ was added.

To analyze the protein content of the pull-down, $500 \mu \mathrm{L}$ of column eluate was concentrated in a microfuge using a Vivaspin500 column (10 kDa cutoff) to a dead volume of $\sim 20 \mu \mathrm{L}$, then diluted 1:1 with $2 \times$ reducing Laemmli sample buffer. Samples $(20 \mu \mathrm{L})$ were run into the stacking gel via SDS-PAGE (80 V, 13 min). Gel bands stained with SimplyBlue Safestain were excised from the stacking portion of the gel and the proteins digested by trypsin or Endoproteinase Glu-C. Liquid chromatography coupled to tandem mass spectrometry (LC-MS/MS) analyses were performed on a Q-Exactive plus mass spectrometer (ThermoFisher Scientific) by staff at the Proteomics Platform of the Mediterranean Institute of Microbiology (Marseille). Processing of the spectra for protein identification was performed with PROTEOME DISCOVERER software (Thermo Scientific, versions 1.4.0.288 and 2.1.0.81).

\section{Proteinase K surface digestion}

Cells were resuspended in TPM at $\mathrm{OD}_{600} 2.0$, followed by addition of $200 \mu \mathrm{g} / \mathrm{mL}$ Proteinase $\mathrm{K}$ and a brief vortex pulse to mix. An aliquot $(50 \mu \mathrm{L})$ was immediately removed at $\mathrm{t}$ $=0$ and placed into a tube containing $5 \mu \mathrm{L}$ of $100 \%$ trichloroacetic acid (TCA). Digestion mixtures were incubated at room temperature on a rocker platform, with aliquots removed every $15 \mathrm{~min}$ and placed into respective pre-aliquoted tubes of TCA. Upon removal of digestion reaction aliquots, TCA-containing sample tubes were heated at $65^{\circ} \mathrm{C}$ for $5 \mathrm{~min}$, chilled on ice, 
1082

1083

1084

1085

1086

1087

1088

1089

1090

1091

1092

1093

1094

1095

1096

1097

1098

1099

1100

1101

1102

1103

1104

1105

1106

1107

1108

1109

1110

1111

1112

then sedimented at $14000 \times g(5 \mathrm{~min})$. Following supernatant removal, precipitated protein pellets were washed via resuspension in $500 \mu \mathrm{L}$ of $100 \%$ acetone. Samples were then sedimented as before $(14000 \times g, 5 \mathrm{~min})$, followed by careful aspiration of the supernatants. Tubes were left uncapped overnight in the fume hood to promote evaporation of residual acetone, followed by storage at $-80{ }^{\circ} \mathrm{C}$ until needed. Precipitated protein pellets were resuspended in $50 \mu \mathrm{L} 1 \times$ Laemmli sample buffer (with reducing agent as indicated) and analyzed via SDS-PAGE and Western immunoblot.

\section{Motility and fluorescence analysis}

For phase-contrast and fluorescence-microscopy on agar pads, cells from exponentiallygrowing cultures were sedimented and resuspended in TPM buffer to $\mathrm{OD}_{600} 5.0$, spotted $(5 \mu \mathrm{L})$ on a glass coverslip, then overlaid with a pad of 1.5\% agar prepared with TPM. For motility analysis, cells were left to adhere for 5 min prior to imaging at $32^{\circ} \mathrm{C}$ using a TE2000-E-PFS microscope (Nikon) with a 40× objective and a CoolSNAP HQ2 camera (Photometrics) with Metamorph software (Molecular Devices). AglZ-YFP fluorescence was imaged using a monolithic aluminum microscope (homemade) equipped with a $1.49 \mathrm{NA} / 100 \mathrm{X}$ objective (Nikon Instruments) and imaged on an iXon DU 897 EMCCD camera (Andor Technology). Illumination was provided by a $488 \mathrm{~nm}$ DPSS laser (Vortran Stradus), and sample positioning was performed using a P611 three-axis nanopositioner (Physik Instrument). Instrument control was programmed in LabView (National Instruments) providing integrated control of all components. Cell gliding speeds were calculated using the MicrobeJ module for FIJI ${ }^{85}$. Gliding cell montages were generated using FIJI. Kymograph panels were generated using the FIJI Kymograph Builder function. AglZ-YFP clusters were detected manually and tracked with the MTrackJ FIJI plugin. Using an R software script, the points of the AglZ-YFP cluster trajectories ( $\mathrm{x} 0, \mathrm{x} 1, \ldots, \mathrm{xn}$; $\mathrm{y} 0$, $\mathrm{y} 1, \ldots, \mathrm{yn})$ were used to calculate the mean square displacement (MSD) at time

$$
t=d^{2} t=\left(x_{t}-x_{0}\right)^{2}+\left(y_{t}-y_{0}\right)^{2}: \quad M S D(t)=\frac{1}{t} \sum_{0}^{t} d_{t}^{2}
$$

For total internal reflection fluorescence microscopy (TIRFM), imaging of real-time AglZ-YFP trafficking was performed as previously detailed in chitosan-coated polydimethylsiloxane (PDMS) microfluidic channels ${ }^{8}$. In brief, cells were injected into the chamber and left to adhere (30 min) without flow, with unadhered cells then removed via manual 
1113 injection with TPM. TIRFM was performed on attached cells with active autofocus using an

1114 inverted microscope with 100× oil-immersion Plan-Achromat objective, atop a closed-loop

1115 piezoelectric stage. AglZ-YFP was excited with a 488-nm laser, with emission collected by the

1116 objective, through a dichroic mirror and bandpass filters, and captured by an emCCD camera.

1117 For imaging of the YFP channel in real time, 500 images were captured at $20 \mathrm{~Hz}^{8}$.

\section{Flow chamber construction and bead assay}

Prior to experiments, $1 \mathrm{~mL}$ of M. xanthus DZ2 WT+AglZ-YFP and mutant DZ2

1122 and resuspended in $400 \mathrm{~mL}$ TPM buffer. Flow chambers were made by combining two layers of

1123 double sided tape, a $1 \mathrm{~mm}$-thick glass microscope slide, and a $100 \mu \mathrm{m}$-thick glass cover slip

1124 (\#1.5) as previously described ${ }^{86}$. The tape was separated to allow a final volume of

1125 approximately $60 \mu \mathrm{L}$. Agarose (40 $\mu \mathrm{L}$ at $0.7 \%)$ dissolved in $6 \mathrm{M}$ DMSO was injected into the

1126 chamber and allowed to sit at room temperature for $15 \mathrm{~min}$. The chamber was washed with 400

$1127 \mu \mathrm{L}$ TPM then injected with $M$. xanthus cells $(60 \mu \mathrm{L})$ and left at room temperature to facilitate

1128 cell attachment to the agarose-coated surface for $30 \mathrm{~min}$. Unattached cells were then thoroughly

1129 washed away with a total of $2 \mathrm{~mL}$ TPM media containing $10 \mathrm{mM}$ glucose. The flow chamber

1130 was then mounted onto the microscope for imaging. For bead experiments, $1 \mu \mathrm{L}$ of uncoated

1131 polystyrene beads (diameter $520 \mathrm{~nm}$ ) (Bangs Laboratories) were washed and diluted in $1 \mathrm{~mL}$

1132 TPM containing $10 \mathrm{mM}$ glucose and injected into the flow chamber. Beads were optically

1133 trapped and placed about a third of the cell length away from the pole of the immobilized cell of

1134 interest.

\section{Bead tracking and video analysis}

1137 For a chosen M. xanthus cell (WT or mutant), 3-min movies were recorded and analyzed

1138 using a custom MATLAB tracking code. The code uses filtering mechanisms to subtract the

1139 image background from that of the cell-attached bead. Firstly, an internal MATLAB centroid

1140 function identified the $x, y$ pixel values of the centre of the bead for each frame in the video,

1141 followed by pixel value conversion to microns. This was then used to compute motor-driven

1142 bead runs and velocities for each cell. The threshold value for a run was previously determined

1143 by disabling molecular motors and decreasing bead motion in WT cells by carefully injecting 20 
$1144 \mu \mathrm{M}$ of nigericin, a $\mathrm{pH}$-gradient/proton motive force-inhibitory drug, into the mounted flow

1145 chamber. This drug concentration decreased bead velocity but not motor force production

1146 translated to the beads. In these previous experiments, $40 \mu \mathrm{M}$ nigericin was used, leading to

1147 negligible bead motion ${ }^{12}$.

\section{Flow cytometry}

Analysis of the presence of $\mathrm{CglB}$ in $\mathrm{mCherry}^{+}$cells within a mixed population was performed with strains TM1380 (or TM1290) and TM1365, positive and negative for the

1152 mCherry marker, respectively. Fluorescence-activated cell sorting (FACS) was performed with

1153 a Bio-Rad S3E cell sorter. The blue laser (488 nm, $100 \mathrm{~mW})$ was used for forward (FSC) and

1154 side scatter (SSC) signals and the green laser $(561 \mathrm{~nm}, 100 \mathrm{~mW})$ for excitation of mCherry.

1155 Signals were collected using the emission filter FL3 (615/25 nm). Bacterial samples in TPM

1156 buffer (maximum optical density of 0.1 ) were run in the low-pressure mode at $\sim 10,000$ particles

1157 per second. The threshold on FSC was $0.15 \%$ and the voltages of the photomultipliers were 403, 1158299 and 722 volts for FSC, SSC and FL3, respectively. The density plots obtained (small angle

1159 scattering FSC versus wide angle scattering SSC signal) were gated on the population of interest 1160 and filtered to remove multiple events. Populations of 300,000 - 500,000 events were used and 1161 analyzed statistically using Prosort or FlowJo software. For sorting in "purity" mode, up to 60

1162 million events were collected and at least ten tubes of $3.5 \mathrm{~mL}$ were used for sorting high-height 1163 peak values of mCherry fluorescence. A total volume of $35 \mathrm{~mL}$ was collected and pooled, 1164 followed by addition of 10\% TCA to precipitate total protein content in the tube. Samples were 1165 sedimented via ultracentrifuge $\left(164700 \times g, 1 \mathrm{~h}, 4{ }^{\circ} \mathrm{C}\right)$, then the pellet was resuspended in 500 $1166 \mu \mathrm{L}$ of TPM, sedimented again $\left(22065 \times \mathrm{g}, 30 \mathrm{~min}, 4^{\circ} \mathrm{C}\right)$, and later used for Western-blot 1167 analysis. 


\section{SUPPLEMENTAL INFORMATION TITLES AND LEGENDS:}

1169 Supplementary Figure S1: Defining the Structures of GItA, B, H, and CgIB

1170 A) GltA (i) tertiary structure homology model (based on the OprF $\beta$-barrel protein from

1171 Pseudomonas aeruginosa), (ii) overlay of intra-protein amino acid contact positions from the

1172 tertiary structure model (black) vs. evolutionarily-coupled amino acid positions from the primary

1173 structure (grey) (with conserved positions between the two datasets indicated in red), (iii)

1174 alignment with PDB 4RLC for MODELLER input.

1175 B) GltB (i) tertiary structure homology model (based on the OprF $\beta$-barrel protein from

1176 Pseudomonas aeruginosa), (ii) overlay of intra-protein amino acid contact positions from the

1177 tertiary structure model (black) vs. evolutionarily-coupled amino acid positions from the primary

1178 structure (grey) (with conserved positions between the two datasets indicated in red), (iii)

1179 alignment with PDB 4RLC for MODELLER input.

1180 C) GltH (i) tertiary structure homology model (based on the OmpA $\beta$-barrel protein from

1181 Shigella flexneri), (ii) overlay of intra-protein amino acid contact positions from the tertiary

1182 structure model (black) vs. evolutionarily-coupled amino acid positions from the primary

1183 structure (grey) (with conserved positions between the two datasets indicated in red), (iii)

1184 alignment with PDB 3NB3 for MODELLER input.

1185 D) $\alpha$-GltA and $\alpha$-GltB Western immunoblots from whole-cell extracts from different $\Delta g l t$

1186 mutants resolved via reducing SDS-PAGE.

1187 E) CglB (i) overlay of intra-protein amino acid contact positions from the tertiary structure

1188 model (black) vs. evolutionarily-coupled amino acid positions from the primary structure (grey)

1189 (with conserved positions between the two datasets indicated in red), (ii) alignment with PDB

1190 3TXA for MODELLER input. See also Figure 2A. For the template alignments in figure panels

1191 A, B, C, E: residue colouration is based on the conservation score as determined by Jalview:

1192 maroon, 10 (out of 10); red, 9; orange, 8; yellow, 7. Conservation scores $\leq 6$ have not been

1193 displayed to enhance the clarity of the figure. Secondary structure properties for each protein are

1194 indicated above/below the aligned sequence, based on the respective PDB entry and GltA/B/H/T

1195 secondary structure prediction via JPred, with $\beta$ strands (green arrows) indicated. 
A

(i)

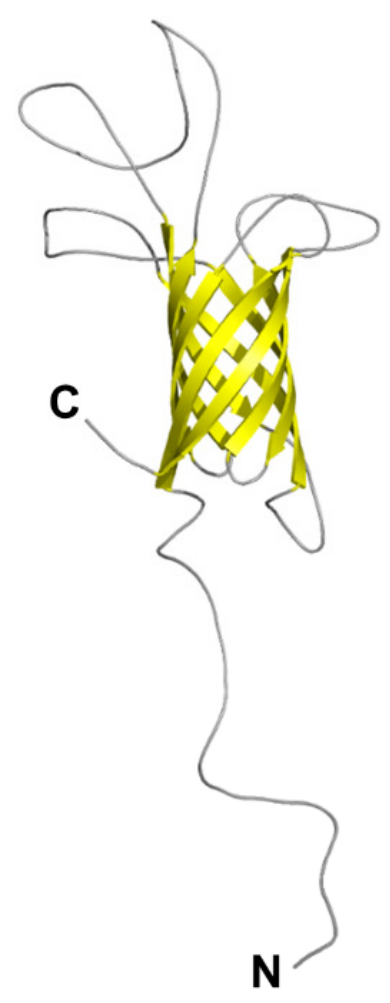

(ii)

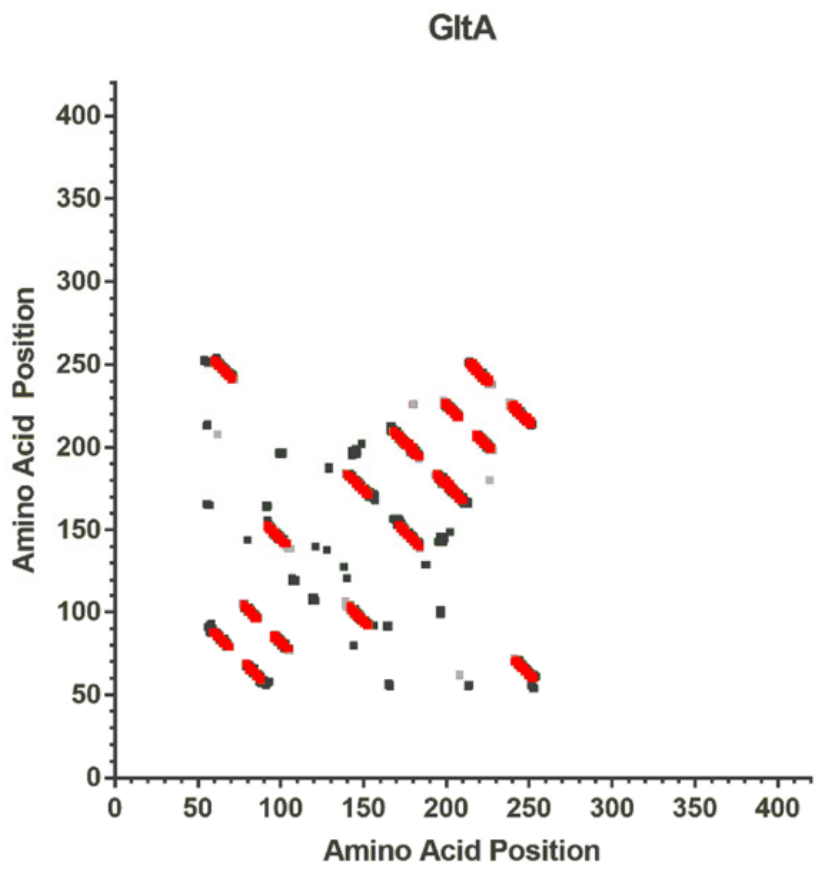

(iii)

GltA : QTTEEAEAGDVSEVDKDRLGPLRERVRPVSGHVFLKKGRFEFESPATLSIRDAFYSKYIFGGTLTHPME : 91 4RLC_A : ------------------------QGQNSVEIEAFGKRYE-----ADLYGGSIGYFLTD : 63

GltA : TLGVSLRVGYINTVAGAAQKCTFGDGGEGSTRGCVPPTLDELDGNAPGQIKLLGGADVQWAPIYGKVSL : 161 4RLC_A : DVELALSYGEYHDV--------------------------VHGNLTSLDAIYH--EG--- : 102

GItA : LAETFVHFDYYIAGASVVCYRGPGDSLAEAQNYLTPGANLGVGARFFLNRWITLRTELRDLIYVEKGT : 231 4RLC_A : --TPGVGLRPYVSAGLAHQNITNINSD---SQGRQQMTMANIGAGLKYYFTENFFAKASLDGQYGLEK-- : 165 
B

(i)

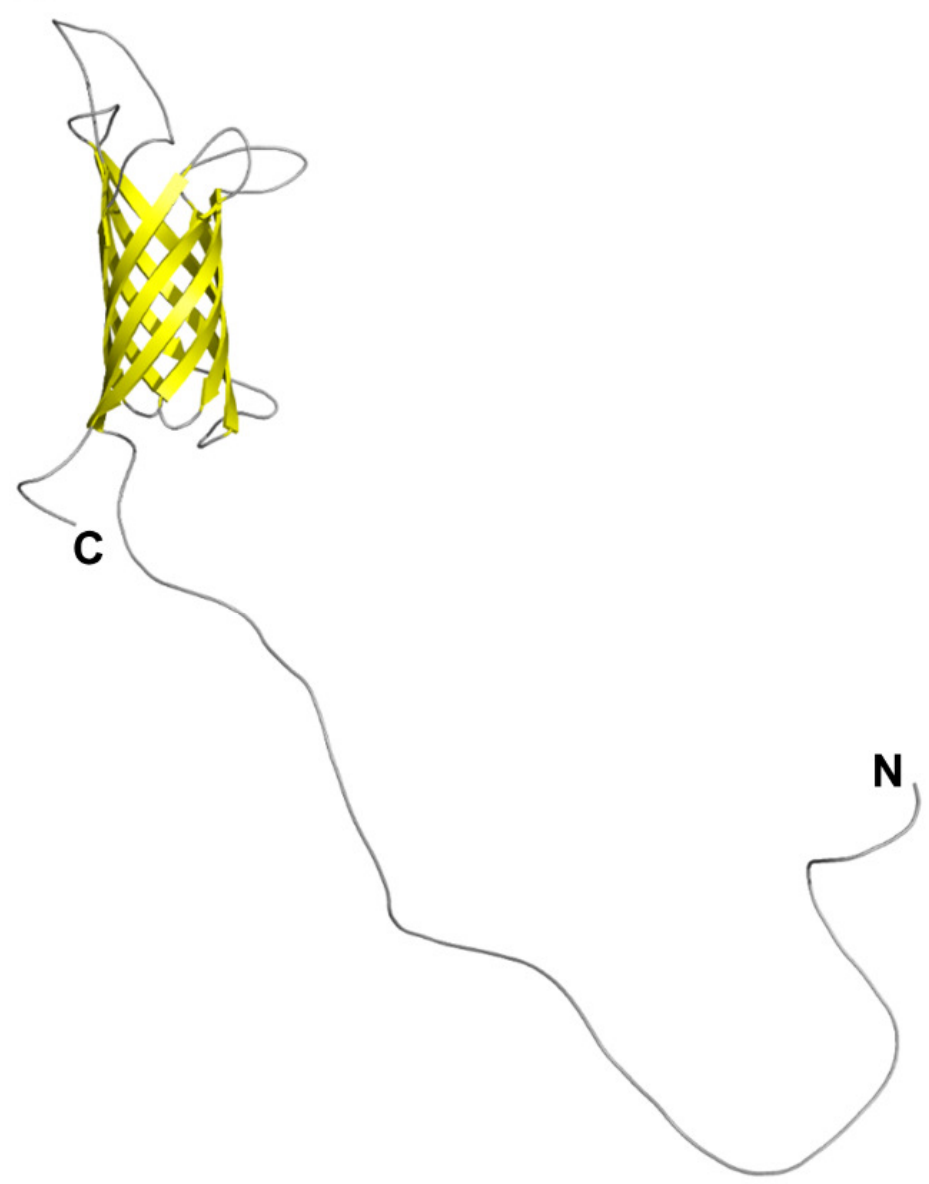

(ii)

GItB

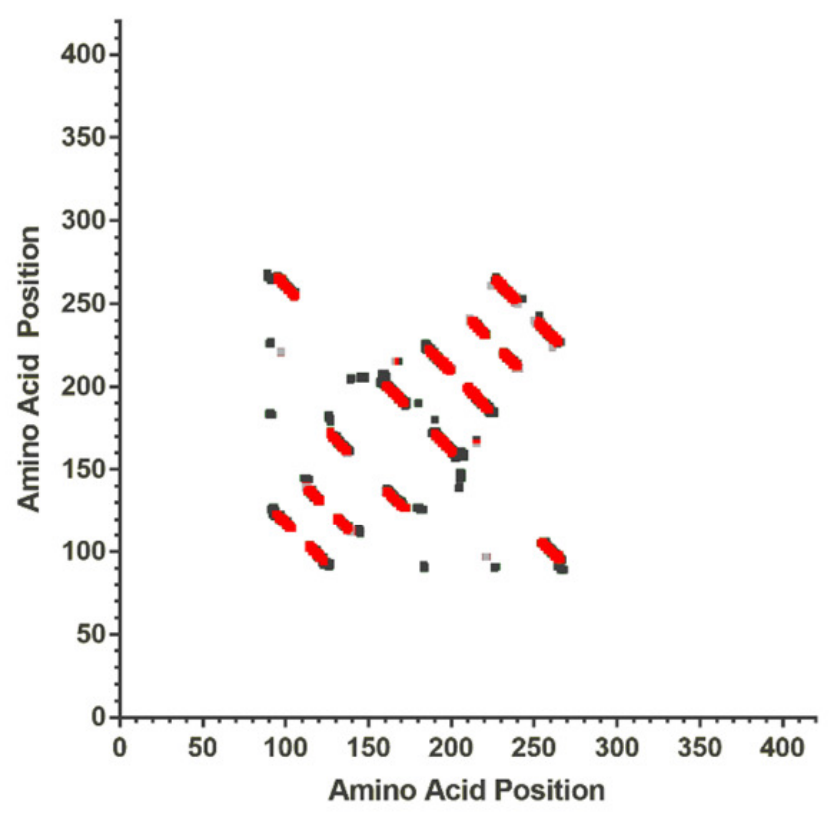

(iii)

GltB : QSQEGMGLDLTDESQAESSQDAESPAPPPMEEATPAAASRPADEPLEADPQLPLTDITQEDRVKSVQRKV : 89

4RLC_A : -

GItB : YLKKGRFEITPLVSLSVNDP---FYSKVGLSVRGAYYLADTIAVSARASLMQVVPSDDVRTAKRTFNSKI : 156 4RLC_A : -QGQNSVEIEAFGKRYE-------ADLYGGSIGYFLTDDVELALSYGEYH-----DV-------- : 77

GltB : YYSVPQWSAMGDVEWTSPIYGKVAFLNSILHEDGYLAGAGVVNTETSAL--PGRGLNPAADLGIGMREVA : 224 4RLC_A : ---VHGNLISLDAIYH-------EGTPGVGLRPYVSAGLAHQNITNINSDSQGRQQMTMANIGAGLKYYF : 147

GltB : QDYIAVNVALINTSYVDQPLGSSKGAIQNVMTLNAGISLFLPFKSTGRDSE : 275

4RLC_A : TENEFAKASIDGQYGLEK----------GEWMAGLGVGFNE---------- : 184 
C

(i)

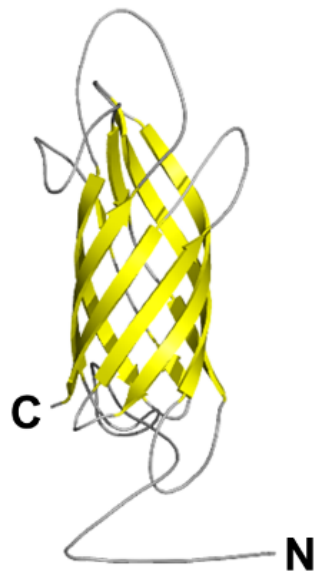

(ii)

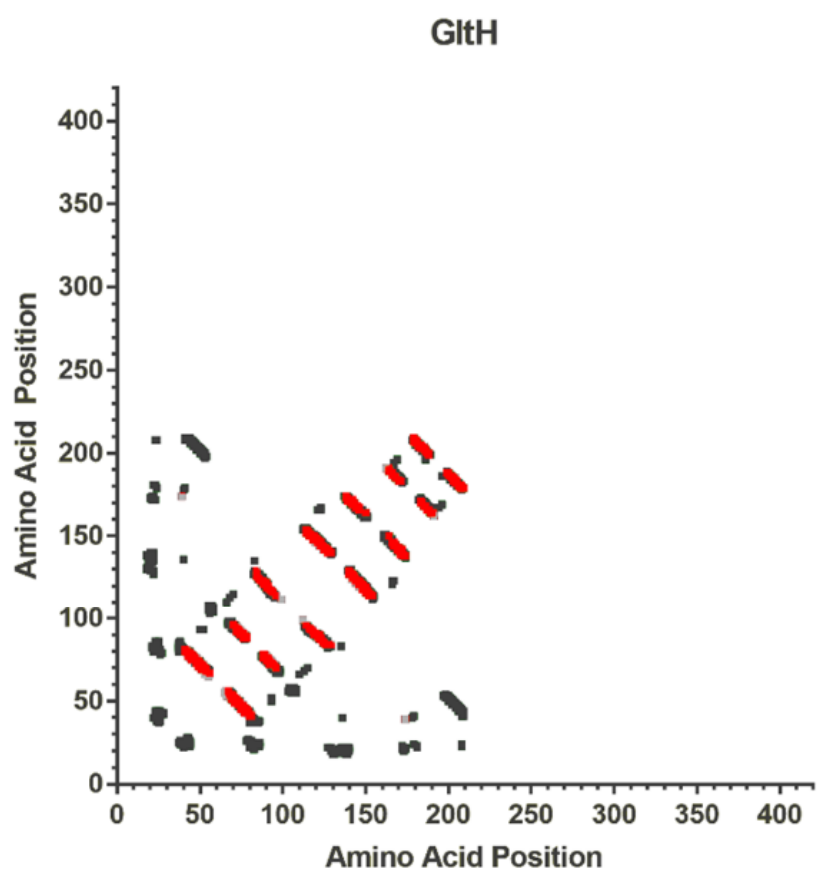

(iii)

\section{Predicted signal peptide}

GltH : MKALASLALCASFVLPTVASAQQPTTAQGDRPAVTFDEIERGIYFAVLGGPLFITNPPAAEGTPRP : 66

3NB3_A : ---------------------------APKDNTWYTGAKLGWSQ---------- : 38

GltH : FSSGPMAQVEVGVDLGEHVSVGL-FLMGSSVRTGAQYVGNSGGAVSGDFSTLIPGAVLRARLVGEA : 131 3NB3_A : HENKLGAGAFGGYQVNPYVGFEMGYDWLGRMPY------------AYKAQG-VQLTAKLGYPIT : 89

GltH : DSQEVKRTWFYRAGAGYAMFSPQRL----LPDSDILVFAGPGVEYYTRLRHFSVGLEVTGQYLVS : 193 3NB3_A : ----DDLDIYTRLGGMVWRADTYSNVYGKNHDTGVSPVFAGGVEYAI-TPEIATRLEYQWMN--- : 146

Glth : GGSFGFAVAPNIRYAF : 209

3NB3_A : -----GMLSLGVSYRE : 157 
D

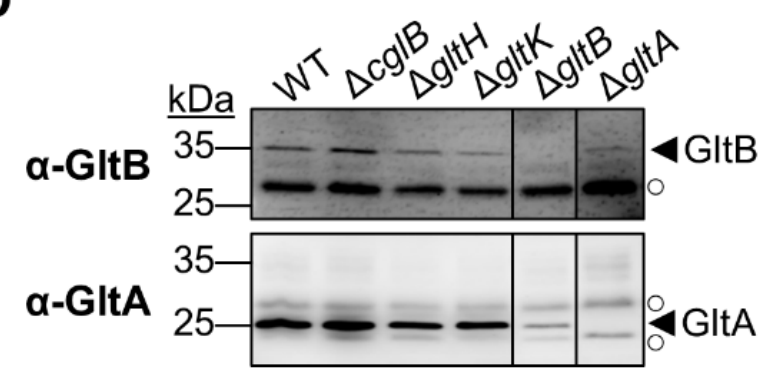




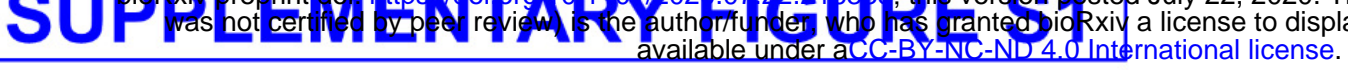

$\mathbf{E}$

(i)

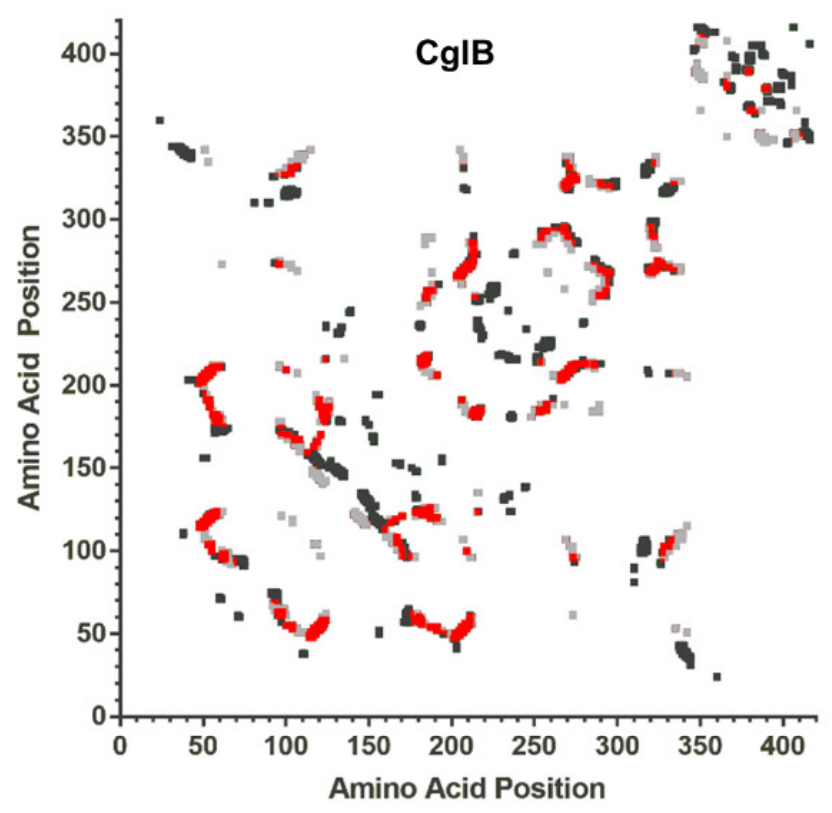

(ii)

CglB : COTYDEEPVEPLAIAOTTVEEVIKAROSKPNIMLLVDTSGSMTYPVNPSPACDVEFKGS IVPCGGEAPCN : 89 GBS104: KNKYKIELTVEG---KTTVET--KELNOPLDVVVLLDNSNSMNN------ERANN-------------- : 241

Cglв : VDVCPTRWTTLOSVVPOFLENSG--RFVRFALTTYPET--RGGESIPDLCRASTAGALI---------KT: 146 GBS104:----SORALKAGEAVEKLIDKITSNKDNRVALVTYASTI FDGTEATVSKGVADONGKALNDSVSWDYHKT: 307

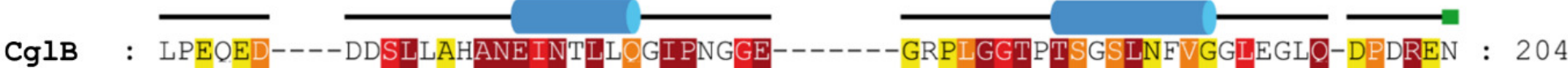
GBS104: TFTATMHNYSYLNLTNDANEVNILKSRIPKEAEHINGDRTLYOFGATFTOKALMKANEILETQSSNARKK : 377 $\longrightarrow$ - - - - -

CglB : FVILLTDGLPNCNAANFNS------------------GANPEL-----CKCTI---EGND----- : 238 GBS104: LIFHVTDGVPTMSYAINFNPYISTSYONOFNSFLNKI PDRSGILOEDFI INGDDYOIVKGDGESFKLFSD：447 CglB : GBS104: RKVPVTGGTTOAAYRVPONQLSVMSNEGYAINSGYIYLYWRDYNWVYPFDPKTKKVSATKOIKMHGEPTT: 517

CglB : VTAVRELHEKGIOTIVIGFGAETAVGDGPAVLEAMARAGGFRRTCSAERPCGEGDTCNPTTGLCNRSFFO : 324 GBS104: LYFNGNIRPKGYDIETVGIGVNGDPGATPLEAEKEMOSISSKTE--------------------NYTN: 565

CglB : AGN----AAELASALEEISLAVKI-PEPCIIRLDGP RPTDPK-------LLVVYVEEGERTPSSDSTWTL : 382 GBS104: VDDTNKIYDELNKYEKTIVEEKHS IVDGNVTDPMGEMIEFOLKNGQSFTHDDYVLVGND------GSOLK : 629 


\section{Supplementary Figure S2: Importance of CglB to Gliding Motility and Linked Behaviours}

1202

1203

1204

1205

1206

1207

1208

1209

1210

1211

1212

1213

1214

1215

1216

1217

1218

1219

1220

1221

1222

1223

1224

1225

1226

1227

1228

1229

1230

1231

A) Single-cell gliding speeds for M. xanthus OM-module mutant strains ( $\mathrm{n}=100$ cells) on hard $(1.5 \%)$ agar. The lower and upper boundaries of the boxes correspond to the 25 th and 75 th percentiles, respectively. The median (line through centre of boxplot) and mean $(+)$ of each dataset are indicated. Lower and upper whiskers represent the $10^{\text {th }}$ and $90^{\text {th }}$ percentiles, respectively; data points above and below the whiskers are drawn as individual points. Asterisks denote datasets displaying statistically significant dataset differences $(p<0.0001)$ relative to WT, as determined via 1-way ANOVA with Tukey’s multiple comparisons test.

B) Ratio of number of Cys residues per gliding motility complex protein, divided by the total number of amino acids in that protein.

C) Single-cell gliding speeds for WT M. xanthus DZ2 $(\mathrm{n}=700$ cells) on hard $(1.5 \%)$ agar supplemented with increasing concentrations of DTT to reduce disulphide bonds of proteins in contact with the substratum. The lower and upper boundaries of the boxes correspond to the 25 th and 75 th percentiles, respectively. The median (line through centre of boxplot) and mean $(+)$ of each dataset are indicated. Lower and upper whiskers represent the $10^{\text {th }}$ and $90^{\text {th }}$ percentiles, respectively; data points above and below the whiskers are drawn as individual points. Asterisks denote datasets displaying statistically significant dataset differences $(p<$ 0.0001 ) relative to $0 \mathrm{mM}$ DTT treatment, as determined via 1-way ANOVA with Tukey's multiple comparisons test.

D) Polymertropism response for various $g l t$ and $a g l$ deletion mutant strains. Mean results are displayed +/- SEM, with the number of biological replicates $(n)$ used to analyze each strain as follows: WT (20), $\Delta c g l B(16), \Delta g l t K(19), \Delta g l t B(11), \Delta g l t A(15), \Delta g l t C(15), \Delta g l t J(16), \Delta g l t I$ (15), $\Delta g l t H(20) \Delta g l t G(18), \Delta g l t F(16), \Delta g l t E(14), \Delta g l t D(17), \Delta a g l R(11), \Delta a g l Q(6), \Delta a g l S$ $(5)$.

E) $\alpha$-CglB Western immunoblot of CglB MIDAS motif amino acid substitution mutants from whole-cell extracts. Non-adjacent lanes on the blot are separated by vertical black lines.

F) Single-cell gliding speeds on hard (1.5\%) agar for M. xanthus DZ2 $\Delta c g l B(\mathrm{n}=120$ cells) complemented with $\mathrm{CglB}_{\mathrm{WT}}$ or $\mathrm{CglB}_{\mathrm{D} 56 \mathrm{~A}}$ ectopically expressed from the attB phage-attachment site in the chromosome. The lower and upper boundaries of the boxes correspond to the 25 th and 75th percentiles, respectively. The median (line through centre of boxplot) and mean $(+)$ of each dataset are indicated. Lower and upper whiskers represent the $10^{\text {th }}$ and $90^{\text {th }}$ percentiles, 
1232 respectively; data points above and below the whiskers are drawn as individual points. Asterisks

1233 denote datasets displaying statistically significant dataset differences $(p<0.0001)$ compared to

1234 strains harbouring either the pSWU30 empty-vector control or the $\mathrm{pCglB} \mathrm{D}_{\mathrm{D} 6 \mathrm{~A}} \mathrm{VWA}$-domain

1235 mutant CglB complementation construct, as determined via 1-way ANOVA with Tukey's

1236 multiple comparisons test.

1237 G) Single-cell gliding speeds for M. xanthus DZ2 $\Omega$ pilA ( $\mathrm{n}=110$ cells) on chitosan-coated glass

1238 in a PDMS microfluidic chamber in the presence and absence of $\mathrm{Ca}^{2+}$ ions. The lower and upper

1239 boundaries of the boxes correspond to the 25 th and 75 th percentiles, respectively. The median

1240 (line through centre of boxplot) and mean $(+)$ of each dataset are indicated. Lower and upper

1241 whiskers represent the $10^{\text {th }}$ and $90^{\text {th }}$ percentiles, respectively; data points above and below the

1242 whiskers are drawn as individual points. Asterisk denotes datasets displaying statistically

1243 significant differences $(p<0.0001$, as determined via two-tailed Mann-Whitney test. 
A CglB Single-Cell Gliding Deficiency

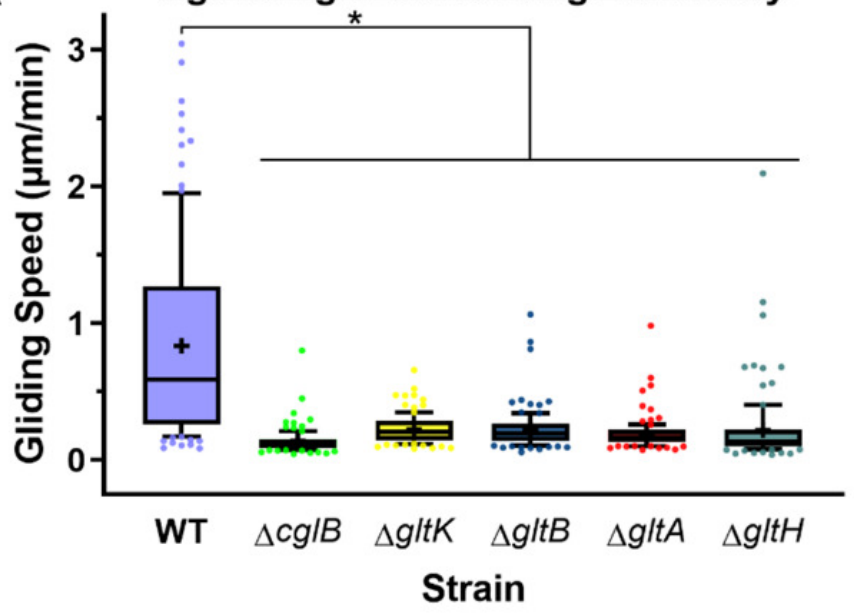

C

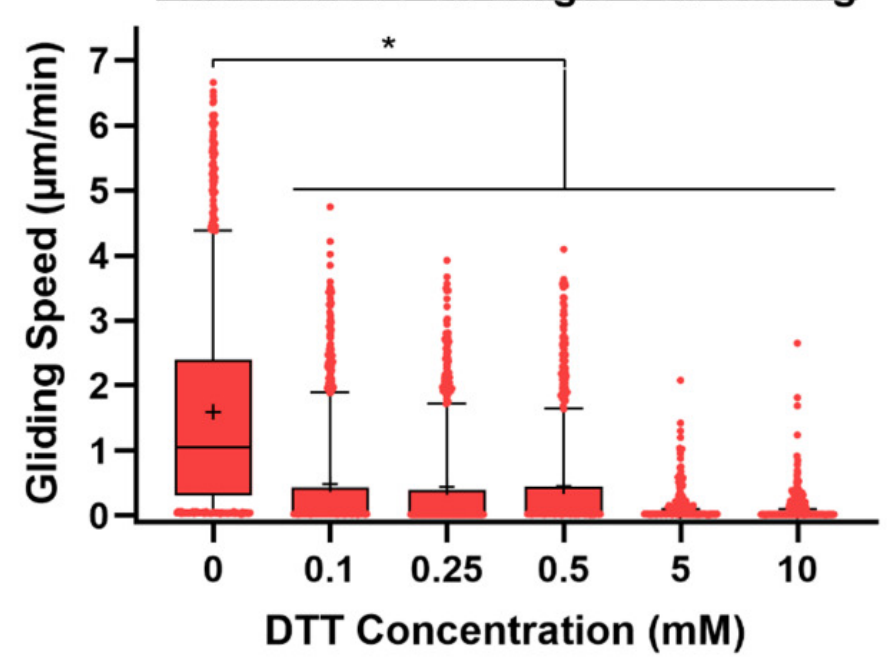

E

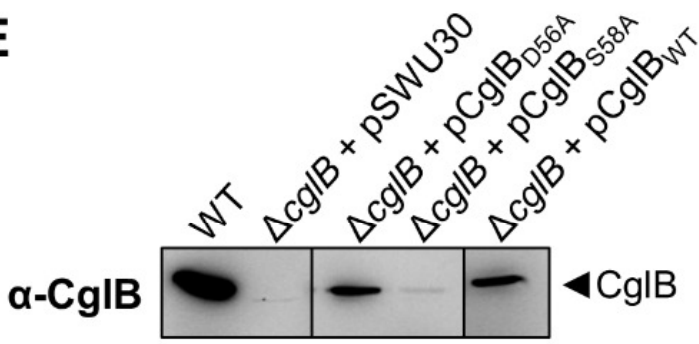

$\mathbf{F}$

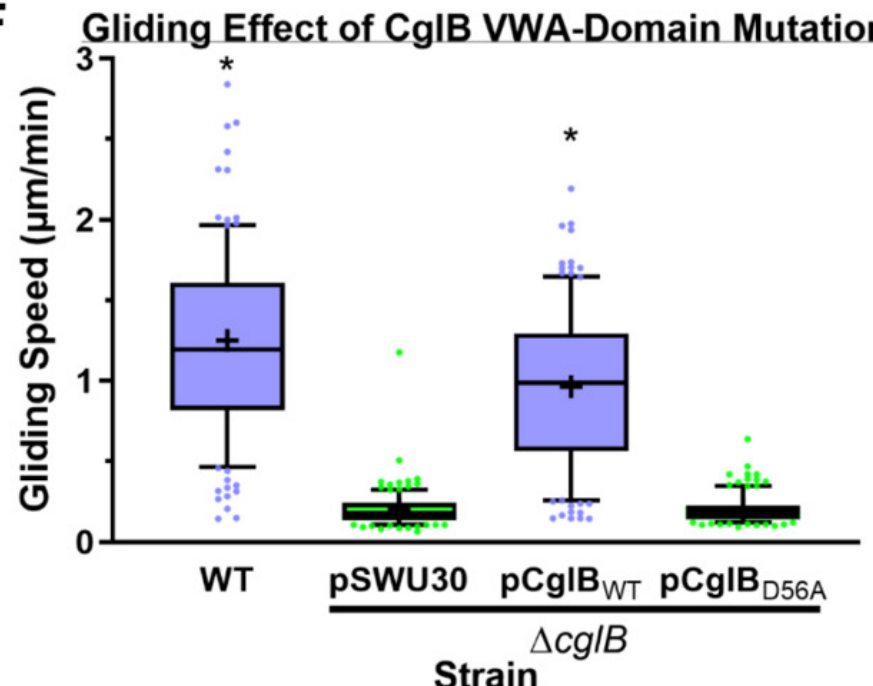

B

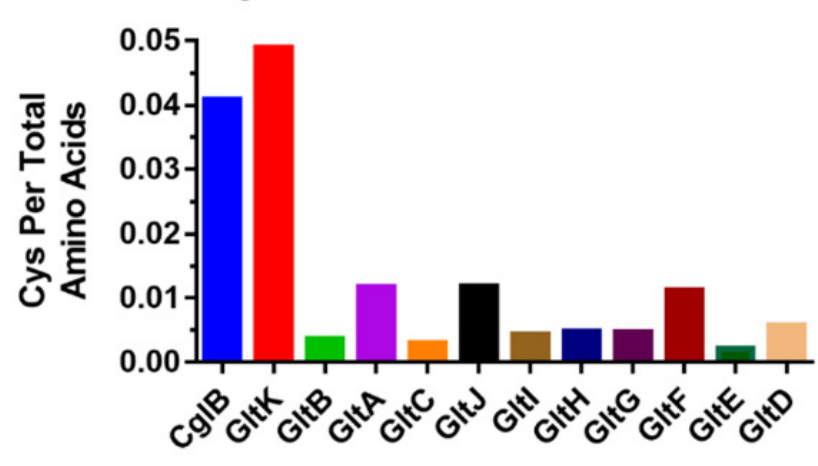

D

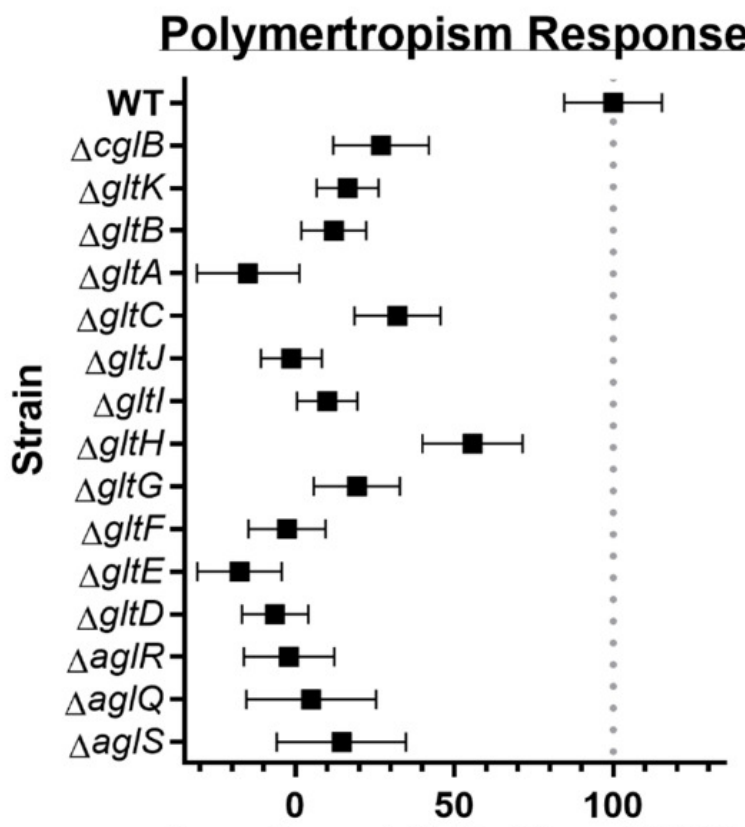

Avg. Aspect Ratio/Time (\%WT)
G Effect of $\mathrm{Ca}^{2+}$ on Single-Cell Gliding

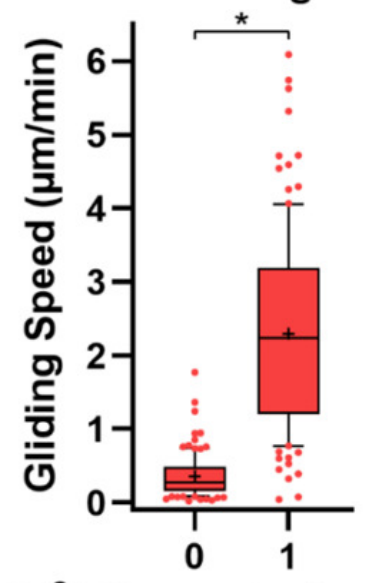

$\mathrm{Ca}^{2+}$ Concentration (mM) 


\section{Supplementary Figure S3: CglB Co-Occurrence and Gene Synteny in Bacteria}

1246 Taxonomic distribution and co-occurrence of $a g l$ and glt genes in bacteria. Bootstrap values at

1247 each node are indicated as follows: 100 (out of 100), $\mathbf{0} ; 90-99, \mathbf{\Delta} ; 80-89, \mathbf{\square} ; 70-79, \boldsymbol{\bullet} ; 60-69$,

$1248-50-59, \star ;<49, \mathbf{X}$. Colour of gene hit indicates synteny with the G1 gltDEFGHIJ (dark

1249 blue) or $\mathrm{G} 2$ gltKBAC (blue) gene clusters or lack thereof (light blue), respectively; herein,

1250 synteny denotes a minimum of three genes in the vicinity of each other. 


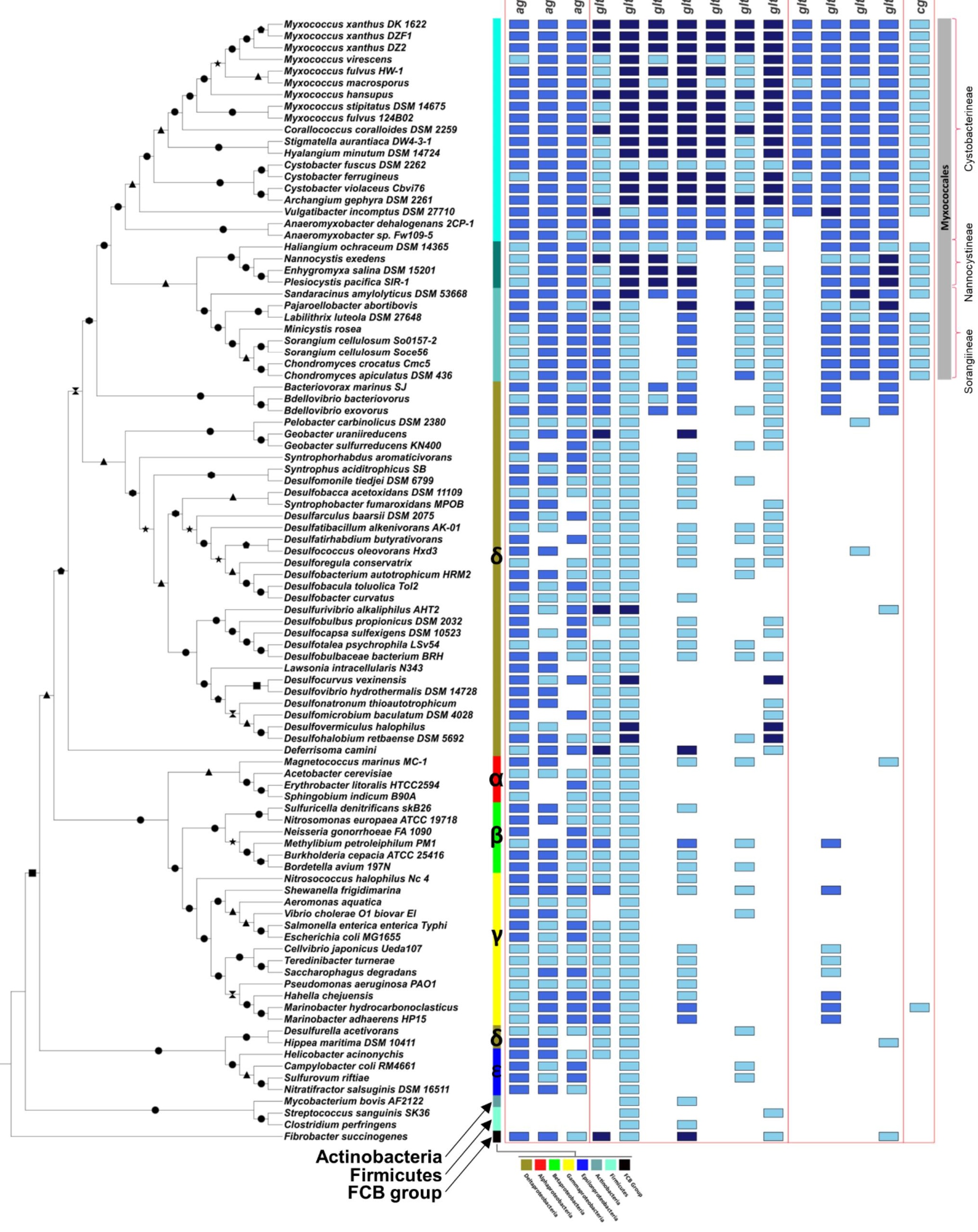


1252 Supplementary Figure S4: Role of CglB in Agl-Glt Complex Localization and Directed

1253 Surface Transport

1254 A) In-gel fluorescence (i) scan and (ii) densitometry analysis of AglZ-YFP levels in WT vs.

$1255 \Delta c g l B$ crude-cell lysates resolved via SDS-PAGE. Fluorescence levels were analyzed across six

1256 biological replicates and are displayed +/- SEM. Despite a higher mean value for AglZ-YFP

1257 levels in $\Delta c g l B$ cells than in WT cells, this difference was not statistically significant, as

1258 determined via Wilcoxon signed-rank test performed relative to "100" ( $p=0.0938)$.

1259 B) Montage of M. xanthus gliding time course displaying AglZ-YFP localization (white

1260 arrowheads) on hard agar via epifluorescence microscopy. Images were acquired at $10 \mathrm{~s}$

1261 intervals. See also Fig. 2C.

1262 C) Kymograph of AglZ-YFP localization in M. xanthus cells on chitosan-coated PDMS

1263 microfluidic chambers via TIRFM. Arrows in orange denote sequential kymograph slices over

1264 time. Arrows in cyan indicate positions of trafficked Agl-Glt clusters in the cell. The manner

1265 in which various fluorescent cluster tracking data were obtained have been indicated in the

1266 example images. See also Fig. 2E-H.

1267 D) Representative time course of polystyrene bead position tracking along the length of a cell.

1268 E) Speed of Agl-Glt complex trafficking via TIRFM (of AglZ-YFP) on chitosan-coated glass

1269 surfaces in PDMS microfluidic chambers for WT $(\mathrm{n}=260$ clusters $)$ and $\Delta g l t K(\mathrm{n}=371$ clusters $)$

1270 strains. The distribution of the two datasets are is significantly different, as calculated via

1271 unpaired two-tailed Mann-Whitney U-test $(p<0.05)$. See also Fig. 2F and Supplementary Fig. 1272 S4C. 


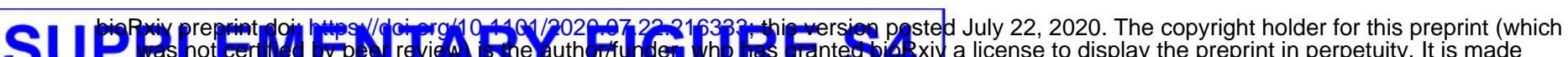

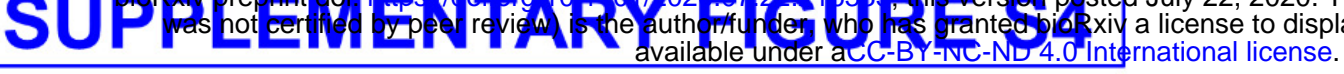

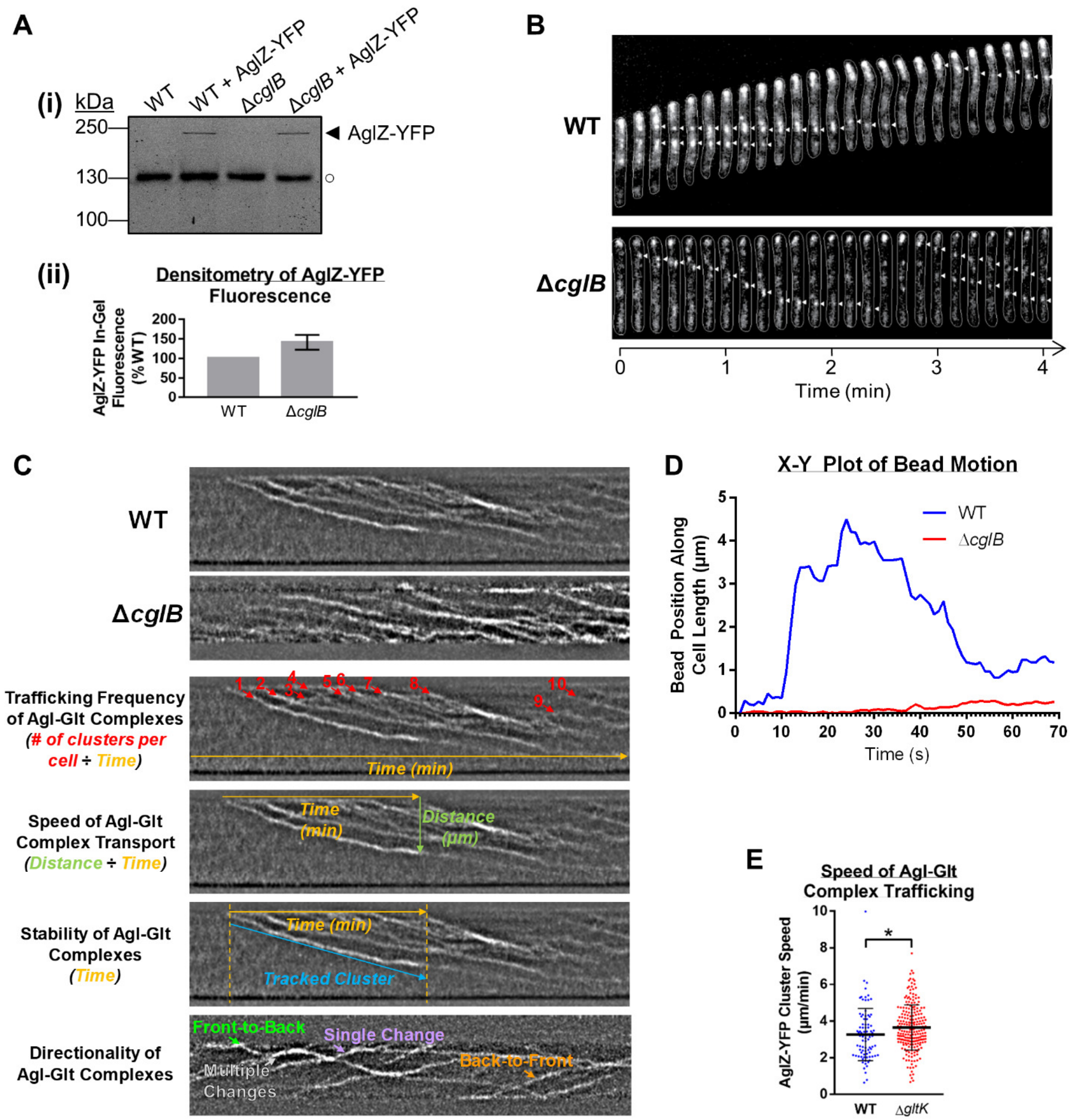




\section{Supplementary Figure S5: Possibility of Post-Translational Processing of CglB}

1275 A) Protein samples from WT cells resuspended in TPM buffer and digested with exogenous

1276 Proteinase K. Aliquots of the digestion mixture were removed at 15-min intervals and TCA-

1277 precipitated to stop digestion. The higher, darker zone on the blot corresponds to a section of the

1278 same blot image for which the contrast has been increased to highlight lower-intensity protein

1279 bands. Legend: 4 , full-length $\mathrm{CglB}$; ○, loading control (non-specific protein band labelled by $\alpha$ -

$1280 \mathrm{CglB} \mathrm{pAb).}$

1281 B) Concentrated supernatant samples from $\Delta g l t$ mutants that exhibit depleted levels of cell-

1282 associated $\mathrm{CglB}$. Equivalent supernatant volumes from different strains were concentrated in a

1283 centrifuge using $3 \mathrm{kDa}$-cutoff protein concentrator columns, followed by TCA treatment of

1284 precipitate proteins. Legend: 4, full-length CglB. See also Fig. 3B.

1285 C) Peptides identified via trypsin/V8 digestion and mass spectrometric analysis of

1286 immunoprecipitated $\mathrm{CglB}$ from $\Delta g l t B$ culture supernatant. Legend: grey, predicted signal

1287 peptide; green, trypsin-derived peptide; cyan, V8-derived peptide; red box, N-terminal tract of

1288 CglB unaccounted for by mass spectrometry.

1289 D) $\alpha$-CglB Western immunoblot demonstrating the resumption of CglB release from EDTA1290 grown cells upon transfer to an EDTA-free minimal buffer (TPM) or rich medium (CYE).

1291 Legend: 4 , full-length CglB; $\leftarrow$, CglB degradation band; PEDA, parent strain (WT or $\Delta g l t B$ )

1292 grown in the presence of EDTA. See also Fig. 3E. 


\section{A CglB Intrinsic Proteinase K Insensitivity}

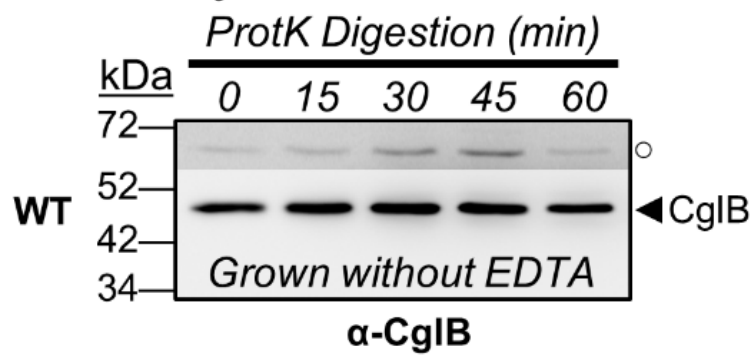

B Spin Column-Concentrated Culture Supernatants

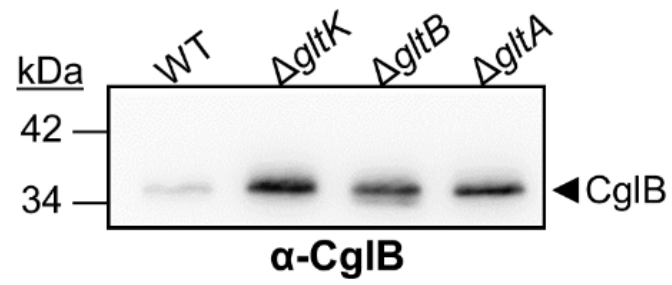

C

$>\mathrm{CglB}$

MRSKLPLLSALSVGAVVLACQTYDFEPVEPLALAQTTVEEVIKARQSKPNIMLLVDTSGSMTY PVNPSPACDVEFKGSIVPCGGEAPCNVDVCPTRWTTLQSVVPQFLENSGRF

VRFALTTYPETRGGESI PDLCRASTAGALLKTLPEQEDDDSLIAHANEINTLLQGIPNGGEGRPLGGTPTSGSLNFVGGLEGLQDPDRENFVILLTDGLPNCNAANPNSGANPE WFBSTIFIT:T

GLODPIRE

LCKCTIEGNQCQSGYLNRGCLDTDASVTAVRELHEKGIQTIVIGFGAETAVGDGPAVLEAMARAGGFKRTCSAERPCGEGDTCNPTTGLCNRSFFQAGNQAELASALEEI SLAV TTEATH:

KIPEPCLIRLDGPQRPTDPKLLVVYVEGERTPSSDSTWTLNDDGVRFTGQICERILASTPEAPVKIEVRAIRQR

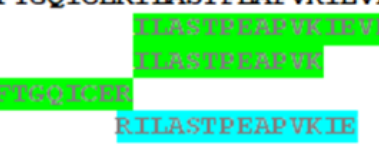

D
D
$P_{\text {EDTA }}$

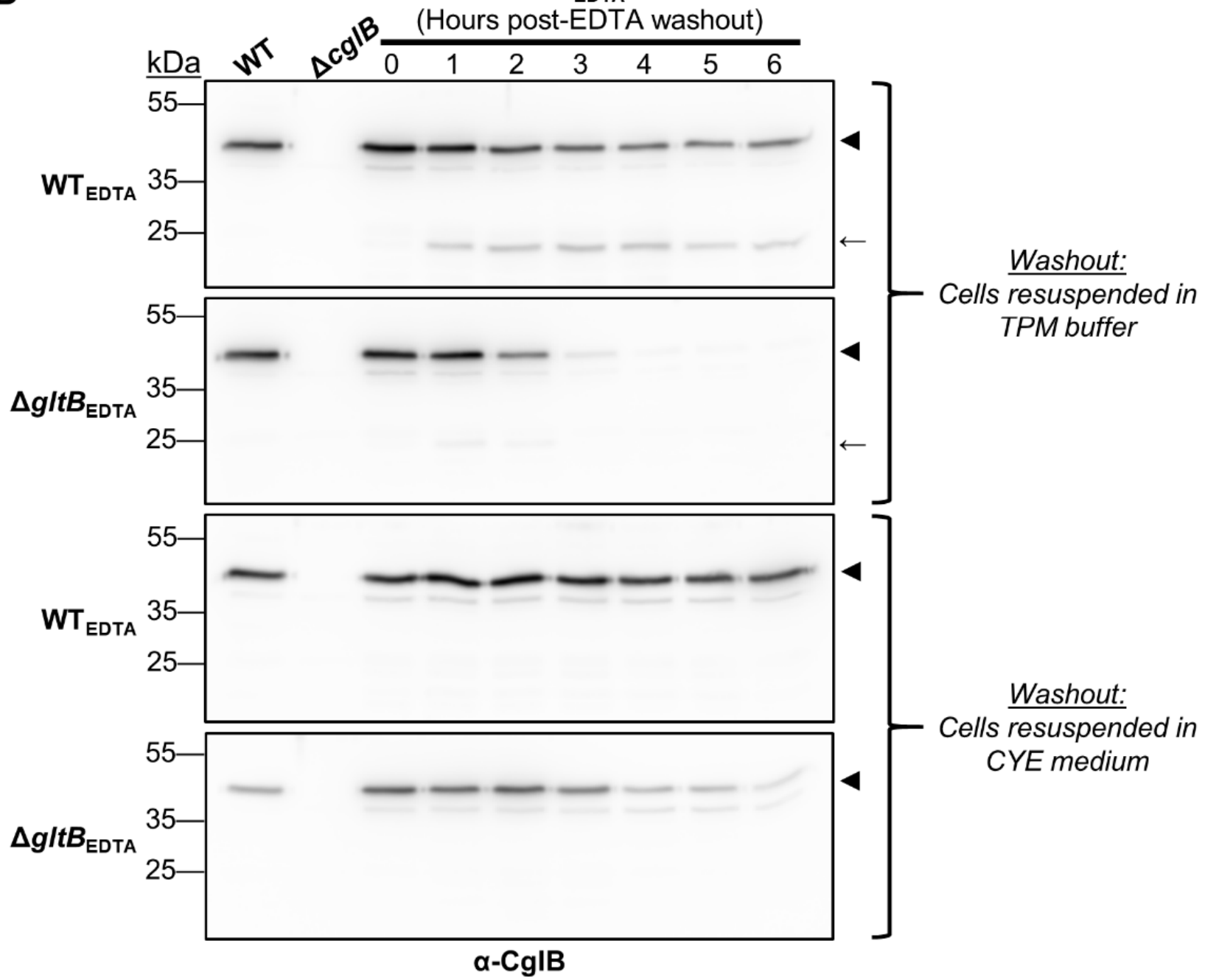


bioRxiv preprint doi: https://doi.org/10.1101/2020.07.22.216333; this version posted July 22, 2020. The copyright holder for this preprint (which

was not certified by peer review) is the author/funder, who has granted bioRxiv a license to display the preprint in perpetuity. It is made available under aCC-BY-NC-ND 4.0 International license.

\section{Supplementary Figure S6: Exploration of GltK Function}

1295 Motility restoration in cells following trans-complementation via OME. Bottom panels (scale

1296 bar: $20 \mu \mathrm{m}$ ) are magnified views of the corresponding upper panels (scale bar: $1 \mathrm{~mm}$ ). 


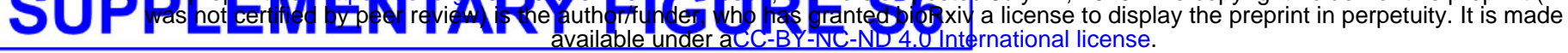

$\Delta a g I Q$ $x$

WT

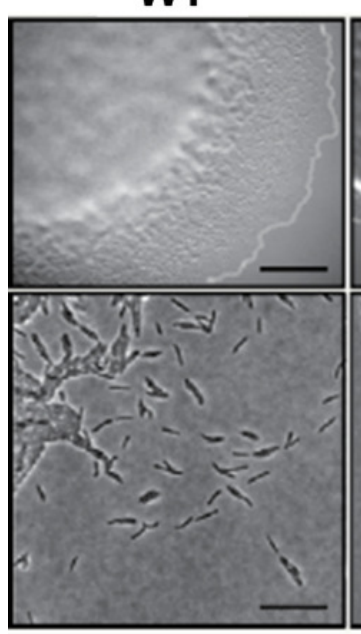

$\Delta a g I Q$

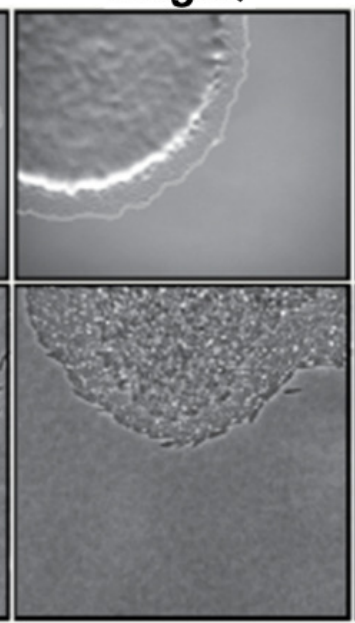

$\Delta g / t A$

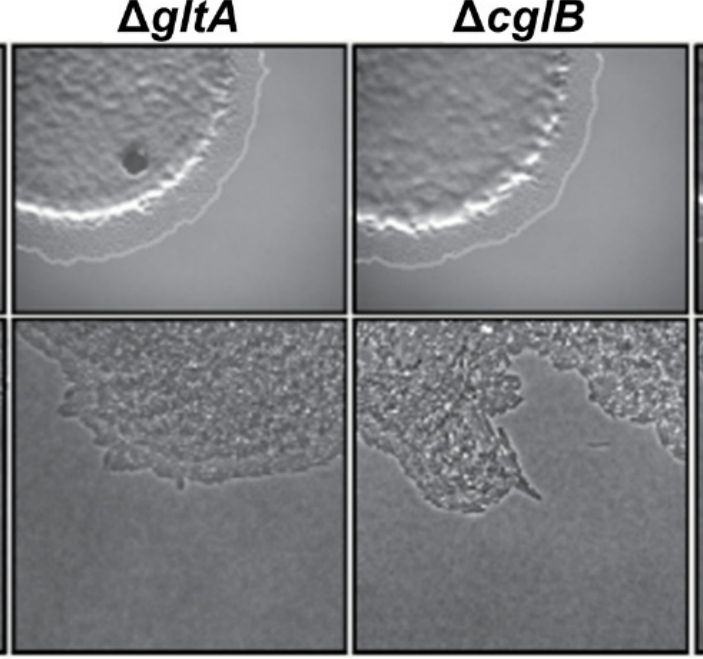

$\Delta g / t A$

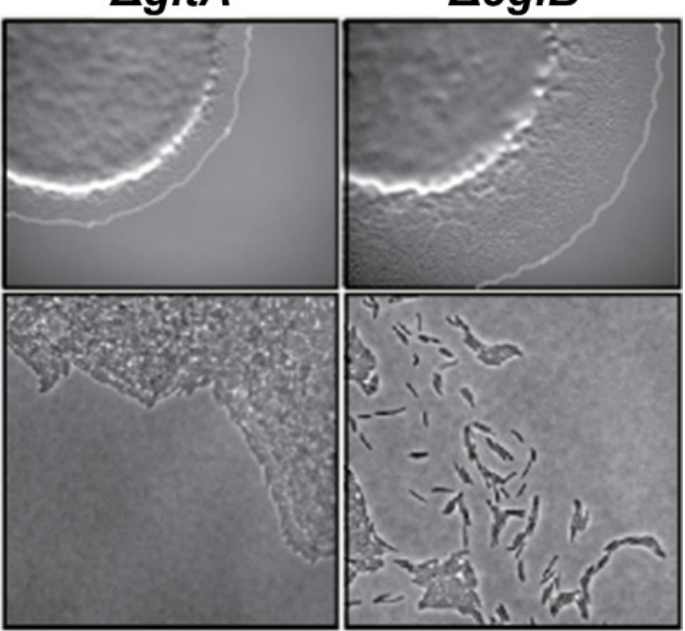
$\Delta c g / B$

$\Delta g / t A$ $x$ 
bioRxiv preprint doi: https://doi.org/10.1101/2020.07.22.216333; this version posted July 22, 2020. The copyright holder for this preprint (which

was not certified by peer review) is the author/funder, who has granted bioRxiv a license to display the preprint in perpetuity. It is made available under aCC-BY-NC-ND 4.0 International license.

\section{Supplementary Table S1: Strains of M. xanthus Used in this Study}

1299 Myxococcus xanthus strains used in this study. 


\section{Supplementary Table S1: Myxococcus xanthus strains used in this study}

\begin{tabular}{|c|c|c|c|}
\hline$\underline{\text { Strain }}$ & Genotype/Description & Construction & Source or Reference \\
\hline $\mathrm{DZ2}$ & WT & Wild type & Laboratory collection \\
\hline TM770 & $\Omega c g / B$ & $\mathrm{DZ2} \Omega \mathrm{cg} / \mathrm{B}$ & This work \\
\hline TM913 & $\Delta c g / B$ & $\mathrm{DZ2} \Delta c g / B$ & This work \\
\hline TM600 & $\Delta g / t K$ & $\mathrm{DZ2} \Delta g / t K(\mathrm{pBJ} \Delta g / t K)$ & Luciano et al., 2011 \\
\hline TM603 & $\Delta g / t B$ & $\mathrm{DZ2} \Delta g / t B(\mathrm{pBJ} \Delta g / t B)$ & Luciano et al., 2011 \\
\hline TM606 & $\Delta g / t A$ & $\mathrm{DZ2} \Delta g / t A(\mathrm{pBJ} \Delta g / t A)$ & Luciano et al., 2011 \\
\hline TM570 & $\Delta g l t C$ & $\mathrm{DZ2} \Delta g / t C(\mathrm{pBJ} \Delta g / t C)$ & Luciano et al., 2011 \\
\hline TM646 & $\Delta g / t J$ & $\mathrm{DZ2} \Delta g / t J$ & This work \\
\hline TM731 & $\Delta g / t \mid$ & $\mathrm{DZ2} \Delta g / t \mathrm{l}$ & This work \\
\hline TM149 & $\Delta g / t H$ & $\mathrm{DZ2} \Delta g / t H(\mathrm{pBJ} \Delta g / t H)$ & Luciano et al., 2011 \\
\hline TM135 & $\Delta g / t G$ & $\mathrm{DZ2} \Delta g / t G(\mathrm{pBJ} \Delta g / t G)$ & Luciano et al., 2011 \\
\hline TM136 & $\Delta g / t F$ & $\mathrm{DZ2} \Delta g / t F(\mathrm{pBJ} \Delta g / t F)$ & Luciano et al., 2011 \\
\hline TM148 & $\Delta g / t E$ & $\mathrm{DZ2} \Delta g / t E(\mathrm{pBJ} \Delta g / t E)$ & Luciano et al., 2011 \\
\hline TM142 & $\Delta g l t D$ & $\mathrm{DZ2} \Delta g / t D(\mathrm{pBJ} \Delta g / t D)$ & Luciano et al., 2011 \\
\hline TM1157 & $\Delta g / t K \Delta g / t H$ & TM149 $\Delta g / t K(\mathrm{pBJ} \Delta g / t K)$ & This work \\
\hline TM1156 & $\Delta g / t B \Delta g / t H$ & TM149 $\Delta g / t B(p B J \Delta g / t B)$ & This work \\
\hline TM1158 & $\Delta g / t A \Delta g / t H$ & TM149 $\Delta g / t A(p B J \Delta g / t A)$ & This work \\
\hline TM1154 & $\Delta g l t B \Delta g / t A$ & DZ2 pBJ114- $\triangle g l t B A$ & This work \\
\hline TM829 & $W T+a g I Z-Y F P$ & $\mathrm{DZ2}$ pBJAgIZ-YFP & Mignot et al., 2007 \\
\hline TM1181 & $\Delta c g / B+a g l Z-Y F P$ & TM913 aglZ-YFP (pBJAglZ-YFP) & This work \\
\hline TM1159 & $\Delta c g l B+c g / B_{\mathrm{WT}}$ & TM913 cg/B $B_{\mathrm{WT}}\left(\mathrm{p} C \mathrm{~g} \mid \mathrm{B}_{\mathrm{WT}}\right)$ & This work \\
\hline TM1149 & $\Delta c g / B+c g / B_{D 56 A}$ & TM913cg/B $B_{D 56 A}\left(p C g \mid B_{D 56 A}\right)$ & This work \\
\hline TM1153 & $\Delta c g / B+c g / B_{558 A}$ & TM913cg/B $B_{S 58 A}\left(p C g \mid B_{S 58 A}\right)$ & This work \\
\hline TM1290 & $\Delta c g \mid B+$ IMss-mCherry & $\begin{array}{l}\text { TM913 IMss-mCherry } \\
\text { (pSWU10-PpilA-IMss-mCherry) }\end{array}$ & This work \\
\hline TM1365 & $\Delta a g l Q \Delta g / t K$ & TM146 $\Delta a g / Q(\mathrm{pBJ} \Delta g / t K)$ & This work \\
\hline TM1367 & $\Delta c g l B \Delta g l t K$ & TM913 $\Delta c g / B(p B J \Delta g / t K)$ & This work \\
\hline TM1380 & $\begin{array}{l}\Delta c g / B \Delta g / t K \\
+ \text { IMss-mCherry }\end{array}$ & $\begin{array}{l}\text { TM1367 } \Delta c g / B \Delta g l t K \\
\text { (pSWU10-PpilA-IMss-mCherry) }\end{array}$ & This work \\
\hline
\end{tabular}


bioRxiv preprint doi: https://doi.org/10.1101/2020.07.22.216333; this version posted July 22, 2020. The copyright holder for this preprint (which

was not certified by peer review) is the author/funder, who has granted bioRxiv a license to display the preprint in perpetuity. It is made available under aCC-BY-NC-ND 4.0 International license.

\section{Supplementary Table S2: Fold-Recognition Hits of CgIB to Various VWA-Containing}

\section{Proteins}

1303 Select fold-recognition hits of structural homologues in the PDB to CglB, as identified via

1304 HHpred. The strength of the hits is anchored by the strong detection of a von Willebrand Factor

1305 type A domain. 
bioRxiv preprint doi: https://doi.org/10.1101/2020.07.22.216333; this version posted July 22, 2020. The copyright holder for this preprint (which was not certified by peer review) is the author/funder, who has granted bioRxiv a license to display the preprint in perpetuity. It is made

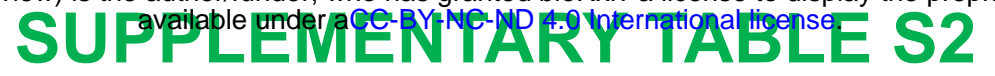

Supplementary Table S2: HHpred fold-recognition hits in the PDB to CglB

\begin{tabular}{|c|c|c|c|c|c|c|c|}
\hline$\underline{\text { PDB Hit }}$ & $\underline{\text { Name }}$ & Probability & $\underline{\text { E-value }}$ & $\underline{\text { Score }}$ & $\frac{\text { Aligned }}{\text { Coils }}$ & $\underline{\text { Identities }}$ & Similarity \\
\hline 1MF7_A & $\begin{array}{l}\text { Integrin } \alpha \mathrm{M} \\
\text { (Homo sapiens) }\end{array}$ & 99.4 & $6.4 \mathrm{E}-14$ & 123.84 & 187 & $19 \%$ & 0.191 \\
\hline 4FX5_A & $\begin{array}{l}\text { von Willebrand } \\
\text { factory type A } \\
\text { (Catenulispora } \\
\text { acidiphila) }\end{array}$ & 99.36 & $3 e-13$ & 140.21 & 199 & $19 \%$ & 0.161 \\
\hline 4OKR_A & $\begin{array}{l}\text { Micronemal } \\
\text { protein MIC2 } \\
\text { (Toxoplasma } \\
\text { gondii) }\end{array}$ & 99.34 & $3.8 \mathrm{E}-13$ & 127.97 & 180 & $20 \%$ & 0.242 \\
\hline 4F1J_B & $\begin{array}{l}\text { TRAP } \\
\text { (Plasmodium } \\
\text { falciparum) }\end{array}$ & 99.18 & $1.1 \mathrm{E}-11$ & 110.16 & 178 & $17 \%$ & 0.257 \\
\hline 3TXA_A & $\begin{array}{l}\text { GBS104 tip pilin } \\
\text { (Streptococcus } \\
\text { agalactiae } \\
\text { serogroup V) }\end{array}$ & 99.13 & 7.2E-12 & 136.34 & 188 & $17 \%$ & 0.239 \\
\hline
\end{tabular}

